\title{
$(341)$
}

XIX. A Monograph of the Genus Saxifraga. By Mr. David Don. Communicated by A. B. Lambert, Esq. V.P.L.S.

Read February 20, 1821.

$I_{N}$ the following monograph of a very. interesting and difficult genus of plants, my principal object is to endeavour to determine the limits of species on more satisfactory grounds than I conceive has hitherto been done. As for six or seven years, during which my attention has been directed to this subject, I have had opportunities of cultivating many species of Saxifraga, both foreign and British, and of observing the greater part of the latter in their native habitats, I hope, in some cases at least, to have been enabled to fix on those distinguishing marks which are most constant in determining the species.

It has been proposed by some botanists to divide Saxifraga into several genera : these subdivisions appear to me, however, to rest on very insufficient grounds; and that the genus as it now stands, consisting of sections which gradually pass into each other, is truly natural.

The species of Saxifraga, although most abundant in the higher latitudes, are still very widely extended over the surface of the globe. In the polar regions, many of them are found even near the level of the sea; and within the tropics, on the summits of the loftiest mountains; but the cold and elevated regions of the north of Asia, Europe and America are the favourite habitats of the genus.

voL. XIII.

$2 \mathbf{Y}$

I have 
$342 M r$. D. Don's Monograph of the Genus Saxifraga.

I have been particularly careful in the selection of synonyms; these I have considerably augmented and corrected, as will hereafter appear; doubtful ones I have in most instances excluded, as they would unnecessarily increase the bulk of the paper, without adding to its utility. For many of the new species contained in this paper $\mathrm{I}$ am indebted to the splendid Herbarium of the late much-lamented President of the Royal Society, the Right Honourable Sir Joseph Banks, Bart., whose death will be long felt throughout the scientific world; and whose name, whose talents and liberality are too well known to require any additional eulogium from my feeble pen. To Aylmer Bourke Lambert, Esq. I am also infinitely indebted for liberally permitting me to examine the species contained in his vast collection; and especially in that portion comprising the Herbarium of the celebrated Pallas.

I have divided the genus into sections and subdivisions, to both of which characters are given; those of the sections being derived from the parts of fructification, and those of the subdivisions from the form of leaves and other differences in habit. Without any further remark, I shall now beg leave to lay before the Society a Synopsis of the genus. 
Conspectus et Separatio Saxifrag a Generis.

SAXIFRAGA. Linn., Juss.

Syst. Linn. Decandria digynia.

Ord. Nat. SAxifragere. Juss.

Char. Essentialis. Calyx 5-fidus. Petala 5, integra. Stamina 10. Styli 2, persistentes. Capsula 2-locularis, 2-valvis è stylis persistentibus birostris : intra rostra foramine orbiculari aperiens, polysperma. Semina minuta, lævia.

Sectio 1. Bergenia, Monch.

Calyx campanulatus, 5-fidus, extus rugosus : segmentis conniventibus. Petala unguiculata, calyce inserta. Stamina fauce calycis inserta; filcmenta subulata; anthera subrotundæ. Styli intus cavi seminibus pleni! basi coaliti, demùm turgidi et in capsulam profundè bipartitam transientes. Stigmata semiglobosa, glabra. Semina cylindracea.

Herbæ perennes. Radix crassa, lignosa. Folia ampla carnosa. Petioli stipulis integris membranaceis secus bases utrinque adnatis instructi! Scapi crassi, denudati. Flores thyrsoideo-paniculati, rubri.

Species.

1. crassifolia

2. cordifolia

3. ligulata.

Sectio 2. Gymnopera.

Calyx 5-phyllus, reflexus. Petala hypogyna, sessilia. Stamina hypogyna; filamenta clavata; antherce reniformes. Styli conniventes. Stigmata simplicia, imberbia. Capsula subrotunda, nuda. Semina sphærica.

Herbx 
344 Mr. D. Dow's Monograph of the Genus Saxifraga.

Herbæ caspitosa, perennes, brevè surculosa. Folia carnosa, indivisa, plerumque cartilagineo-serrata. Scapi erecti, ramosi. Flores parvi, paniculati, rosei ant albi, punctati.

Species.
4. Geum
7. arguta
5. hirsuta
8. stellaris
6. umbrosa
9. leucanthemifolia
7. cuneifolia
10. sarmentosa
5. spicata
11. erosa.
6. Nelsoniana

Sectio 3. Leiogyne.

Calyx profundè 5-fidus. Petala in plurimis sessilia. Stamina fauce calycis inserta ; filamenta subulata.' Styli recti. Stigmata orbiculata, planiuscula, imberbia. Capsula à calyce libera. Semina subrotunda.

Herbæ rarò suffrutices, humiles. Radix fibrosa in pluribus granulosa. Caules flexuosi, sapiùs multiflori, polyphylli. Folia in aliis reniformia, lobata, in aliis linearia, indivisa. Flores albi aut lutei.

\section{§. Foliis lobatis.}

Species.

12. rotundifolia

13. hybrida

14. granulata

15. bulbifera

16. cernua

17. sibirica

18. nudicaulis
19. bracteata

20. rivularis

21. nutans

22. orientalis

23. cymbalaria

24. hederacea. 
Mr. D. Don's Monograph of the Genus Saxifraga. 345

§. Foliis indivisis.

Species.

25. Hirculus

26. flagellaris

27. myosotifolia

28. aizoides

29. bronchialis

30. tenella
31. brachypoda

32. juniperina

33. aspera

34. hispidula

35. bryoides

36. cherlerioides.

Sectio 4. Micranthes.

Calyx 5-partitus, patens. Petala parva, sessilia, patentia, calyce inserta. Stamina calyce inserta; filamenta brevissima, subulata. Styli brevissimi, crassi. Stigmata capitata, glabra. Capsula depressa à calyce libera.

Herbæ pexennes. Radix fibrosa. Scapi multiflori. Folia indivisa, patentia, lanceolata v. ovata, serrata v. crenata. Flores corymbosi, parvi, albi v. favescentes, in paniculam terminalem dispositi.

Species.

37. hieracifolia

38. pensylvanica

39. semipubescens

40. ' virginiensis
41. nivalis

42. longiscapa

43. davurica

44. pyrolifolia.

Sectio 5. SAXIfRAGE VERE.

Calyx 5-fidus. Petala sessilia, perigyna. Stamina perigyna; filamenta plana, sensim attenuata. Stigmata patentia, plana, spathulata, pube brevi barbata. Capsula calyce obvoluta et arctè connata. Semina obovata.

Herbæ perennes v. rarissimè annuc, humiles, densè caspitosce plerumque surculosa. Folia indivisa v. variè partita in pluribus rosulata. 
S46 Mr. D. Dow's Monograph of the Genus Saxifraga.

rosulata. Caules polyphylli rarò nudi, multi v. paucifori. Flores albi v. lutei aut rarissimé rosei.

§. Foliis indivisis plerumque rosulatis impetiolatis.

Species.
45. Cotyledon
46. lingulata
47. Aizoon
48. intacta
49. mutata
50. media
51. Lapeyrousii
52. aretioides
53. burseriana
54. retusa

55. oppositifolia

56. cæsia

57. diapensioides

58. fimbriata

59. serpyllifolia

60. parnassifolia

61. androsacea

62. spathulata

63. sedioides

64. tenera.

§. Foliis 5-3-partitis petiolatis.

Species.

$\begin{array}{ll}\text { 65. geranioides } & \text { 78. incurvifolia } \\ \text { 66. irrigua } & \text { 79. denudata } \\ \text { 67. maderensis } & \text { 80. Sternbergii } \\ \text { 68. pedatifida } & \text { 81. pulchella } \\ \text { 69. ceratophylla } & \text { 82. tridentata } \\ \text { 70. obtusifida } & \text { 83. andicola } \\ \text { 71. ajugifolia } & \text { 84. cæspitosa } \\ \text { 72. affinis } & \text { 85. stellata } \\ \text { 73. pentadactyla } & \text { 86. Bonplandii } \\ \text { 74. latifida } & \text { 87. magellanica } \\ \text { 75. decipiens } & \text { 88. exarata } \\ \text { 76. hirta } & \text { 89. Pavonii } \\ \text { 77. platipetala } & \text { 90. pedemontana }\end{array}$

91. moschata 
Mr. D. Don's Monograph of the Genus Saxifraga. $\quad 347$

91. moschata

92. muscoides

93. pygmæa

94. tricuspidata

95. tridactylites

96. petræa

97. adscendens
98. cuneata

99. globulifera

100. hypnoides

101. condensata

102. elongella

103. leptophylla

104. lætè-virens.

\section{DESCRIPTIONES SPECIERUM.}

Sectio 1.

1. S. crassifolia, foliis ovalibus obtusissimis glabris serrulatis, petalis elliptico-oblongis.

S. crassifolia. Linn. Dec. ii. p. 27. t. 14. Willd. Sp. Pl. ii. p. 644. Bot. Mag. t. 196. Persoon Synop. i. p. 488. Hort. Kew. iii. p. 67.

S. foliis ovalibus crenulatis, caulibus nudis. Gmel. Sib. iv. p. $166 . t .66$.

Habitat in Siberiæ alpibus. 4. (v. v. c.)

Radix crassa, lignosa, rudimentis foliorum emarcidorum crebrè tecta. Folia petiolata, ovalia, obtusissima, carnosa, glaberrima, lucida, serrulata. Petioli teretes. Stipula latissimè dilatatæ, glabræ secùs bases petiolorum decurrentes. Scapi pedales, denudati, nitidi, purpurei, angulati, crassitie ferè digiti. Panicula coarctata. Pedunculi alterni, racemosi, nutantes. Pedicelli unilaterales, numerosi. Flores campanulati, magni, rubri. Lacinia calycince conniventes, oblongæ, obtusæ. Petala ellipticooblonga, multinervosa. 
2. S. cordifolia, foliis orbiculato-cordatis serratis glabris, petalis subrotundis.

S. cordifolia. Hazvorth Misc. Nat. 157. Hort. Kew. ed. 2. 3. p. 67 .

Geum saxatile rotundifolium majus, flore purpureo. Amm. Ruth. n. 90.

Habitat in Siberiæ alpibus. 4 . (v. v. g.)

Pracedenti simillima, at major et robustior. Folia orbiculatocordata, carnosa, ampla, serrata, glabra, lucida. Petioli longiores. Scapus brevior, crassior, angulatus, glaber, lucidus. Panicula thyrsoidea. Pedunculi alterni breviores, racemosi, nutantes. Pedicelli numerosi, unilaterales. Flores campanulati, majores, rubri. Lacinice calycina conniventes, breviores et latiores. Petala subrotunda, multinervia.

This plant, although it has been long considered as only a variety of the preceding species, nevertheless affords sufficient marks to keep it distinct; and these characters are always constant when raised from seed. It is not, as some have supposed, a garden hybrid or variety. It was found wild in Siberia both by Dr. Amman and the celebrated Pallas, in whose Herbarium, now in the possession of A. B. Lambert, Esq., there are several native specimens.

3. S. ligulata, foliis orbiculato-cordatis, denticulatis, ciliatis, utrinque hirsutis, scapo filiformi dichotomo, petalis latè orbiculatis.

S. ligulata. Wallich in Act. Soc. Asiat. xiii. p. 398. cum figurâ.

S. Pacumbis. Buchanan Mss.

Habitat in Nepaliæ, et Bengalæ orientalis, alpibus. $B u$ chanan, Wallich. 4 . (v. s. in Herb. Lamb.) 
Mr. D. Don's Monograph of the Genus Saxifraga. 349

Radix horizontalis, lignosa, crassitie digiti, rudimentis foliorum emarcidorum imbricatim tecta. Folia ampla, orbiculato-cordata v. rariùs ferè obovata, utrinque scabra, hirsutissima, margine tenuiter denticulata et pilis crebris ciliata; suprd venis prominentibus reticulata. Petioli brevissimi, teretes, quàm in præcedentibus, breviores. Stipula latissimè membranaceo-dilatatæ, secus bases petiolorum decurrentes, ad margines ciliis paleaceis longis cuspidatis instructæ. Scapus erectus, gracilis, filiformis, nudus, laviusculus; apice bifurcus. Flores rubri, præcedentibus majores, campanulati, in racemis cernuis unilateralitèr dispositi. Pedicelli calycesque scabriusculi. $\mathbf{C a}$ lycis Lacinia brevissimæ, rotundatæ. Petala latè orbiculata, multinervia.

This remarkable and truly distinct species was first discovered on the mountains of Nepal by a distinguished naturalist, Dr. Francis Hamilton (formerly Buchanan), from whom there are very excellent specimens of it in the Lambertian Herbarium. Others have been more recently received from Dr. Wallich, by whose collectors they have been gathered both in the mountains of Nepal and the eastern parts of Bengal. This plant is one of many instances which manifests that striking similarity which exists between the vegetation of Nepal and that of the northern regions of Tartary.

\section{Sectio 2.}

4. S. Geum, foliis reniformibus crenatis, utrinque pilosis ; adultis confertis patentibus, petiolis longissimis teretiusculis villosis, laciniis calycinis ovatis obtusis.

S. Geum. Linn. Sp. Pl. 574. Scop. Carn. ed. 2. n. 491. Willd. Sp. Pl. ii. p. 448 . Lam. Encycl. vi. p. 682 . Lapeyr. Sarif. Pyren. p. 46. t. 24. (bona.) Lam. et Decand. 
Flor. Franc. iv. p. 379. Persoon Synop. i. p. 488. Hort. Kew. ed.2.3. p.68. Engl. Bot.t.1561. (optima.) Sternberg. Saxif. p. 15.

S. punctata. Sternb. loc. cit. p. 18.

S. foliis reniformibus obtusè crenatis, caule simplici nudo. Gmel. Sib. iii. p. 161. t.65. f. 1.

Geum folio subrotundo minori, pistillo floris rubro. Magn. Hort. p. 88. t. 88.

Sanicula montana rotundifolia minor. Bauh. Pin. 243.

Sedum montanum rotundifolium minus album non guttatum. Moris. Hist. iii. p. 478. sect. 12. t. 9. f. 12. (mala.)

$\beta$. foliorum paginâ utrinque glabrâ.

S. elegans. Mackay in literis.

\%. triplò major; foliorum paginâ utrinque glabrâ, paniculâ magis diffusâ, petalis majoribus pulchrè punctatis.

Habitat in Sibiriâ ; nec non in Pyrenæor. Helvetiæ et Hiberniæ alpibus copiosè, $\beta$ et $\gamma$ in Hiberniæ montibus. J.T. Mackay. 4 . (v. v. c.)

Planta cæspitosa. Radix fibrosa. Folia anni præcedentis persistentia, conferta, rigida, humi patentia ; juniora erecta, longè petiolata, reniformia, coriacea, crenata: crenaturis imbricatis obtusissimis vix cartilagineis; suprà saturatè viridia ; subtùs rubescentia ; utrinque avenia, pilis rigidis instructa. Petioli longissimi, subteretes, villosi, nunquam dilatati. Scapus erectus 4-6-pollicaris, pilis viscidis densè tectus. Panicula ramosissima, multiflora: ramuli multiflori, variè furcati. Bractea parvæ, carnosæ, lineares, obtusæ. Pedicelli breves calycesque pilis glanduliferis crebrè tecti. Lacinice calycis ovatæ, obtusæ, obscurè 3-nerves. Petala ovalia, punctis flavis et puniceis ad basin instructa. Antherce flavæ. Pistilla staminibus breviora.

5. S. hir- 
5. S. hirsuta, foliis ovalibus acutè serratis basi rotundatis cordatisve utrinque pilosis; adultis erectis, petiolis longissimis teretiusculis villosis, pedicellis elongatis unifloris.

S. hirsuta. Linn. Sp. Pl. 574. Mill. Dict. n.6. Willd. Sp. Pl. ii. p. 647. Lapeyr. Fl. Pyren. Saxif. p. 45. t. 23. (optima.) Lam. Encycl. vi. p. 681. Engl. Bot. t. 2322. (bona.) Hort. Kew. ed.2.3.p.68. Lam. et Decand. Flor. Franc. iv. p. 378. Sternb. Saxif. p. 14.

Sedum serratum, folio pallido, flore elegantèr punctato. Moris. Hist. 3. 12. t. 9. f. 17.

$\beta$. foliis subrotundo-cordatis utrinque glabris.

Habitat in rupibus humidis alpium Pyrenaicarum et Hibernicarum, $\beta$ cum $\alpha$ in Hiberniâ. J.T. Mackay. 4 . (v.v.c.)

Planta cæspitosa. Radix fibrosa. Folia omnia longè petiolata, erecta, ovalia, coriacea, utrinque pallidè viridia, pilis rigidiusculis adspersa ; basi vel rotundata v. cordata ; margine serrata: serraturis subdistantibus, triangularibus, acutis. Petioli longissimi, erecti, teretiusculi, densè villosi ; suprà canaliculati. Scapi erecti, palmares aut pedales, Hexuosi, villis viscidis tecti. Panicula divaricatim ramosissima. Pedicelli elongati, uniflori, calycesque pilis glanduliferis obsiti. Lacinia calycina ovatæ, obtusæ, obscurè 3-nerves. Petala ovali-oblonga, alba punctis numerosis fulgidis rubris et flavis instructa oculo armato 5-nervia. Filamenta alba, pistillis longiora. Antherc rubræ.

This species appears intermediate between S. Geum and umbrosa; with Geum it agrees in the form of its petioles, and in its leaves being cordate at the base; and with $S$. umbrosa in its more oval, smooth, and paler green leaves and larger flowers with bright-coloured spots. From both, however, it appears sufficiently distinct to rank as a species. Moris. Hist. 3. 12. t.9.f.17. 
given as a synonym of punctata, certainly belongs to this plant. Magnol. Hort. Monsp. t. 87 . ought with more propriety to be referred to $S$. Geum.

6. S. umbrosa, foliis obovatis retusis cartilagineo-crenatis glaberrimis ; adultis confertis patentibus, petiolis brevibus compresso-dilatatis, pedicellis paucifloris.

S. umbrosa. Sp. Pl. 574. Mill. Icon. 141.f.2. Willd. Sp. Pl. ii. p. 647. With. Brit. 403. Lapeyr. Pyren. Saxif. p.44. t.22. (bona.) Lam. Encycl. vi. p.680. Smith Brit.ii. p. 450. Engl. Bot. 633. Hull. Brit. 92. Persoon Synop. i. p. 488. Lam. et Decand. Fl. Franc. iv. p. 378. Hort. Kew. iii. p. 67. Sternb. Saxif. p. 14.

Geum folio subrotundo minori, pistillo floris rubro. Tournef. Inst. 251.

B. punctata, foliis subrotundis argute dentato-serratis ; adultis erectis, petiolis longioribus.

S. punctata. Linn. Sp. Pl. 574. (exclus. syn. Moris. Hist.) Willd. Sp. Pl. 2. p. 646. (exclus. syn. Moris. Hist.)

$\gamma$. serratifolia, foliis oblongo-ovatis inciso-serratis; adultis erectis, petiolis longioribus.

S. serratifolia. Mackay in literis.

Habitat $\alpha$ in alpibus Pyrenaicis et Hibernicis, $\beta$ et $\gamma$ in Hiberniæ montibus. D. Mackay. 4. (v. v. c.)

Planta cæspitosa. Radix fibrosa. Folia anni præcedentis persistentia, densè conferta, humi patentia; juniora erecta, brevè petiolata, obovata, retusa, cartilagineo-crenata : crenaturis subimbricatis, utrinque viridia glaberrima. $\mathrm{Pe}$ tioli compresso-dilatati, suprà plani, ad marginem villis mollibus tenuitèr ciliati paginâ foliorum vix longiores. Scapus erectus, flexuosus, villis viscidis tectus. Panicula divaricatim ramosa. Pedicelli breves, paucitlori, calyces- 
Mr. D. Don's Monograph of the Genus Saxifraga. 353

que pilis brevibus glanduliferis confertè instructi. Lacinice calycis ovatæ, obtusæ, obscurè trinerves. Petala ovalia, conspicuè trinervia: nervis ramosis, roseo-alba punctis numerosis coccineis et flavis pulcherrima.

Saaifraga umbrosa is readily distinguished from the two preceding species by its flat, dilatated, and much shorter petioles; by the leaves never being cordate at the base ; and lastly, by the serratures being more distinctly cartilaginous at their margins. The variety $\beta$. I believe to be Linnæus's $S$. punctata: it differs from $\alpha$. by the greater length of its petioles, and by the older leaves being loose, and always erect, never confert and spreading on the ground as in var. $\alpha$; the var. $\gamma$. is very near akin to $\beta$, only differing in its leaves being oblong-ovate. They both likewise differ from $\alpha$. by the large and sharp serratures of their leaves. The synonyms of Morison and Miller, quoted by Linnæus, evidently belong to hirsuta. The Count de Sternberg, in his excellent monograph of the genus, has described for $S$. punctata the Siberian S.Geum, which differs in no respect from the European one, as I have examined excellent specimens of it in the Pallasian Herbarium in the possession of A. B. Lambert, Esq. These specimens agree exactly with Gmelin's figure quoted by him.

7. S. cuneifolia, foliis cuneiformibus repando-crenatis glabris ; adultis confertis patentibus : petiolis, linearibus angustissimis nudis, laciniis calycinis oblongis acutis, petalis spathulatis.

S. cuneifolia. Linn. Sp. Pl. 574. Scop. Curn. 490. t. 13. Schmied. Fasc. t. 12. n.37. Willd. Sp. Pl. ii. p.647. Lapeyr. Pyren. Saxif. p.45. Waldst. et Kitaib. Hung. i. p.43. t. 44. (media.) Lam. Encycl. vi. p.681. Lam. et Decand. Fl. Franc. iv. p. 377. Hort. Kerv. ed.2.3. p.68. Sternb. Saxif. p. 14. 
354 Mr. D. Don's Monograph of the Genus Saxifraga.

Saxifraga punctata. Gunn. Norv. n. 1076. Act. Haf. x. p. 445. t. 3. $f .10$.

S. foliis petiolatis obtusis, caule fragili nudo ramoso. Hall. Helv. n. 974.

Cotyledon altera olim Matthioli. Bauh. Hist. iii. p. 684 .

Cotyledon aut Sedi species quædam. Gesn. Fasc. xix. $t$. 12. f. 37. (bene.)

ß. davurica, foliis opacis dentatis, floribus majoribus.

S. davurica. Hort. nec Willd.

Habitat $\propto$ in alpibus Pyrenæor. Helvetiæ, Styriæ, Hungariæ et Norvegiæ ; $\beta$ in Sibiriâ? u . (v. v. c.)

Planta cæspitosa, duplò minor. Radix fibrosa. Folia anni præcedentis persistentia, conferta, humi patentia ; juniora erecta, cuneiformia, petiolata, utrinque glaberrima, repando-crenata, rigidè coriacea, basi attenuata. Petioli lineares, angustissimi, rigidi, fragiles, nudi, margine cartilaginei. Scapus erectus, flexuosus, rigidus, fragilis, villis viscidis rarè adspersus. Panicula divaricatìm ramosa: rami dichotomi. Pedicelli calycesque pilis glandulosis instructi. Lacinia calycina oblongæ, acutæ, obscurè uninerves. Petala spathulata, basi angustata, puncto luteo, subsolitario instructa, sub microscopio trinervia : nervis ramosiusculis. Stamina pistillis ferè duplo longiora; filamenta alba; anthere fulvæ.

8. S. spicata, foliis longè petiolatis orbiculato-cordatis argutè serratis venosis pilosis, petiolis basi dilatatis, racemo elongato spiciformi, laciniis calycinis brevissimis obtusis.

S. Geum. Pursh Fl. Amer. Septent. i. p. 311.

Habitat in Insulâ Sledge dictâ ad oras occidentales Americæ septentrionalis. D. Nelson. $u$. (v. s. in Herb. Banks.)

Plinta 
Mr. D. Don's Monograph of the Genus Sarifiaga. 355

Planta crespitosa. Radix fibrosa. Folia omnia erecta longè petiolata, orbiculato-cordata, conspicuè venosa, grossè et acutè serrata, utrinque pilosa ; petioli longissimi ; basi dilatati, subtùs striato-nervosi, margine villis mollibus ciliati. Scapus pedalis, teres, erectus, villis viscidis tectus. Racemus elongatus, apice attenuatus, variè dichotomus, multiflorus. Pedicelli brevissimi, numerosi, pube brevi glutinosâ, ut et calyces, tecti. Lacinice calycince brevissimæ, obtusæ. Petala elliptico-oblonga, punctata? 3-nervia: nervis ramosis flexuosis. Genitalia petalis triplo longiora ; filamenta longissima, gracilia ; pistilla elongata, recta.

The above species is widely different from the $S$. Geum, with which Pursh has confounded it. It is distinguished by its nerved and dilated petioles. The leaves are all erect, broader, orbiculato-cordate, veined and serrated; their teeth large, acute. Flowers on dichotomous peduncles, disposed in a long tapering raceme. The lacinix of the caly $x$ are much shorter and broader. The stamens twice the length of those of S.Geum, and longer than the petals. The only specimens I have seen of this very distinct plant are preserved in the Banksian Herbarium, and were collected in Sledge Island, on the north-west coast of America, by Mr. David Nelson, a very indefatigable botanist, who accompanied the celebrated Captain Cook in his third voyage, and who has made many interesting discoveries in those regions.

9. S. Nelsoniana, foliis orbiculato-cordatis subpeltatis inciso-serratis, petiolis longissimis filiformibus, thyrso ovato.

Habitat ad Caput Newnham dictum, ad oras occidentales America borealis. David Nelson. 4 . (v.s. Herb. Banks.)

Planta subcæspitosa. Radix fibrosa. Folia omnia erecta, longè 
$356 M r$. D. Don's Monograph of the Geaus Saxifraga.

longè petiolata, orbiculato-cordata, subpeltata, coriacea, suprà glabra, subtùs hirsuta, inciso-serrata: serraturis magnis acutis. Petioli longissimi filiformes, æquales, undique villosi. Scapus palmaris, erectus, simplicissimus, teres, villis longis mollibus undique tectus. Flores brevè pedicellati, albi, magnitudine $S$. nivalis, in thyrso ovato terminali densè dispositi. Lacinice calycince triangulariovatæ, acutæ. Petala ovalia, parva, alba, impunctata? Filamenta alba. Pistilla elongata, recta.

Hanc speciem pulcherrimam et omnind distinctam nomine inventoris peritissimi atque indefessi lubens condecoravi.

10. S. arguta, foliis reniformi-rotundatis inciso-serratis glabris, petiolis filiformibus, scapo gracili lævi, laciniis calycinis oblongis acutis.

Habitat ad atas occidentales Americæ septentrionalis. D. Menzies. 4 . (v. s. in Herb. Banks.)

Radix fibrosa. Folia longè petiolata, reniformi-rotundata, profundè inciso-serrata, utrinque glabra. Petioli longissimi, filiformes, graciles. Scapus lævis, gracilis. Panicula simplicissima. Flores albi, magnitudine S. stellaris. Lacinice calycis oblongæ, acutæ. Petala ovalia, unguiculata, multinervosa, punctata? Pistilla brevissima.

11. S. stellaris, foliis aggregatis rhombeo-ovatis sessilibus acutè dentatis: basi integerrimis angustatis, petalis ovatis acutis æqualibus unguiculatis, scapo subsimplici.

S. stellaris. Linn. Sp. Pl. 572. Flor. Dan. t. 23. (bona.) Jacq. Coll. i. p. 202. t. 13. (optima.) Scop. Carn. i. 292. t. 13. (media.) Huds. Angl. 179. Lightf. Scot.i. p. 220. With. Brit. 402. Willd. Sp. Pl. ii. p. 644. Engl. Bot. t. 167 . 
Mr. D. Don's Monograph of the Genus Saxifraga. 357

t. 167. (bona.) Lapeyr. Pyren. Saxif. p. 490. Lam. Encycl. vi. p.680. Smith Brit. ii. p.448. Persoon Synop. i. p. 488. Lam. et Decand. Fl. Franc. iv. p. 379. Hort. Kew. ed. 2. 3. p. 68. Sternb. Saxif. p. 11. Wahlenb. Lapp. p. 114.

S. foliis rhomboideis acutè serratis, caule nudo ramoso. Hall. Helv. n. 973.

S. foliis lanceolatis dentato-serratis, caule nudo simplici. Linn. Suec. 335, 367.

S. caule nudo simplici, foliis lanceolatis dentatis, petalis acutis. Linn. Lapp. 175.

Sanicula Myosotis floribus albicantibus ferè umbellatis. Pluk. Alm. p. 331. ejusd. Phytog. t. 58.f. 2. (bene.)

Sedum montanum hirsutum mucronato et dentato folio, flore ' albo guttato. Moris. Hist. iii. p. 478. s. 12. t. 9. f. 13. (bene.)

Sanicula alpina aliquatenus affinis. Bauh. Hist. iii. $p .708$.

B. elata, scapi plures, pedales.

$\gamma$. angustifolia, foliis angustioribus longioribusque apice paucidentatis.

d. Schleicheri, foliis obovatis repando-crenatis, scapo flexuoso humiliore.

S. stellaris. Schleicher in literis.

๕. Bellardi, acaulis ; foliis subrotundis repandis, flore sessili.

S. Bellardi. Allion. Pedem. n. 1536. t. 88. f. 1. Willd. Sp. Pl. ii. p.645. Sternb. Saxif. p. 2.

Habilat a Scotiæ et totius Europæ alpium petrosa humida et scaturigines; $\beta$ et $\gamma$ in Sibiriâ (Pallas); $\delta$ in alpibus Helveticis (Schleicher); $\varepsilon$ in alpibus Pedemontanis (Bellardi). 4 . (v. v. $\alpha$ sp. $\delta$ cult.; $\beta$ et $\gamma$ v. s. in Herb. Pallasio, nunc Lamb.) 
Planta in cæspitibus densis parvulis vegetans. Radix fibrosa. Folia conferta, sessilia, rhombeo-ovata, apice acutè dentata, basi integerrima, angustata, utrinque pilis setosis adspersa ; suprà nitida. Scapus subnudus, 2-4-pollicaris in $\beta$ pedalis, villis mollibus viscidis instructus. Panicula simplex, pauciflora. Pedunculi dichotomi calycesque pilis glandulosis leviter tecti. Bractea ovatæe, acutæ, integræ. Lacinice calycine ovato-acutæ, 3-nerves. $P e-$ tala ovata, acuta, alba, æqualia, unguiculata, elegantissimè 3-nervia (nervis simplicibus rectis); basi maculis 2 aureis instructa : dorso carinata. Filamenta alba. Anther c croceæ. Pistilla brevissima, crassa.

12. S. leucanthemifolia, foliis confertis lanceolato-cuneatis acutè grossèque dentatis, basi integerrimis angustatis, scapo ramosissimo diffuso, petalis ovatis acutis unguiculatis; tribus exterioribus majoribus.

S. leucanthemifolia. Mich. Amer. Bor. i. p. 268. Lapeyr. Pyren. Saxif. p. 49. t. 25. Lam. Encycl. vi. p. 679. Pursh Amer. Septent. i. p.311. Sternb. Saxif. p. 10.

S. Clusii. Gouan Illust. p. 28. (exclus. synon.) Lam. et Decand. Flor. Franc. iv. p. 380.

Habitat in alpibus Pyrenaicis, et in Americâ boreali. * (v. v. c. et s. sp.)

Planta cæspitosa. Radix fibrosa. Folia conferta, erecta, lanceolato-cuneata, apice acutè grossèque dentata, basi integerrima, angustata, utrinque pilis setosis instructa. Scapus subnudus, 4-6-pollicaris, flexuosus, diffusè ramosissimus, villis viscidis tectus. Rami dichotomi. Pedicelli elongati, graciles, uniflori, pube brevi glutinosâ vestiti. Lacinice calycince ovatæ, obtusæ. Petala ovata, acuta, 
acuta, inæqualia, unguiculata, triplinervia: nervis ramosis, flexuosis; tria exteriora majora, basi biguttata; duo interiora multò minora, immaculata.

Oвs. Pracedente triplo major, in plurimis tamen similis, at notis indicatis abundè diversa.

13. S. sarmentosa, stolonibus reptantibus, foliis orbiculato-cordatis latè lobato-crenatis discoloribus pilosis, petalis unguiculatis; duobus exterioribus maximis flaccidis.

S. sarmentosa. Linn. Suppl. p. 240. Thunb. Japon. p. 182. Schreb. Monog. Dionea, p. 16. t. 2. f.3. (media.) Ait. Hort. Kew. ed. 1. 2. p. 79. Lam. Encycl. vi. p. 684. Persoon Synops. i. p. 488.

S. ligulata. Murr. in Comment. Gött. 1781. p. 26. t. 1. Schkika. Kampf. Amøn. 870. Jacq. Misc. ii. p. 327. ejusd. Icon. var. 1. t. 80. (optima.)

Habitat in Imperii Japonarum locis montosis et humidis inque lapidosis (Kampfer, Thunberg); etiam in Chinâ. 4. (v. v. c.)

Planta cæspitoša, stolonifera. Radix fibrosa. Stolones axillares, latè reptantes, ad genicula suprà comam parvam foliorum et infrà fibras nonnullas progredientes. Folia numerosa, patentia, orbiculato-cordata, longè petiolata, lobato-crenata: crenaturis latissimis obtusis, utrinque pilis setosis adspersa, suprà opacè viridia, fasciis albis ; subtùs rubra. Scapi palmares, aut pedales, erecti, petiolique pilis rigidiusculis viscidis deflexis undique vestiti. Panicula ramosa, laxiflora. Bractece lanceolatæ, mucronatæ, pedicellique pube glutinosâ obsitæ. Lacinia calycince latè ovatæ, obtusæ, conspicuè trinerves. Petala unguiculata : unguibus capillaribus; tria interiora parva, 
Mr. D. Don's Monograph of the Genus Saxifraga.

cordata, acuta; horum lateralia basi maculâ flavâ notantur, at centrale punctis duobus puniceis ad basin munitum est ; duo exteriora maxima, lanceolata, acuta, flaccida, 3-nervia : nervis flexuosis, ramosis.

14. S. erosa, foliis lanceolatis acutis glabris runcinato-serratis, paniculâ divaricatâ pyramidatâ, pedicellis elongatis unifloris, petalis oblongo-ovalibus obtusis unguiculatis.

S. erosa. Pursh Amer. Boreal. i. p. 311.

$\beta$. foliis hirsutis.

Habitat $\propto$ in rivulis lapidosis montium excelsiorum Carolinæ et Virginiæ. Pursh. $\beta$ in horto Chelseano colitur. 4 . (v. v. c.)

Planta cæspitosa. Folia numerosa, erecta, lanceolata, acuta, erosè runcinato-serrata, basi integra in petiolum angustata, utrinque glabra, lucida. Scapi stricti, pedales v. sesquipedales, teretes, pilis viscidis patentibus undique tecti. Panicula divaricata, ramosa, laxiflora, pyramidata. Pedicelli elongati, filiformes, uniflori, calycesque pilis glanduliferis crebrè instructi. Lacinice calycis ovatæ, obtusæ, obscurè uninerves. Petala oblongo-ovalia, alba, unguiculata, 3-nervia : nervis simplicibus strictis, puncto flavo solitario ad basin instructa. Filamenta alba. $A n-$ therc aureæ.

\section{Sectio 3.}

$\S$ Foliis lobatis.

15. S. rotundifolia, foliis reniformibus inæqualitèr grossèque dentatis; caulinis petiolatis, petalis lanceołatis acutis.

S. rotundifolia. Linn.Sp. Pl.576. Mill. Dict.n.5. ejusd. Icon. t. 141. (media.) Scop. Carn. ii. n. 488. Willd. Sp. Pl. ii. p. 651. Curt. Magaz. 424. (bona.) Lapeyr. Py- 
Mr. D. Don's Monograph of the Genus Saxifraga. 361

ren.Saxif. p. 50. t. 26. (optima.) Lam. Encycl.vi. p. 688. Persoon Synop. i. p. 489. Hort. Kerv. ed. 2. 3. p. 69. Sternb. Saxif. p. 17.

$S$. foliis caulinis reniformibus dentatis petiolatis, caule paniculato. Gmel. Sib. iv. p. 162.

S. foliis reniformibus acutè serratis hirsutis petiolatis, caule ramoso. Hall. Helv. n. 975.

S. foliis reniformibus acutè crenatis, caule ramoso folioso. Hort. Cliff. 167. Roy. Lugdb. 453.

Sanicula montana rotundifolia major. Bauh. Pin. 243.

Sanicula alpina. Cam. Evit. 764. Gesn. Fasc. xix. t. 10. f. 25.

$\beta$. repanda, major et robustior, foliis latioribus.

S. repanda. Sternb. loc. cit. p. 17. t. 5.

S. rotundifolia. Marsch. a Bieberst. Fl. Taurico-Cauc. i. p. 315. Steven de Saxif. Cauc. in Mem. Mosq. iv. p. 76.

Habitat a in Austriæ, Helvetiæ et Sibiriæ alpibus; $\beta$ in alpestribus Caucasicis. 4 . (v. v. $\alpha$ et $\beta$ c.)

Planta densè cæspitosa. Radix fibrosa. Caules erecti, rigidi, flexuosi, foliosi, palmares pedalesve. Folia radicalia reniformia, longè petiolata, inæqualitèr grossèque dentato-serrata ; suprà lucida, pilis setosis adspersa ; subtùs pubescentia; caulina petiolata radicalibus conformia nisi magis inæqualitèr et profundiùs dentata : petioli semiteretes, undique villosi. Panicula divaricata, laxa. Bractea lineares longitudine pedicellorum. Pedicelli calycesque pilis glandulosis tecti. Calyx patens; lacinix oblongæ, obtusiusculæ, obsoletè 3-nerves. Petala lanceolata, acuta, alba, punctis minutis coccineis adspersa, 3-nervia : nervis simplicibus. Filamenta alba. Anthera pallidæ.

OBs. 
Oвs. Var. $\beta$ ex mente Clariss. Steveni ab rotundifoliâ non differt, tamen mihi in hortis semper in omnibus partibus, præter flores, majorem et robustiorem apparuit.

16. S. hybrida, foliis radicalibus petiolatis cuneato-rotundatis crenatis; caulinis minutis integris, caule paniculato. Sternb. Saxif. p. 17. t. 8. f. 3.

Habitat in alpibus Pyrenaicis. 4 .

Hanc plantam nec vivam neque siccam vidi. Præcedenti valdè affinis videtur, at modó figura Sternbergii fidenda: abundè discrepat staturâ minori et graciliori ; foliis basi acutis nec cordatis ; caulinisque minutis, integris, subsessilibus.

17. S. granulata, foliis radicalibus reniformibus inciso-lobatis ; caulinis petiolatis, laciniis calycinis lanceolatis obtusis, petalis spathulatis.

S. granulata. Linn. Sp. Pl. 576. Huds: Angl. 182. Flor. Dan. 514. With. Brit. 405. Willd. Sp. Pl. ii. p. 651. Lam. Illust. t. 372. f. 1. (mala.) ejusd. Flor. Franc. iii. p. 532. Ibid. Encycl. vi. p. 689. Engl. Bot. t. 500. (bona.) Smith Brit. ii. p. 453. Lapeyr. Pyren. Saxif. p. 52. Hort. Kew. ed. 23. p.69. Sternb. Saxif. p. 16.

S. foliis caulinis reniformibus obtusè lobatis, caule ramoso, radice granulatâ. Hort. Cliff. 167. Fl. Suec. 350.

S. foliis radicalibus reniformibus obtusè dentatis, caulinis palmatis. Hall. Helv. n. 976.

S. rotundifolia alba. Bauh. Pin. 309.

S. alba. Dod. Pempt. 316.

Sedum rotundifolium erectum, radice granulatâ. Moris. Hist. iii. p. 474. § 11. t. 9. f. 23. (bona.)

$\beta$. Horibus plenis. 
Mr. D. Don's Monograph of the Genus Saxifraga. 363

\%. multicaulis, caulibus pluribus brevioribus, foliis circinatoincisis.

S. granulata, $\beta$. multicaulis. Lapeyr. loc. cit. t. 27.

Habitat $\alpha$ in apricis et nemoribus Europæ borealis et meridionalis, ubique obvia ; $\beta$ in hortis colitur ; $\gamma$ in alpibus Pyrenaicis. Lapeyrouse. 4 . (v.v.sp.)

Radix granulata. Caules erecti, 4-6-unciales pedalesve, ramosi, foliosi, multiflori, villis mollibus viscidis crebrè obsiti. Folia radicalia petiolata, reniformia, inciso-lobata, utrinque hirsuta : petiolis villosis ; caulina petiolata, palmata. Bractece lanceolatæ, obtusæ. Pedicelli elongati, uniflori, calycesque pube glutinosâ instructi. Flores magni, campanulati, candidi. Lacinice calycince lanceolatæ, obtusæ, 3-nerves. Petala spathulata, triplinervia : nervis ramosis flexuosis.

18. S. bulbifera, foliis radicalibus reniformibus petiolatis crenatis; caulinis sessilibus inciso-lobatis, laciniis calycinis triangulari-ovatis acutis, caule ramoso multifloro.

S. bulbifera. Linn. Sp. Pl. 577. Willd. Sp. Pl. ii. p. 651. (exclus. synon. Gunn. Norv. et Flor. Dan.) Lam. Encycl. vi. p. 690. (exclus. synon. Gunn. Norv. et Flor. Dan.) Persoon Synop. i. p. 489. Lam. et Decand. Fl. Franc. iv. p. 369. Sternb. Saxif. p. 15. t. 12. f. 1. (bona.)

Sedum rotundifolium erectum soboliferum. Moris. Hist. iii. p. 474. \$12. t. 9. f. 24. (optima.)

Sedum ad folia bulbos gerens. Bauh. Pin. 309. Col. Ecplir. i. p. 318. t. 317. (bona.)

Habitat in Europæ australis pratis saxosis et umbrosis, in Hispaniâ (Pavon). u. (v. s. in Herb Banks. et Lamb.) 
Radix granulata. Caules erecti, palmares vedales, teretes, ramosi, multiflori, pilis viscidis instructi. Folia radicalia reniformia, obtusè crenata, utrinque pilosa, longè petiolata: petiolis villis viscidis confertè tectis; caulina omnia sessilia, inferiora inciso-dentata, superiora ovato-oblonga, integra, in axillis bulbos gerentia. Pedunculi elongati, uniflori calycesque pube glutinosâ tecti. Flores candidi præcedente minores. Lacinia calycis triangulari-ovatæ, acutæ. Petala spathulata, triplinervia: nervis flexuosis ramosissimis.

This is undoubtedly the true Linnæan S. bulbifera, which is confined to the southern parts of Europe. It is therefore remarkable, that so accurate an observer as Wahlenberg should have described it as a Lapland plant, nearly related to cernua, if really specifically distinct from that species, which indeed I am rather inclined to doubt. The figure of Flora Danica, quoted by Willdenow and others, belongs evidently to $S$. cernua.

19. S. cernua, foliis glabris petiolatis ; radicalibus reniformibus inciso-lobatis ; caulinis palmatis, laciniis calycinis ovatis obtusis, petalis spathulatis emarginatis, caule simplicissimo subunifloro.

S. cernua. Linn. Sp. Pl. 577. Flor. Dan. t. 22. (mala.) Gunn. Norv. n. 528. t. 9. f.2. (bona.) Willd. Sp. Pl. ii. p. 552. With. Brit. 405. Lapeyr. Pyren. Saxif. p. 52. Lam. Encycl. vi. p. 690. Smith Brit. ii. p. 453. Engl. Bot. t.664. (bona.) Persoon Synop. i. p. 489. Wahlenb. Lapp. 116. Sternb. Saxif. p. 18. t. 12. f. 2.

S. foliis palmatis, caule simplici unifioro. Linn. Fl. Lapp. 172 t.2. f. 4. (bona.) Hort. Cliff. 167. Fl. Suec. 351. 373.

B. caule 
Mr. D. Don's Monograph of the Genus Saxifraga. 365

$\beta$. caule subramoso paucifloro.

Fl. Dan. t. 390. S. bulbifera. Wahlenb. Lapp. 116?

Habitat in summis alpibus Lapponicis, Pyrenaic., Helvetic., Scotic.; $\beta$ in Lapponiæ? et Norvegiæ alpibus, nec non in Sibiriâ (Pallas). u. (v. v. $\alpha ; \beta$ s. in Herb. Pallas. nunc Lamb.)

Radix squamata; squamæ carnosæ e basibus petiolor. foliorum primordialium enatæ. Caulis erectus, 4-6-uncialis, simplicissimus, flexuosus, foliosus, læviusculus, pi lis raris brevibus adspersus. Folia radicalia petiolata, reniformia, glabra, inciso-lobata: lobis ovatis acutis; caulina petiolata, glabra ; inferiora palmata; superiora indivisa, ovata, ad axillas bulbis parvis aggregatis instructa. Flos solitarius, terminalis, magnus, campanulatus, candidus, nutans. Pedicellus brevis, pilis brevibus viscidis, ut et calyx, levitèr adspersus. Lacinic calycince ovatæ, obtusæ. Petala spathulata, triplinervia: nervis flexuosis ramosissimis.

20. S. Sibirica, foliis hirsutis petiolatis; radicalibus reniformibus palmatis; caulinis digitatis, pedicellis elongatis remotis, petalis obovatis: nervis simplicibus, caule filiformi ramoso.

S. Sibirica. Linn. Sp. Pl. 577. Willd. Sp. Pl. ii. p. 653 . Lam. Encycl. vi. p. $693 . \quad$ Persoon Synop. i. p. 489. Sternb. Saxif. p. 23. t. 25.

S. foliis reniformibus acutis digitatis, caule ramoso folioso. Gmel. Sib. iv. p. 162. n. 74 .

S. granulata. Steven. de Saxif. Cauc. in Mem. Mosq. iv. p. 77. n.3? (exclus. synon.) Marsch. Fl. Taur. Cauc. i. p. 315 ? (exclus. synon.)

S. grandiflora. Sternb. Saxif. t. 12. f. 4? 
S. cymbalaria. Marsch. d̀ Bieb. Suppl. Fl.Taur.Cauc. p.292? (exclus. synon. Willd.)

Habitat in Sibiriâ (Gmelin, Pallas), in alpium Caucasicarum saxosis prieruptis? Steven, Marschall ì Bieberstein. 4. (v. s. in Herb. Pallas. nunc Lamb.)

Radis squamata, fibras numerosas emittens, rudimentis foliorum emarcidorum supernè instructa. Caules filiformes, graciles, 4-5-pollicares, ramosi, adscendentes, foliosi, villis viscidis levitèr instructi. Folia radicalia longè petiolata reniformia, lobato-palmata: Iobis ovatis acutis, utrinque hirsuta; caulina digitata, inferiora petiolata, superiora sessilia. Petioli graciles, omnes villosi. Pedicelli remoti, elongati, capillares, uniflori, calycesque levitèr pubescentes. Lacinice calycince ovatæ, obtusiusculæ. Petala obovata, alba, triplinervia: nervis rectiusculis, simplicibus.

The above description was taken from specimens in the Pallasian Herbarium, in the possession of A. B. Lambert, Esq. Sternb. $t$. 25. corresponds exactly with these specimens; but the leaves of the latter are more deeply lobed than represented in the figure. The $S$. grandiflora Sternb. t. 12. f. 4., which is the granulata of Steven, and the S. cymbalaria of Marschall's Flora Taurica, I am inclined to think belongs also to this plant; but having never seen specimens of it, I am unable to decide. The roots of this section, whether scaly or fibrous, scarcely afford any specific character, as they have all a tendency to become scaly.

21. S. nudicaulis, foliis reniformibus palmatis glabris, floribus paniculatis, laciniis calycinis acutis, scapo nudo.

Habitat ad oras occidentales Americæ borealis. David Nelson. 4. (v. s. in Herb. Banks.) 
Mr. D. Don's Monograph of the Genus Saxifraga. 367

Radix fibrosa. Scapi erecti, nudi, 4-5-pollicares, teretes, glabriusculi. Folia radicalia reniformia, petiolata petiolis glabris, lobato-digitata, utrinque glabra: lobis ovatis mucronatis. Flores paniculati, magnitudine S. rivularis, albi. Pedicelli calycesque pilis glandulosis levitèr obsiti. Lacinice calycince triangulari-ovatæ, acutæ. Petala parva, obovata, calyce longiora, triplinervia: nervis rectiusculis, simplicibus. Filamenta gracilia stylos æquantia.

22. S. bracteata, foliis radicalibus caulinisque longè petiolatis reniformibus inciso-lobatis, floribus congesto-corymbosis bracteatis.

Habitat in Sibiriâ orientali. D. Merk. 4. (v. s. in Herb. Pallas. nunc Lamb.)

Planta cæspitosa. Radix fibrosa. Caules adscendentes, flexuosi, foliosi, teretes, ramosi, villis viscidis tecti, 3-5unciales. Folia radicalia reniformia, lobato-crenata: lobis obtusis latis, utrinque nudiuscula, longè petiolata; caulina longè petiolata inciso-lobata. Petioli basi dilatati villis longis tecti. Flores congesto-corymbosi, bracteati, albi, illis S. cernuce paulò majores. Bractece numerosæe, latissimæ, indivisæ. Pedicelli calycesque pilis glandulosis suppediti. Lacinice calycine latè ovatæ, obtusæ,

- obscurè trinerves. Petala obovata, alba, calyce paulo longiora, triplinervia : nervis simplicibus, rectiusculis.

23. S. rivubaris, caule debili simplicissimo, foliis reniformibus longè petiolatis glabris, floribus subternis sessilibus bracteatis.

S. rivularis. Linn. Sp. Pl. 577. Fl. Lapp. n.174. t.2.f.7. (bona.) Fl.Dan. 118. Gunn. Norv. n.479. Gmel.Sib. iv. p. 170. Willd. Sp. Pl. ii. p.652. Lam. Encycl, vi. p.690. 
Smith Brit. ii. p. 454. Engl. Bot. t. 2275. (optima.) Wahlenb. Lapp. p.117. Pursh Fl. Amer. Septent. i. p.312. Sternb. Saxif. p. 19. t. 12. f.3.

Habitat in Europæ summis alpibus, nempè in Lapponiâ (Linn., Wahlenberg), in Norvegiâ (Gunner), in Sibiriâ (Gmelin), in cacumine alpis Ben Lawers dicti Scotiæ (Dickson, G.Don). ๑. (v. v.)

Planta annua, lætè virens, debilis. Radix fibrosa. Caules adscendentes, gracillimi, bipollicares, oligophylli, supernè villis viscidis instructi. Folia omnia reniformia, longè petiolata, utrinque petiolisque glabra, 5-6-lobata: lobis ovato-rotundatis obtusissimis. Flores terminales, subterni, sessiles, parvi, albi, bracteati. Bractece subovatæ, obtusæ, trifidæ vel indivisæ, sessiles, ad basin florum insidentes et illos æquantes. Lacinia calycince ovatæ, obtusissimæ, rectæ, conniventes. Petala ovalia, obtusa, triplinervia, subdistantia, calycem parùm superantia. Stamina petalis breviora.

24. S. nutans, caule unifolio, racemo nutante paucifloro, laciniis calycinis lanceolatis acutis.

Habitat ad oras occidentales Americæ septentrionalis insulam Unalaska dictam. David Nelson. 4. (v. s. in Herb. Banks.)

Planta cæspitosa. Radix fibrosa, rudimentis foliorum emarcidorum suprà tecta. Caules erecti, 3-4-unciales, teretes, parcè pubescentes, basi decumbentes, medio geniculati, folio unico instructi. Folia radicalia longè petiolata, reniformia, grossè inciso-dentata, utrinque pilis rigidis brevibus adspersa : petiolis hirsutis, latissimè membranaceo-dilatatis; caulinum solitarium, petiolatum, conforme. 
Mr. D. Dow's Monograph of the Genus Saxifraga. $\quad 369$

forme. Flores racemosi, candidi, magnitudine S.bulbiferce. Racemus nutans, 4-5-florus. Pedicelli breves calycesque pilis glanduliferis confertè obsiti. Lacinice calycina lanceolatæ, acutæ, sub oculis armatis trinerves. Petala obovata, triplinervia : nervis flexuosis, ramosissimis.

S. orientalis, foliis radicalibus rotundatis; caulinis cuneatis acutè grossèque dentatis, laciniis calycinis ovatis acutis, petalis ovalibus : nervis simplicibus.

S. orientalis. Jacq. Obs. ii. p.9.t.34. (optima.) Willd.Sp. Pl. ii. p. 658. (exclus. synon. Tournef:) Lam. Enoycl. vi. p. 700. Persoon Synop. i. p. 489. Steven de Saxif.Cauc. in Mem. Mosq. iv. p. 78.

S. reticulata. Sternb. Saxif. p. 21. t. 13. S. paradoxa. ejusd. p.22.t. 14?

Habitat in Oriente. $\odot$. (v. s. in Herb. Banks. et Lamb.)

Planta annua. Radix gracilis, fibrosa. Caules erectiusculi, ramosi, flexuosi, læviusculi, basi decumbentes, foliosi. Folia radicalia rotundata, longè petiolata, basi nunquam: cordata, grossè æqualitèr dentata: dentibus magnis ovatis, acutis, utrinque glabra, lucida, venis nigrescentibus reticulata; caulina cuneata, petiolata, basi acuta, apice acutè 5-loba; floralia subopposita, lanceolata, acuta, integerrima, vix petiolata. Petioli graciles, filiformes, parcè glandulosi. Pedunculi longissimi, capillares, uniflori, calycesque pilis brevissimis glandulosis levitèr adspersi. Lacinice calycina brevè ovatæ, acutæ, obscurè trinerves. Petala ovalia, sessilia, aurea, calyce duplo longiora, triplinervia : nervis simplicibus rectiusculis.

26. S. cym- 
26. S. cymbalaria, foliis inferioribus reniformibus longissimè petiolatis obtusissimè 5-lobis ; summis trilobis indivisisve, laciniis calycinis oblongis obtusis, petalis ovatis acutis : nervis ramosis.

S. cymbalaria. Linn. Sp. Pl. 579. Smith Prod. Fl. Grac. i. p. 277. Fl. Grec. Icon. ined. 378.

S. hederacea. Marsch. d Bieberst. Fl. Taur. Cauc. i. p. 317. (exclus. synon.)

S. exigua foliis cymbalariæ. Buxb. Cent. ii. p. 40. t. 45. f. 2. (mala.)

Geum orientale rotundifolium supinum;flore aureo. Tournef. Cor. 18.

Habitat in Oriente (Tournefort, Buxbaum), in Parnasso, Delphi, aliisque Gracia montibus (Sibthorp). ๑. (v.s. in Herb. Banks.)

Planta annua, debilis. Radix tenuissimè fibrosa. Caules numerosi, foliosi, gracillimi, ramosissimi, flexuosi, flaccidi, pilis glanduliferis lævissimè adspersi. Folia inferiora longissimè petiolata (petiolis capillaribus), reniformia, subpeltata, leviter 5-loba: lobis rotundatis, utrinque glaberrima, suprà nitida et venis tenuissimis reticulata ; summa brevè petiolata, triloba v. indivisa. Pedicelli longissimi, capillares, oppositifolii, uniflori, calycesque læviusculi. Flores parvi, aurei. Lacinice calycis oblongæ, obtusæ, reflexæ, conspicuè trinerves. $\mathrm{Pe}$ tala ovata, acuta, trinervia (nervis ramosis flexuosis), basi rotundata, brevissimè unguiculata, bipunctata.

97. S. hederacea, foliis inferioribus acute trilobis; summis ovatis integrıs, laciniis calycinis ovatis acutis, petalis subrotundis unguiculatis.

S. hede- 
Mr. D. Don's Monograph of the Genus Saxifraga. 371

S. hederacea. Linn. Sp. Pl.579. Willd. Sp. Pl. ii. p. 658. Persoon Synop. i. p. 489. Smith Prodr. Fl. Grec. i. p. 278. Fl. Grec. Icon. ined. 379.

S. cretica annua minima, hederaceo folio. Tournef. Cor. 18. Habitat in Cretâ (Tournefort), in rupibus humidis umbrosis Cretæe et Cypri (Sibthorp). ๑. (v. s. in Herb. Banks.)

Planta exigua, annua. Radix capillaceo-fibrosa. Caules plures, filiformes, flaccidi, ramosissimi, pilis brevissimis glanduliferis levitèr adspersi. Folia inferiora subovata, breviùs petiolata, triloba: lobis brevè ovatis, acutis, utrinque glaberrima, nitida, venis tenuissimis reticulata ; summa integra, ovata, acuta. Pedicelli elongati, capillares, uniflori, parcè glandulosi. Flores parvi, albi. Lacinice calycina erectæ, brevè ovatæ, acutæ, trinerves. Petala subrotunda, unguiculata, trinervia: nervis ramosis, flexuosis. Capsula semi-infera.

Much confusion has hitherto prevailed respecting the three preceding species. Sir James Edward Smith appears to be the only botanist who has examined, or even understood, the S. cymbalaria and hederacea of Linnæus; the characters of these he has very considerably amended in his admirable Prodromus Flor Grece. The S. orientalis of Jacquin and Willdenow, given by him as a synonym of $S$. cymbalaria, is a very distinct plant. All three have a general affinity together; but their characters are abundantly distinct. The above descriptions of S. cymbalaria and hederacea were taken from authentic specimens preserved in the Banksian Herbarium, and were collected by the late Dr. Sibthorp during his travels in Gréece*.

* Specimens of Saxifraga hederacea, gathered lately in Crete by Dr. Sieber of Prague, are now in the Lambertian Herbarium.

§. Foliis 
§. Foliis indivisis.

28. S. Hirculus, folins lanceolatis obtusis nudis, laciniis calycinis lanceolatis obtusis, petalis spathulatis multinervibus.

S. Hirculus. Linn. Sp. Pl.576. Fl. Dan. t.200. Huds. Angl. 181. Hoffm. Germ. 144. Roth. Germ. i. 184. ii. 468. With. Brit. 404. Willd. Sp. Pl.ii. p.649. Lam. Encycl. vi. p. 686. Smith Brit. ii. p. 451. Engl. Bot. t. 1009. (optima.) Persoon Synop. i. p. 489. Sternb. Saxif. p. 29.

S. flava. Lam. Fl. Franc. iii. p. 529.

S. foliis caulinis lanceolatis alternis nudis inermibus, caule erecto. Linn. Suec. ii. n. 370. Gmelin Sib. iv. p. 165. t. 65. f. 3. (bona.)

S. petalis latissimis luteis lineatis. Hall. Helv. 399. $t .8$.

Sedum palustre nardi celticæ foliis, flore luteo. Moris. Hist. iii. p. 477. \$ 12. t. 8. f. 5 .

Sedum angustifolium autumnale, flore luteo guttato. Ibid. f. 6 .

Geum angustifolium autumnale, flore luteo guttato. Dill. in Raii Synop. 355.

Chamæcistus frisicus, foliis nardi celticæ. Bauh. Pin. 466.

Chamæcistus frisicus. Ger. Em. 1284.

$\beta$. caule pedali multifloro, pedunculis villosissimis.

Habitat a in Suecia, Helvetiæ, Lapponiæ, Sibiriæ, Germaniæ et Angliæ paludibus turfosis ; $\beta$ in Sibiriâ orientali $(M e r k)$. $\psi(\alpha$ v. v. c. $\beta$ v. $s$ in Herb. Pallas. nunc Lamb.)

Planta cæspitosa, pulchra, lætè-virens, glabra, surculosa. Radix fibris longis nigris composita. Surculi numerosi, foliosi, procumbentes, glaberrimi. Caules erecti, 4-6unciales rarissimè pedales, foliosi, glabri, pauci rarius multiflori. 
Mr. D. Don's Monograph of the Genus Saxifraga. 373

multiflori. Folia alterna, lanceolata, obtusa, integerrima, utrinque glabra, basi in petiolum angustata. Pedunculi longi, stricti, uniflori, villis fuscis glutinosis confertè tecti. Flores magni, speciosi, aurei. Lacinice calycina lanceolatæ, obtusæ, ciliatæ, conspicuè 5-nerves : nervis simplicibus, marginalibus parallelis, approximatis, medio a cæteris remoto. Petala spathulata, aurea, multinervia, apice retusa, punctis croceis instructa, basi brevissimè unguiculata, intus ad basin lacunâ oblongâ nectariferâ ex rimâ bivalvi apicibus acutis munita :. nervis rectis, simplicibus, basi junctis. Filamenta lutea. Antherce croceæ.

29. S. myosotifolia, flagellis nullis, foliis ovatis acutis muticis setosis, caule nudiusculo trifloro, laciniis calycinis latè ovatis, petalis subrotundis unguiculatis.

Habitat in Sibiriâ. Pallas. 4. (v. s. in Herb. Pallas. nunc Lamb.)

Planta patens, cæspitosa. Radix lignosa fibris numerosis instructa. Surculi brevissimi, erecti, conferti. Caules subnudi, erecti, biunciales, fragiles, 2-3-flori, pilis setosis undique obsiti. Folia conferta, patentia, ovata, acuta, mutica, pilis setosis ad marginem ciliata et utrinque adspersa, basi in petiolum brevem angustata. $P e-$ dunculi elongati, uniflori, calycesque pilis glanduliferis crebrè tecti. Flores ochroleuci. Lacinia calycis latèovatæ, acutæ, muticæ. Petala subrotunda, unguiculata, 5-nervia; nervis simplicibus. Filamenta compressa, lutescentia, longitudine petalorum. Antherce flavæ. Styli breves, crassi.

30. S. flagellaris, flagellis axillaribus capillaribus, foliis obovatospathulatis aristatis cartilagineo-ciliatis, laciniis calycivot. XIII. $3 \mathrm{c}$ nis 
374. Mr. D. Don's Monograph of the Genus Saxifraga.

nis lanceolatis, petalis obovatis sessilibus, caule folioso 1-3-floro.

S. flagellaris. Sternb. Saxif. p. 25. t.6. (media.) Steven de Saxif. Cauc. in Mem. Mosq. iv. p. 79. Marsch. à Bieberst. Suppl. Fl. Taur. Cauc. p. 291.

S. setigera. Pursh Amer. Septent. i. p. 312.

S. aspera. Marsch. d Bieberst. Fl. Taur. Cauc. i. p. 314. (exclus. synon.)

Habitat in alpibus Caucasicis (Adams), ad Caput Newnham dictum ad oras occidentales Americæ borealis (David Nelson), in Insulâ Melville dictâ in sinu maris Grœnlandici, Baffin's Bay Anglicè dicto (Sabine, Fisher). 4. (v. s.)

Planta cæspitosa, flagellifera. Flagelli e axillis foliorum enati, longissimi, capillares, nudi, patentes, ad apices comâ parvâ foliatâ instructi. Caules erecti, sịmplicissimi, sesqui- bi-pollicaresve, foliosi, 1-3-flori, pilis glandulosis instructi. Folia radicalia, conferta, patentia, impetiolata, spathulata, utrinque nuda, margine spinulis cartilagineis ciliata, apice calloso-aristata; caulina alterna, obovata. Pedicelli brevissimi, uniflori, calycesque pube glutinosâ tecti. Flores aurei magnitudine S. Hirculi. Lacinice calycince lanceolatæ, acutæ, extus setosæ. Petala sessilia, obovata, multinervia : nervis parallelis apice dichotomis.

This singular species was first discovered by Mr. David Nelson, in Captain Cook's third voyage, at Cape Newnham on the north-west coast of America, from whence the specimens in the Banksian Herbarium were brought. - It has since been found on the Caucasian alps; and in the late polar expedition it has been abserved in great plenty on the newly-discovered island named

Melville 
Mr. D. Don's Monograph of the Genus Saxifraga. 375

Melville Island. For specimens from thence I am indebted to the kindness of Joseph Sabine, Esq. Pursh is wrong in stating the flowers to be small and white. The S.myosotifolia, which agrees with it in general habit, has numerous erect, short and leafy shoots. Leaves ovate, somewhat acute, awnless, ciliated, and slightly clothed on both sides with stiff bristly hairs. The stem is almost leafless. Peduncles long, erect. The lacinice of the calyx short, triangular-ovate. Petals round, cream-coloured, furnished with a claw, and five straight, simple nerves. The flowers are smaller, and the plant is wholly destitute of the naked filiform sarmenta so remarkable in S. flagellaris.

31. S. aizoides, foliis linearibus mucronatis glabris spinulosociliatis, laciniis calycinis latè ovatis, petalis lanceolatooblongis trinervibus.

S. aizoides. Linn. Sp. Pl. 576. With. Brit. 404. Smith Brit. ii. p. 452. Engl. Bot. t. 39. (optima.) Lam. Encycl. vi. p. 687. Sternb. Saxif. p. 25. t. 8. f. 1. Lam. et Decand. Fl. Franc. iv. p. 377. Wahlenb. Lapp. p. 115. ejusd. Carpath. 117.

S. autumnalis. Linn. Sp. Pl. 575. Huds. Angl. 180. Mill. Dict. n. 10. Fl. Dan. t. 72. Lightf. Scot. i. p. 222. Scop. Carn. i. 293. t. 14. Willd. Sp. Pl. ii. p. 650.

S. foliis linearibus sparsis glabris. Fl. Suec. 357.371.

S. foliis subulatis sparsis. Fl. Lapp. 178.

S. foliorum margine ciliari, floribus luteis maculosis. Hall. Helv. 399.

S. angustifolia autumnalis, flore luteo guttato, foliis florum magis acuminatis. Breyn. Cent. 106, t. 48.

S. alpina angustifolia, flore luteo guttato. Raii Synop. 353. Sedum alpinum, flore pallido. Bauh. Pin. 284. Moris. Hist. iii. p. 4 77. s. 12. t. 6. f. 3. 
Sedum minus rv. Clus. Hist. ii. p. 60.

Sedum alpinum primum. Clus. Pann. 485. Ger. Em. 516. Habitat in alpium Helvetiæ, Lapponiæ, Styriæ, Angliæ et Scotiæ rupibus et petrosis humidis copiosissimè. 4. (v. v. sp.)

Planta virens, in cæspitibus planis vegetans. Radix fibrosa. Surculi numerosi, procumbentes, densè foliosi. Caules erecti 2- rariùs 3-pollicares, foliosi, teretes, multiflori, pube viscidâ tecti. Folia alterna, linearia, patentia, utrinque glaberrima, lucida, apice cartilagineo-mucronata margine spinuloso-ciliata. Pedunculi breves, uniflori, pube glutinosâ vestiti, in æstivatione decurvati. Flores subracemosi, flavi. Lacinice calycince latè ovatæ, obtusæ, margine membranâ tenui sæpiùs ad apicem parùm laceratâ cinctæ. Petala patentia, lanceolato-oblonga, calycem superantia, punctis croceis instructa, triplinervia : nervis simplicibus rectis.

I have followed Wahlenberg in uniting the S. aizoides and autumnalis of Linnæus. The Lapland and Swedish plant differs in no respect from ours, and the leaves are but rarely naked at their margins. We sometimes meet however with such in seedling plants and others before the flowering season.

32. S. bronchialis, foliis confertis lineari-subulatis triquetris mucronatis spinulis cartilagineis ciliatis, laciniis calycinis ovatis, petalis oblongis, caule oligophyllo multifloro.

S. bronchialis. Linn. Sp. Pl.572. Willd.Sp. Pl. ii. p.644. Lam. Encycl. vi. p. 679.

S. foliis imbricatis subulatis ciliatis spinosis, caule subnudo multifloro. Gmel. Sib. iv. p. 164. t. 65. f. 2. (bona.)

ß. lenensis, 
$\beta$. lenensis, surculis brevioribus, foliis longioribus patentibus longè mucronatis, paniculâ majore patente fastigiatâ.

Habitat a in Sibiriâ (Gmelin), in Sibiriâ orientali (Merk), ad oras occidentales Americæ borealis (Nelson); $\beta$ ad flu-

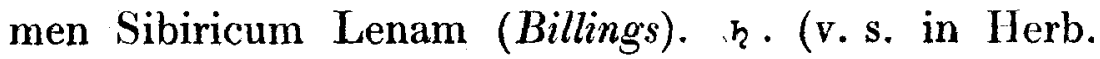
Banks. et Lamb.)

Planta suffrutescens. Radix lignosa, ramosa, fibriș pluribus longis instructa. Surculi plures, erecti, lignosi, ramosi, crebrè foliosi, basi rudimentis foliorum emarcidorum tecti. Caules digitales rariùs palmares, flexuosi, rigidi, fragiles, oligophylli, glabri. Folia crebra, imbricata, lineari-subulata, triquetra, rigida, glabra, margine spinulis cartilagineis albis ciliata, apice mucrone calloso instructa; caulina pauca, parva, adpressa, linearia, longe-mucronata versus apicem caulis sensìm minora. Panicula parva, multiflora. Pedicelli dichotomi calycesque levissimè glandulosi. Flores parvi, ochroleuci. Lacinice calycis breves, latè ovatæ, mucronulatæ Petala oblonga, sessilia, punctis numerosis minutis croceis instructa, conspicue triplinervia: nervis simplicibus. Filamenta gracilia, lutea. Anthera crocex.

33. S. tenella, foliis confertis lineari-subulatis planis pungentibus ciliatis, caule gracili oligophyllo paucifloro, laciniis calycinis lineari-lanceolatis, petalis obovatis.

S. tenella. Wulfen in Jacq. Collect. iii. p. 144. t. 17. (bona.) Willd. Sp. Pl. ii. p.643. Lam. Encycl. vi. p.678. Persoon Synop. i. p. 488. Sternb. Sarif. p. 30.

S. nitida. ejust. t. 10. f. 4 ?

Habitat in Carinthiæ alpibus. Wulfen. 4.

Planta suffrutescens? cæspitosa. Radix fibrosa. Surculi numerosi, 
378 Mr. D. Don's Monograph of the Genus Saxifraga.

numerosi, basi decumbentes et rudimentis foliorum emarcidorum tecti. Caules plures, erecti, sesqui-v. bi-unciales, gracillimi, læves, oligophylli, pauciflori. Folia conferta, imbricata, lineari-subulata, saturatè viridia, suprà plana, subtùs carinata, utrinque glabra, nitida, apice spinulâ corneâ aciculari terminata, margine ciliata; caulina adperssa, sparsè remota, parva, plana, aristnta. Pedunculi terni, longi, capillares, uniflori, ferè in racemulum dispositi, calycesque pilis brevissimis glanduliferis levitèr suppediti. Lacinia calycis lineari-lanceolatæ, aristatæ. Petala obovata, alba, immaculata, calycem superantia, obscurè tri" plinervia. Filamenta gracilia, alba. Antherc flavæ.

Præcedenti affinis ; sed triplò minor et gracilior, atque notis indicatis diversa. S. nitida Clariss. Sternbergi vix ullo dubio huic pertinet, figura ejus quæ ad siccam facta est omnino mala, et hìnc colorem luteum floribus attribuet.

34. S. brachypoda, foliis linearibus planis pungentibus trinervibus margine spinulosis, flore terminali solitario brevèpedunculato, petalis obovatis.

Habitat in Nepaliæ alpibus. Wallich. 4. (v. s. in Herb. Lamb.)

Radix fibrosa. Caules plures, adscendentes, simplicissimi, foliosi, pilis setosis undique tecti. Folia alterna, linearia, plana, glabra, trinervia, suprà nitida, subtùs glauca, apice spinulâ aciculari terminata, margine spinulis armata, basi subamplexicaulia. Flos aureus, terminalis, solitarius, brevè-pedunculatus, magnitudine S. asperce. Calyx et pedunculus pilis setosis patentibus glanduliferis confertè obsiti : laciniæ ovatæ, mucronatæ, conspicuè trinerves, margine 
Mr. D. Don's Monograph of the Genus Saxifraga. $\quad 379$ margine spinulis ciliatæ. Petala obovata, calyce longiora, triplinervia : nervis simplicibus rectis. Stamina pistillis vix longiora; filamenta flava; anthere croceæ.

35. S. juniperina, caulibus suffruticosis proliferis, foliis interruptè confertissimis subulato-triquetris rigidis pungentibus, floribus spicatis, petalis obovatis.

S. juniperina. Marsch. à Bieberst. Fl. Taur. Caue. i. p.314. Ibid. Supplem. p. 291. Sternb. Saxif. p.31.t.10. (media.) Steven de Saxif. Cauc. in Mem. Mosq. iv. p. 79.

Habitut in alpibus Caucasicis (Pallas), in Caucasi rupium fissuris, circa portas Caucasicas et ad radices alpis Kaischaur frequens (Marschall a Bieberstein). $\psi$. (v. s. in Herb. Pallas. nunc Lamb.)

Planta suffrutescens. Radix lignosa fibris numerosis crassiusculis instructa. Caules numerosi, digitales, erecti, rigidissimi, confertè foliosi, apice prolifero-ramosi, basi rudimentis foliorum emarcidorum vestiti. Folia interruptè confertissima, subulata, subtriquetra, rigida, glabra, suprà planiuscula, bisulcata, subtùs carinâ planiusculâ, apice spinâ aciculari instructa, basi tenuissimè serrulata. Spicc terminalis, brevis, brevè-pedunculata, 6-10-flora. Pedicelli recti, brevissimi, pube glutinosâ densè obsiti. Bractece lineares, obtusæ, glandulis ciliatæ. Flores lutei magnitudine S. asperce. Lacinice calycis ovato-oblongæ, mucronatæ, trinerves, ciliatæ. Petala obovata, triplinervia, calyce longiora.

36. S. aspera, foliis planis lineari-lanceolatis pungentibus spinulis ciliatis, petalis obovatis : nervis ramosis, caule ramoso.

S. aspera. Linn. Sp. Pl: 575. Ger. Prov. 423. Jacq. Aust. 
Mr. D. Don's Monograph of the Gemus Sarifraga.

Aust, v. p. 44. t. app. 31. (bona.) Mill. Dict. n. 14. Willd. Sp. Pl. ii. p. 649. Lapeyr. Pyren. Saxif. p. 36. Lam. vi. p. 678. Persoon Synop. i. p. 489 . Sternb. Saxif. p. 29.

S. foliis simplicibus ciliatis, caule ramoso. Hall. Helv. 403.

S. sedi foliis crenatis asperis. Scheuch. It. ii. p. 140. t. 20. f. 3 .

Sedum alpinum, foliis crenatis asperis. Baul. Pin. 284. Prod. 132. Gesn. Fasc. xxii. t. 6. f. 27. (bene.)

Sedum alpinum hispidum ferè spinosum, flore pallido. Bauh. Hist. iii. p. 695. Moris. Hist. iii. p. 479, s. 12. t. 10. f. 25.

Sedum minimum alpinum villosum alterum. Park. Theat. 798.

Habitat in alpibus Helveticis et Pyrenaicis. 4. (v. v. c.)

Planta cæsia, hispida, surculosa. Surculi elongati, decumbentes, gemmiferi, villosi, rigidi, rubescentes, densè foliosi. Caules erecti, rigidi, fragiles, 2-3-unciales, ramosi, rubescentes, pauciflori, pilis brevibus hispidulosi. Folia lineari-lanceolata, plana, utrinque nuda, striata, apice mucrone corneo instructa, margine spinulis ciliata. Pedunculi longiusculi, rigidi, subuniflori, calycesque pilis glanduliferis levitèr instructi. Flores magni, lactei. $\mathbf{L} \boldsymbol{a}$ cinice calycince latè ovatæ, mucronatæ, 5-nerves, extus rugosa: marginibus membranaceis nudis. Petala obovata, triplinervia : nervis ramosis flexuosis. Filamenta lutea. Anthera aureæ.

37. S. hispidula, canlibus filiformibus hispidis, foliis ovatis mucronatis setosis utrinque unidentatis, flore terminali subsessili, calycibus setosis.

Habitat 
Mr. D. Don's Monograph of the Genus Saxifraga. 381

Habitat in Nepaliæ alpibus. Wallich. 4. (v. s. in Herb. Lamb.)

Planta tenella. Caules plures, sesqui- vel bi-unciales, simplicissimi, graciles, filiformes, adscendentes, pilis setosis patentibus undique densè tecti. Folia alterna, sessilia, ovata, mucronata, hispida, margine dente parvo aristato utroque instructa. Flos luteus, terminalis, solitarius, brevissimè pedicellatus, in æstivatione nutans. Calyx setis glanduliferis hispidus: lacinia triangulari-ovatæ, aristatæ. Petala parva, suborbiculata, triplinervia: nervis simplicibus rectis. Stamina pistillis longiora; filamenta gracilia, flava; antherce intensè croceæ. Styli apice incurvi.

38. S. bryoides, rosulis globosis, foliis imbricatis subulatis mucronatis ciliatis, laciniis calycinis ovatis obtusis, petalis oblongis, caule oligophyllo unifloro.

S. bryoides. Linn. Sp. Pl.572. Jacq. Misc. ii. p.49. t.5. f.1. (optima.) Scop.Carn. n.497.t.15. Willd. Sp. Pl. ii. p. 643. Lapeyr. Pyren. Saxif. p. 35. Lam. Encycl. vi. p. 678. Persoon Synop. i. p. 488.

S. foliis lanceolatis ciliatis compactis, caule unifloro. Hall. Helv. 969.

S. pyrenaica minima lutea musco similis. Tournef. Inst. 253. Sedum muscosum. Bauh. Hist. iii. p.695. Scheuch. Alp.142. t. $21, f .2$.

Sedum alpinum quartum. Col. Ecphr. ii. p. 66. t.67. f. 1.2.

Habitat in Austriæ, Helvetiæ, Pyrenaic. alpibus. 24. (v.s. in Herb. Banks. et Lamb.)

Planta densè cæspitosa, rosulata. Radix sublignosa fibris pluribus instructa. , Rosula foliorum confertæ, globosæ, vol, XIII. cæsiæ. 
$382 M r$. D. Don's Monograph of the Genus Saxifraga.

cæsiæ. Caules plures, erecti, sesqui- v. bi-unciales, rigidi, uniflori, foliis aliquot minimis adpressis et pilis glanduliferis instructi. Folia densè imbricata, lineari-subulata, subtriangularia, carinata, glabra, suprà concaviuscula, margine ciliis cartilagineis armata: apicibus incurvis mucrone calloso terminatis. Flos ochroleucus magnitudine S.asperce. Calyx levitèr glandulosus: lacinice vvatæ, obtusæ, 5-nerves. Petala oblonga punctis aureis adspersa, trinervia : nervis parallelis simplicibus. Filamenta gracilia. Antherce croceæ.

39. S. cherlerioides, rosulis globosis, foliis densè imbricatis spathulatis mucronatis ciliatis, laciniis calycinis semi-ovatis obtusis, petalis obovatis, caule filiformi multifloro.

S. bryoides? Pallas. Ms.

Habitat in rupibus Kamtschatkæ. D. Merk. 4. (v. s. in Herb. Pallas. nunc Lamb.)

Planta in cæspitibus planis et latis vegetans. Rosula foliorum confertæ, parvæ, globosæ. Caules adscendentes, bipollicares, filiformes, graciles, 4-5-flori, foliis paucis minimis ovatis adpressis ciliatis et glandulis sparsim instructi. Folia creberrimè imbricata, obovato-spathulata, suprà concava, subtùs convexa, margine ciliata : apicibus inflexis mucronatis. Flores corymbosi, ochroleuci, præcedente multò minores. Pedicelli elongati, capillares, uniflori, calycesque glandulis minutis adspersis. Lacinic calycina semi-ovatæ, obtusæ. Petala obovata, calyce dupld longiora, trinervia: nervis simplicibus rectiusculis.

Præcedenti quodammodo accedens, tamen characteres indicati speciem esse distinctissimam monstrant. 


\section{Sectio 4 .}

40. S. hieracifolia, foliis petiolatis ellipticis acutis repando-dentatis glabris, pedicellis aggregatis unifloris in spicam dispositis, petalis lanceolatis acutis.

S. hieracifolia. Waldst. et Kit. Hung. i. p. 17. t. 18. (optima.) Willd. Sp. Pl. ii. p.641. Lam. Encycl. vi.p.674. Geners. Catal. Scepus. n. 229. Wahlenb. Carpath. 119. Persoon Synop. i. p. 487.

S. nivalis v. racemosa. Towns. It. Hung. p. 488. $t$. 15 .

S. rotundifolia. Geners. Elench. Scep. n. 372.

Habilat in alpibus Carpathicis. 4 . (v. s. in Herb. Banks.)

Radix fibris longissimis crassiusculis simplicibus instructa. Folia petiolata, patentia, elliptica, acuta, repando-dentata, dentibus remotis mucronulatis, utrinque glabra, pilis articulatis ciliata. Petioli dilatati, nervosì, margine membranacei. Scapus erectus, palmaris pedalisve, simplicissimus, teres, pilis articulatis glanduliferis undique tectus. Pedicelli elongati, uniflori, in fasciculis 4-6-floris aggregati, et per spicam elongatam digesti : fasciculis inferioribus remotis; supremis approximatis. Bractea lanceolatæ, obtusæ, ad basin cujusdam fasciculi sitæ et pedicellorum longitudine. Calyces pedicellique pilis brevibus glandulosis tecti: laciniæ breves, triangulari-ovatæ, acutæ. Petala ovato-lanceolata, acuta, calyce breviora et angustiora, colore spadiceo-ferrugineo vel lurido. Filamenta brevissima. Antherce flammex. Styli brevissimi, recurvati.

There is a single specimen of this plant in the Banksian Herbarium from Jacquin, and sent by him under the name of $S$. nisalis, a plant with which the Austrian botanists confounded it. 
$384 M r$. D. Don's Monograph of the Genus Saxifraga.

This plant has never, I believe, been introduced into our gardens; the Saxifraga pensylvanica $\beta$. being often kept under the name.

41. S. pensylvanica, foliis impetiolatis lanceolatis sinuato-denticulatis utrinque pilosissimis, scapo ramoso, floribus corymboso-capitatis, petalis linearibus calyce longioribus.

S. pensylvanica. Linn. Sp. Pl. 571. (exclus. synon. Pluken.) Mill. Dict. n. 8. Willd. Sp. Pl. ii. p.640. (ex-clus. synon. Plukenetii.) Lam. Encycl. vi. p.674. Persoon Synop. i. p. 487. Hort. Kew. iii. p.65. Pursh Amer. Septent. i. p. 311.

S. foliis radicalibus denticulatis, caule subnudo piloso ramoso, floribus confertis capitatis. Gron. Virg. 49.

S. noveboracensis. Cold. Noveb. 105.

S. pensylvanica, floribus muscosis racemosis. Dill. Elth. 337. t. 253. f. 328. (bona.)

$\beta$. minor, foliis lævioribus.

Habitat $\alpha$ in Noveboracensis et Virginiæ pratis humidis: $\beta$ in hortis colitur. $\psi$. (v. v. c.)

Radix fibris longissimis crassis simplicibus instructa. Folia numerosa, impetiolata, latè lanceolata, acuta, sinuatodenticulata, utrinque pilis articulatis tecta, sæpiùs palmaria, basi angustata. Scapus erectus, sesqui-v. bi-pedalis, teres, paniculatim ramosus, pilis articulatis patentibus viscidis undique densè tectus. Rami alterni divisi ; inferiores remoti; superiores approximato-conferti. Flores pedicellati, in corymbis densis semiglobosis dispositi. Pedicelli elongati, uniflori, calycesque pilis glanduliferis densissimè obsiti. Lacinia calycis ovatæ, acutiusculæ, obscurè trinerves. Petala linearia, obtusa, uninervia, squalido-alba, calyce duplo longiora. 
Mr. D. Don's Monograph of the Genus Saxifraga. 385

42. S. semipubescens, foliis impetiolatis oblongo-ovalibus obtusis glaberrimis denticulatis, scapo ramoso, floribus corymboso-capitatis, petalis ovalibus calycem subæquantibus.

S. semipubescens. Sweet. Hort. Suburb. 97.

Micranthes semipubescens. Haworth Synop. Succul. append. 321.

S. marilandica. Hortor.

Habitat in Americâ boreali? H . (v. v. c.)

Radix fibris longissimis simplicibus crassis instructa. Folia impetiolata, patentia, oblongo-ovalia, obtusa, crassiuscula, avenia, suprà nitida, margine denticulata. Scapus erectus, pedalis et ultra, ramosus, pilis articulatis glanduliferis levitér tectus. Rami alterni ; inferiores remoti, divisi ; superiores simplices, conferti. Flores pedicellati in corymbis densis semiglobosis dispositi. Pedicelli elongati, uniflori, calycesque pilis glanduliferis instructi. $L a-$ cinia calycince triangulari-ovatæ, acutæ, sub microscopum trinerves. Petala ovalia, obscurè trinervia, flavida, calycem subæquantia.

This plant has been cultivated for many years in our gardens under the name of $S$. marilandica; hence it is supposed to be native of North America, which is very probable, from its affinity with $S$. pensylvanica. I cannot however find it mentioned in any of the books which treat of the plants of that country; and it does not appear to have been even taken up by any one, until Mr. Haworth, the author of Miscellanea Naturalia and Synopsis of Succulent Plants, noticed it in his appendix to the latter work. No doubt can be entertained of its being sufficiently distinct from $S$. pensylvanica, to which it is nearest allied. It is distinguished from it by its oblong-oval, obtuse, and quite smooth leaves, the margins of which are simply denticulated, 
not sinuated as in S.pensylvanica; by the stem being much less hairy; and lastly, by its oval petals, about equal the length of the calyx.

43. S. virginiensis, foliis ovatis acutis dentatis petiolatis, petalis ovalibus : nervis ramosis, scapo paniculatim ramoso.

S. virginiensis. Mich. Amer. Bor. i.p. 269. Lam. Encycl.vi. p. 675. Pursh Amer. Sept. i. p. 310.

S. pilosa. Herb. Banks.

S. vernalis. Willd. Hort. Berol. p. 43. t. 43. ejusd. Enum. p. 459. Sternb. Sarif. p. 8.

S. elongata. ejusd. p. 9. $t .4$.

S. foliis cordatis ovalibus crenatis, corollâ albâ, caule hirsuto aphyllo. Gron. Virg. 160.

Sanicula virginiana alba, folio oblongo mucronato. Pluk. Alm. 331. t. 39. f. 1. et t. 222. f. 5 .

Habitat in Virginiæ, Carolinæ et Novæ-Angliæ montibus, inque Canada. $u$. (v. v. c. et s. sp.)

Planta pulchella, subcrspitosa. Folia patentia, petiolata, ovata, acuta, dentata, utrinque pilis adspersa. Scapus erectus, palmaris, paniculatim ramosus, pilis mollibus glanduliferis undique tectus, rarius foliis $1-2$ munitus. Rami alterni, recti ; inferiores elongati ; omnes subæquales. Flores parvi, albi. Pedicelli numerosi, graciles, uniflori, pube viscidâ suppediti. I Lacinice calycince breves, ovatæ, obsoletè 5-nerves : nervis ramosis. Petala ovalia calyce longiora, trinervia : nervis flexuosis, ramosis.

This plant appears to hold the same place among American vegetation as the $S$. nivalis amidst European. 'This latter plant is not, I am of opinion, to be found in America. I am therefore inclined to think Pursh's nivalis belongs to the present spe- 
Mr. D. Don's Monograph of the Genus Saizifraga. 387

cies; and what convinces me of their being the same is, that there are several specimens in his Canadian Herbarium (now in Mr. Lambert's possession) of S. virginiensis under the name of S. nivalis.

44. S. nivalis, foliis subrotundo-obovatis undulato-crenatis subsessilibus, scapo simplici, floribus congesto-capitatis, petalis subrotundis unguiculatis: nervis simplicibus.

S. nivalis. Linn. Sp. Pl. 573. (exclus. synon. Gron.Virg.) Huds. Angl. 180. Lightf. Scot. i. p. 221. cum fig. (mala.) Willd. Sp. Pl. ii. p. 645. With. Brit.403. Lam. Encycl. vi. p.683. Smith Brit. ii. p. 449. Engl. Bot. t. 440. (bona.) Persoon Synop. i. p. 488. Sternb. Saxif. p. 12. Wahlenb. Lapp. 113.

S. foliis subovatis crenatis, caule nudo, floribus capitatis. Linn. Suec. 354. 368.

S. caule nudo simplici, foliis elliptico-subrotundis crenatis, floribus capitatis. Linn. Suec. 176.t.2.f.5.6. (mala.)

S. foliis oblongo-rotundis dentatis, floribus compactis. Raii Angl. iii. p. 354. t. 16. f. 1 .

Sempervivum minus dentatum. Mart. Spitzb.43. t. F.f. A. Sedum III. Oed. Dan. t. 28. (pessima.)

Habitat in summis alpibus Lapponiæ, Scotiæ, Spitzbergens. et Angliæ borealis: 4 . (v. v: sp.)

Planta subcrspitosa. Folia subrotundo-obovata, undulatocrenata, subsessilia, suprà glabra, subtùs villosa, humi patentia. Scapus erectus, 3-uncialis, simplex, villis viscidis confertè tectus. Flores congestè capitati, bracteati. Bractee lanceolatæ, acutæ, ciliatæ. Pedicelli breves calycesque pube viscidâ obsiti. Lacinice calycis triangulares obscurè trinerves. Petala subrotunda, unguiculata, triplinervia : 
plinervia: nervis simplicibus, primùm candida demùm rubescentia, calycem excedentia. Filamenta brevissima, alba posteà rubescentia.

45. S. longiscapa, foliis ovatis serratis longè petiolatis, thyrso ovato, laciniis calycinis ovatis acutis.

Habitat in Sibiriâ. Pallas 4. (v. s. in Herb. Pallas. nunc Lamb.)

Radix fibrosa. Folia ovata, subacuta, serrata, longè petiolata, plana, utrinque hirsuta. Scapus erectus, palmaris, filiformis, teres, simplicissimus, pilis patentibus glanduliferis densè tectus. Flores thyrsoidei : thyrso ovato, denso. Pedicelli brevissimi, calycesque pube brevi vestiti. Lacinice calycince ovatæ, acutæ, obscurè trinerves. Petala parva, ovata, alba, vix calyce longiora. Filamenta brevissima, alba. Anthera luteæ.

Præcedenti arctè affinis, sed satis diversa videtur: foliis ovatis planis serratis longè petiolatis, scapo duplò longiore, floribus thyrsoideis, petalis ovatis.

46. S. davurica, foliis cuneiformibus longè petiolatis basi attenuatis apice grossè inciso-dentatis, floribus laxè-paniculatis, petalis ellipticis acutis.

S. davurica. Willd. Sp. Pl. ii. p.645. Lam. Encycl. vi. p. 684. Persoon Synop. i. p. 488. Sternb. Saxif. p. 13. S. punctata. Pall. It. iii. app. n. 91. t. P. f. 2. (bona.)

Habitat in summis alpibus Davuriæ prope limitem nivis perpetux. Pallas. 4. (v. s. in Herb. Pallas. nunc Lamb.)

Planta densè cæspitosa. Radix fibrosa. Folia cuneiformia, longè petiolata, utrinque pubescentia, basi attenuata, integerrima, apice grossè acutèque inciso-dentata. Petioli lineares, 
Mr. D. Don's Monograph of the Genus Saxifraga. 389

lineares, plani, basi latè dilatati. Scapi erecti, digitales rariùs palmares, ramosi, pilis glanduliferis parcè obsiti. Flores laxè paniculati., Pedicelli dichotomi calycesque pube glutinosâ tecti. Lacinia calycina triangulari-ovatæ, acutæ. Petala elliptica, acuta, trinervia, alba, basi punctis binis flavis minutis munita.

There are many fine specimens of this very distinct and little known plant in the Herbarium of the celebrated Pallas, in the possession of A. B. Lambert, Esq. Some botanists have supposed this plant to be nearly allied to $S$. cuneifolia; and a slight variety of this is cultivated in the gardens under the name.

47. S. pyrolifolia, foliis ovalibus coriaceis petiolatis glabris nitidis crenatis, floribus paniculatis, petalis linearibus.

Habitat in Kamtschatkâ (Merk), in insulâ oræ occidentalis Americæ borealis Unalaska dictâ (David Nelson). 4. (v. s. in Herb. Banks. et Pallas. nunc Lamb.)

Species distinctissima. Pyrolam refert. Radix lignosa; patens, fusca, fibris instructa, supernè rudimentis foliorum emarcidorum tecta. Folia ovalia, coriacea, petiolata, utrinque glabra, suprà nitida, reticulata, margine crenata. Petioli breves, dilatati, margine membranacei, ciliati. Scapus adscendens, 5-pollicaris, pilis glanduliferis levitèr adspersus. Flores coarctato-paniculati, parvi, albi. Pedicelli multiflori calycesque pube brevi glutinosâ obsiti. Lacinia calyciıa brevissimæ, obtusæ. Petala linearia, calyce longiora. Filamenta pallida. Anthere flavæ. Styli recti. 
Sectio 5 .

\$. Foliis indivisis, plerumque rosulatis impetiolatis.

48. S. Cotyledon, foliis planis spathulatis cartilagineo-serratis, calycibus densè glandulosis : laciniis lineari-lanceolatis, petalis oblongo-spathulatis.

S. Cotyledon. Linn. Sp. Pl. 570. Fl. Dan. t. 241. (optima.) Olaus It. Island. p. 433. Wahlenb. Lapp. p. 111. (exclus. synon. Willd.)

S. pyramidalis Lapeyr. Pyren. Saxif. p. 32. Sternb. Saxif. p. 2. t. 2. Persoon Synops. i. p. 489.

S. pyramidata. Mill. Dict. n. 4.

S. foliis lingulatis radicalibus margine cartilagineo acutè serratis, floribus paniculatis. Linn. Suec. 356. 366.

S. foliis radicalibus in orbem positis: serraturis cartilagineis. Linn. Lapp. 177. t. 2. f. 2.

S. foliorum orâ cartilagineâ, caule triplicato ramoso, petalis immaculatis. Hall. Helv. n. 977.

S. sedi folio flore albo multiflora. Tournef. Inst. 252.

Sedum serratum, flore albo, multiflorum. Dod. Pempt. 113. Robert. Icon. 91.

Habitat in alpibus Lapponiæ, Norvegiæ, Islandiæ, Helvetiæ, Pyrenæorum. 4 . (v. v. c.)

Planta densè cæespitosa. Caules erecti, pedales, pyramidato-ramosissimi, multiflori, foliosi, pilis glanduliferis confertissimè tecti. Folia radicalia in rosulis latè expansis, plana, spathulata, utrinque glabra, suprà lucida, apice rotundata, mucronata, margine acutè argenteoserrata ; caulina brevia, cuneiformia, patentia. Pedunculi multiflori, racemosi, cernui. Flores magni, campanulati, candidi. Calyces pedicellique pilis glanduliferis densè 
Mr. D. Don's Monograph of the Genus Saxifraga. 391

densè obtecti : laciniæ lineari-lanceolatæ, obtusæ. Petala oblongo-spathulata, impunctata, conspicue triplinervia : nervis simplicibus.

49. S. lingulata, foliis lineari-lingulatis canaliculatis tuberculato-crenatis, calycibus densè glandulosis: laciniis semiovatis obtusis, petalis ovalibus.

S. lingulata. Bellardi in Act. Taur. v. p. 226. ejusd. App. ad Fl. Pedem. p. 20.

S. Cotyledon. Mill. Dict. n. 2. Willd. Sp. Pl. ii. p. 638. Lam. Encycl. vi. p.670. Scop. Carn. ed. ii. n. 489?

S. longifolia. Lapeyr. Pyren. Saxif. p. 26.t.11. Persoon Synop. i. p. 487. Lam. et Decand. Fl. Franc. iv. p. 359. ejusd. Synop. p. 317.

S. montana pyramidata, folio longiore. Tournef. Inst. 253.

$\beta$. media, foliis brevioribus, caule supernè paniculato.

S. longifolia $\beta$. media. Sternb. Saxif. p. i. t. 1. a. (bona.) Cotyledon minor. Hort. Eystet. Ord. v. pl. 10, f. 1.

Sedum serratum alterum, foliis longis angustis. Raii Hist. ii. p. 1045. n. 1 .

Sanicula montana crenata, folio longione, pediculo folioso. Pluken. Phyt. t. 222. f. 1.

$\gamma$. crustata, quadrupld minor; foliis angustissimis margine insignitèr crustaceo-porosis, paniculâ pauciflorâ.

S. longifolia $\gamma$. minor. Sternb. l. c.t.1. $b$.

S. crustata. Vest. Man. Bat.p.656. Hoppe Bot.Tasch. 1805. p. 237. t. 1. Bot. Bibl. 1805. p. 42. et 369. Dicks. Hort. Sicc. fasc. 1.

8. subnana, tabelliformis ; cauliculis simplicibus. Lapeyr. loc. cit.

Habitat a in summis alpibus Pyrenæorum et Helvetiæ, in alpibus maritimis aliisque locis alpinis Montregalensi- 
392 Mr. D. Don's Monograph of the Genus Saxifraga.

bus; $\beta$ in Carniolæ et Carinthiæ alpibus, etiam in montibus Pontebanis ; $\gamma$ in alpibus Helveticis, Carniolicis, Carinthiacis et Pyrenæorum; $\delta$ in summis Pyrenæorum. \%. ( $\alpha$ et $\gamma$ v.s $; \beta$ v.v. c.)

Planta densè cæspitosa. Caules erecti, sesquipedales, flexuosi, à basi pyramidato-ramosissimi, foliosi, pilis glanduliferis confertissimè tecti. Folia radicalia in rosulis latè expansis, lineari-lingulata, longissima, rigida, glauca, utrinque glabra, suprà canaliculata, subtùs obtusè carinata, basi ciliata, apice recurvata, margine crustaceoporosa et tuberculato-crenata ; caulina linearia, obtusa, recta, tuberculato-crenata, apice recurvata. Pedunculi longi, patentes, multiflori, calycesque pube brevi glandulosâ ferrugineâ densè obsiti. Flores plani. Lacinice calycince breves, semi-ovatæ, obtusissimæ. Petala ovalia, alba, conspicuè triplinervia (nervis simplicibus), punctis numerosis roseis instructa.

50. S. Aizoon, foliis brevibus cuneatis argenteo-serratis, floribus corymbosis, calycibus glabris: laciniis acutis, petalis suborbiculatis.

S. Aizoon. Murr. Syst. ed. 14. p. 411. Jacq. Austr, v. t. 438. (bona.) Willd. Sp. Pl. ii. p.639. (exclus. synon. Fl. Lapp. et Seguier.Ver.) Lapeyr. Pyren. Saxif. p. 33. Lam. Encycl. vi. p. 672. (exclus. Fl. Lapp. et Seguier. Ver.) Persoon Synop. i. p. 487. Hort. Kew. ed. 2. 3. p.65. Sternb. Saxif. p. 3. t. 3. f. a. (media.) (exclus. synon. Willd. Hort. Berol. Lapeyr. Pyren. p. 33. t. 15. nec non Linn. Suec. et Lapp. et Seguier. Veron.) Wahlenb. Carpath. p. 116.

S. paniculata. Mill. Dict. n. \$.

S. foliorum orâ cartilagineâ, serratâ, petiolis paucifloris, petalis 
Mr. D. Don's Monograph of the Genus Saxifraga. 393 petalis punctatis. Var. $\beta$. foliis brevioribus et latioribus. Hall, Helv. 978.

S. foliis subrotundis serratis. Tournef. Inst. 252.

Cotyledon minor, foliis subrotundis serratis. Bauh. Pin. 285. Prod. 133. Raii Hist. p. 1046. n. 5.

Sedum montanum roseum, serratum, foliis rubrotundis. Barrel. Icon. t. 1310.

Sedum serratum album bicorne, breviore folio, marginibus argenteis. Moris. Hist. s. 12. t. 9. f. 19.

Cotyledon minus, sedi folio, montanum. Lob. Adv. p. 165.

$\beta$. retusa, dupld minor; foliis brevioribus retusis.

S. Aizoon $\beta$. minor brevifolia. Sternb. loc. cit. t. S. f. $\beta$.

Habitat in Austriæ, Helvetiæ, Carpathiæ et Pyrenæorum alpibus. $\psi$. (v. v. c. $\alpha$ et $\beta$.)

Planta in cæspitibus latis et planis densè vegetans. Caules erecti, firmi, simplices, 4-5-unciales, foliosi, nitidi, pilis glanduliferis levitèr adspersi. Folia radicalia in rosulis conferta et conniventia, cuneiformia, plana, glauca, margine argenteo-serrata, basi ciliata ; caulina obovata, mucronulata, ciliato-serrata, subadpressa. Flores corymbosi, sequenti majores, pulcherrimi. Pedınculi elongati, subbiflori, glabriusculi. Calyx glaberrimus : laciniæ brevètriangulari-ovatæ, acutæ. Petala suborbiculata, oculis armatis trinervia (nervis ramosiusculis), lactea, punctis roseis minutis instructa. Filamenta brevia, compressa. Styli brevissimi.

51. S. intacta, foliis linearibus acutis strictis argutè argenteoserratis, calycibus parcè glandulosis: laciniis obtusis, petalis ovalibus.

S. intacta. Willd.Hort. Berol. ii. p.75. t.75. (bona.) ejusd. Enum. p. 459.

S. recta. 
$394 M r$. D. Don's Monograph of the Genus Saxifraga.

S. recta. Lapeyr. Pyren. Saxif. p. 33. t. 15. (optima.)

S. Cotyledon. Marsch. à Bieberst. Fl. Taur. Cauc. i. p. 313. (exclus. synon.)

S. Aizoon. Steven de Saxif. Cauc. in Mem. Mosq. iv. p. 74. (exclus. synon.)

S. cartilaginea. Sternb. Saxif. p. 5. t. 3. c.

S. foliorum orâ cartilagineâ, serratâ, petiolis paucifloris, petalis punctatis. Var. a. Hall. Helv. 978.

S. sedi folio angustiore, serrato. Tournef. Inst. 252. Seguier. Ver. 448. t. 9. $f .1$.

Sedum serratum album bicorne, longiore folio, marginibus argenteis. Moris. Hist. s. 12. t. 9. f. 20.

Sedum serratum. J. Bauh. Hist. iii. 689.

Aizoum serratum. Val. Cord. Hist. pl. 92.

Habitat in alpibus Tyrolensibus, Pyrenaicis et Caucasicis. 4. (v. v. c.)

Planta in cæspitibus conicis densis vegetans. Caules erecti, palmares v. pedales, præcedenti rigidiores, foliosi, pilis glanduliferis confertè tecti. Folia radicalia in rosulis aggregata, stricta, linearia, acuta, plana, glauca, utrinque glabra, argutè argenteo-serrata, basi ciliata ; caulina spathulata, subadpressa, ciliato-serrulàta. Flores racemosi. Pedicelli subbiflori, incurvi, præcedente breviores, pilis gtanduliferis crebrè tecti. Calyx pilis raris adspersus: laciniæ ovatæ, obtusæ. Petala ovalia, obscurè trinervia (nervis simplicibus rectiusculis), lactea, punctis minutis roseis raris instructa. Filamenta compressa. Styli brevissimi.

Linnæus confounded the three preceding species under S. Cotyledon, a name which I have pneferred retaining to the plant described by him in Flora Lapponica and Flora Suecica, and of which 
Mr. D. Don's Monograph of the Genus Sanifraga. 395

which there is a good figure in Flora Danica. They afford abundant characters to keep them distinct, and these marks always remain constant in cultivation, and when re-produced from seed. The S. Cotyledon is remotely distinct from all of them.

52. S. mutata, foliis planis spathulatis cartilagineo-crenatis ciliatisque, calycibus densè glandulosis : laciniis latè-ovatis acutis, petalis lineari-lanceolatis acuminatis.

S. mutata. Linn. Sp. Pl. 570. Jacq. Icon. Rar. 3. t. 466. (optima,) ejusd. Cellect. i. p. 284. Curt. Mag. 351. Willd. Sp. Pl. ii. p. 640. Lapeyr. Pyren. Saxif, p. 31. Lam. Encycl. vi. p.672. Persoon Synop. i. p. 487. Hort. Kew. ed. 2. 3. p.65. Sternb. Saxif. p. 6.

S. foliorum orâ cartilagineâ rarissimè dentatâ, petalis maculosis. Hall. Helv. 979. t. 16.

S. foliorum limbo cartilagineo integro, spicâ longâ, floribus purpureo-croceis. Hall. Helv. edit. prior. Segu.Ver. iii. p. 199. Burs. XVI. 98.

Geum alpinum majus viscosum, foliis oblongo-rotundis, atro-rubentibus et croceis floribus. Scheuch. $1 t$. ii. p.124.

Habitat in alpibus Helvetiæ, Carniolæ, Italiæ et Pyrenæorum. 4 . (v. s. in Herb. Banks. et Lamb.)

Species distinctissima. Planta densè cæspitosa. Caules erecti, palmares $v$. pedales, foliosi, pilis patentibus glanduliferis confertissimè tecti. Folia radicalia in rosulis latè expansis, spathulata, plana, utrinque glabra, margine cartilagineo-crenata, villis longis numerosis patentibus fimbriata ; caulina obovata, basi ciliata, apice cartilagineo-crenata, Flores paniculati. Pedunculi calycesque pube molli ferrugineâ gुlutinosâ densè tecti. Lacinica calycince latè-triangulari-ovatæ, acutæ, obsoletè nervosæ.

Petala 
$396 M r$. D. Don's Monograph of the Genus Saxifraga.

Petala lineari-lanceolata, acuminata, trinervia, crocea, maculis saturatioribus instructa. Filamenta crocea. Antherce fulvæ.

53. S. media, foliis radicalibus aggregatis lingulatis integerrimis ; margine cartilagineo suprà punctato, petalis obtusis calyce brevioribus. Smith Prod. Fl. Grac. i. p. 276.

S. media. Gouan Illust. 27. Poiret in Lam. Encycl. vi. p.675. t.372. f.6. Fl.Grac. Icon. Ined. 376. Sternb. Sarif. $p .6$.

S. calyciflora. Lapeyr. Pyren. Saxif.p. 28. t. 12. (optima.) Persoon Synops. i. p. 487.

S. cæsia. Linn. Mantiss. 382. nec Sp. Pl. ex Smithio loc. cit.

S. alpina parva, sedi folio, non serrata. Mich. Plant. Rom. et Neap. $n .704$.

Habitat in Pyrenæorum rupibus calcareis (Gouan, La Peyrouse), in Olympi Bithyni cacumine (Sibthorp). 4. (v. s. in Herb. Banks.)

Planta in cæspitibus conicis vegetans. Caules erecti, digitales, simplices, rigidi, villis tortuosis ferrugineis viscidis densè tecti. Folia radicalia in rosulis aggregata, imbricata, lingulata, mucronata, rigida, glauca, utrinque glabra, suprd plana, punctata, subtùs convexa, subcarinata, margine integerrima, cartilaginea, nuda, basi ciliata ; caulina cuneata glanduloso-pilosa. Flores racemosi, bracteati. Pedicelli breves, uniflori, calycesque villis viscidis densè obsiti. Calyces campanulati : laciniæ brevè-triangulari-ovatæ, acutæ, rectæ, conniventes. Petala parva, obovata, atro-purpurea, cum genitalibus intra calycem inclusa.

54. S. La- 
Mr. D. Don's Monograph of the Genus Saxifraga. 397

54. S. Lapeyrousii, foliis radicalibus aggregatis lingulatis integerrimis : margine cartilagineo, floribus paniculatis, petalis obovatis integerrimis conniventibus calyce longioribus.

S. luteo-purpurea. Lapeyr. Pyren. Saxif. p. 29. t. 14. Lam. Encycl. vi. p.675. Persoon Synop. i. 487. Sternb. Saxif. p. 7.

Habitat in Pyrenæorum rupibus calcareis. La Peyrouse. 4 . Pedunculi calycesque pube purpureâ viscidâ densissimè vestiti.

$\mathrm{O}_{\mathrm{B}}$. Species prorsùs mihi incognita nisi ex figurâ et descriptione Clariss. Lapeyrouse, a quibus characterem suprà scriptum desumpsi, verè præcedenti admodùm affinis est ; sed floribus paniculatis et petalis citrinis calyce longioribus videtur differe. Forsàn hybrida inter S. mediam et sequentem.

55. S. aretioides, foliis aggregatis lineari-lingulatis strictis mucronulatis carinatis glaucis cartilagineo-marginatis, caule glutinoso-tomentoso, petalis lineari-spathulatis apice crenulatis.

S. aretioides. Lapeyr. Pyren. Saxif. p. 28. t. 13. Lam. Encycl. vi. p.676. Persoon Synon. i. p. 487. Sternb. Saxif. p.7.

S. pyrenaica lutea minima, sedi foliis densissimè congestis. Tournef. Inst. 253.

Habitat in rupibus calcareis Pyrenæorum (La Peyrouse), in Helvetiæ alpibus Barèges dictis (Prof. Stromeyer). 4. (v. s. in Herbar. Ventenat, nunc in Museo Lessertiano.)

Planta densè cæspitosa. Radices lignosæ. Rosula semiunciales, confertæ, ad bases foliis emarcidis undique VOL. XIII. densè 
$398 M r$. D. Don's Monograph of the Genus Saxifraga.

densè 'imbricatæ. Caules erecti, sesquiunciales, teretes, foliisque caulinis lingulato-linearibus obtusis tomento glutinoso tecti. Folia aggregatim imbricata, lineari-lingulata, stricta, obsoletè mucronulata, glauco-viridia, subtùs obtusè carinata, suprà punctis remotis paucis juxta margines perforata, basi ciliato-denticulata : oris cartilagineis. Flores terni, aurei. Pedicelli calycesque pube glutinosâ densè instructi; lateralibus medium superantibus. Calycis laciniæ brevè ovatæ, acutæ, carnosæ. Petala lineari-spathulata, triplinervia, apice emarginata et crenulata : nervis strictis; lateralibus bifurcis. Stamina inæqualia pistillis breviora ; filamenta pallidè lutea ; anthere aurene.

OBs. Duabus precedentibus affinis, at notis indicatis et plantâ multò minore distinctissima est.

56. S. burseriana, foliis aggregatis subulatis pungentibus lævibus glaucis, caule subunifloro, laciniis calycinis ovatis, petalis subrotundis oræ crispatis : nervis ramosis.

S. burseriana. Linn. Sp. Pl. p. 572. Wulfen in Jacq. Misc. i. p. 152. t. 17.f. 3. (optima.) Willd. Sp. Pl. ii. p. 642. Lam.Encycl. vi. p.677. Persoon Synops. i. p.488. Sternb. Saxif. p. 33. $t$. 10. f. 1.

S. foliis glaucis acutis monanthis, caule folioso. Segu.Ver. iii. p. 201. t. 5. f. 2.

Sedum alpinum, saxifragæ albæ flore. Bauh. Pin. 284. Burs. XVI. 6.

Sedum montanum minimum, caryophylli folio, lacteo flore. Raii Hist. ii. p. 1041. n. 8.

Sedum alpinum quartum. Col. Ecphr. ii. p. 66. f. 4 .

$\beta$. caule subbifloro. Sternb. loc. cit. t. 10. $\beta$.

$\gamma$. Vandelli, foliis ciliatis, caule subquadrifloro. 
Mr. D. Don's Monograph of the Genus Saxifraga. 399

S. burseriana, ß. Jacq. Misc. i. p. 153. Lam. Encycl. vi. p 677. Persoon Synop. i. p. 488.

S. Vandelli. Sternb. Saxif. p. 34. t. 10. f. 3.

S. burseriana. Lapeyr. Pyren. Saxif. p. 35.

S. foliis compactis plicatis pungentibus, caule viscido paucifloro. Hall. Helv. 983. Act. Helv. vi. p. 10.

S. foliis aggregatis subulatis lævibus, caule subnudo multifloro. Vandelli It. Ined. f. 2. (ex Sternb. l. c.)

Sedum minimum Syriacum, luteolo flore saxifragæ albæ. J. Bauh. Hist. iii. p. 696. Lobel. Obs. p. 204. Icon. Pl. 376. Dod. Pempt. p. 132. n. 3. Moris. Hist. iii. p. 476. s. 12. t. 8. f. 1 .

IIabitat $\alpha$ in Taurero Radstattiensi (Hoppe), in alpibus Carinthiæ et Carniolæ (Wulfen, Hohenzwart, Vest), in montibus Lessinensibus (Seguier), Tridentinis (Ray). In monte Grappa prope Bassanum in Italiâ superiori ipse legi. Sternb. loc. cit.

$\beta$. in alpe vicina Stoi Clagenfurtii. Vest.

$\gamma$. in monte Couza non procul a Lario Lacu (Vandelli), in Helvetiæ alpibus (Schleicher, Sternb. loc. cit.) 4. (v. s. a in Herb. Banks.)

Planta densè cæspitosa. Radix lignosa, fibris numerosis instructa. Surculi erecti, brevissimi, basi rudimentis foliorum emarcidorum tecti, apice rosulati. Caules plures, erecti, bipollicares, oligophylli, uniflori, pilis glanduliferis brevibus tecti. Folia aggregata, subulata, triquetra, mucronata, glabra, rigida, glauca; caulina pauca, multò minora, adpressa. Flos magnus, pulcherrimus. Calyx pube glandulosâ obsitus ; lacinia latè ovatæ, acutæ, conspicuè nervosæ. Petala latè subrotunda, lactea, triplinervia, nervis ramosissimis flexuosis flavescentibus lineata : orâ crispatâ. 
57. S. retusa, caule subtrifloro, foliis imbricatis oblongo-trigonis acutis suprà perforato-punctatis, petalis lanceolatis acutis, stylis corollam longè superantibus.

S. retusa. Gouan Illustr. 28. $t$ 18. $f$. 1. Lapeyr. Pyren. Saxif. p.38. t.18. (optima.) Lam.et Decand.Fl. Franc. iv. p.365. Persoon Synop. i. p. 488. Sternb. Saxif. p. 37. Wahlenb. Carpath. 118.

S. imbricata. Lam. Franc. iii. p. 531? S. purpurea. All. Ped. 1531. t. 21. f. 2. (bona.)

S. oppositifolia, $\gamma$. Willd. Sp. Pl. ii. p.648. Lam. Encycl. vi. p. 685 .

S. alpina ericoides, flore purpurascente. Tournef. Inst. 258.

Sedum alpinum ericoides cæruleum. Bauh. Prod. 132. Hist. iii. p. 694 .

Habitat in summis alpibus Pedemontanis, Pyrenaicis et Delphinatis. 4. (v. s.)

Planta cæspitem valdè compactum et durum formans. Surculi procumbentes, rigidi, ramosi, densissimè foliosi. Caules numerosi, erecti, sesqui- v. bi-unciales, rigidi, oligophylli. Folia arctè quadrifariam imbricata, parva, oblonga, trigona, durissima, glabra, nitida, basi ciliata, supra aciem punctis ternis minutis perforata, apice recurvata, acuta. Flores terminales, subterni, purpurei. Pedicelli calycesque pube brevi glandulosâ instructi. Calycis laciniæ oblongo-ovatæ, obtusæ, margine nudæ. Petala lanceolata, acuta, triplinervia: nervis parallelis simplicibus. Filamenta capillaria, pallidè lilacina, corollâ longiora. Anthere violaceæ. Styli stricti, longissimi.

58. S. oppositifolia, caule unifloro, foliis imbricatis ovatis planis obtusis ciliatis, laciniis calycis latè ovatis obtusis, petalis obovatis 5 -nervibus, genitalibus corolla brevioribus.

S. op- 
Mr. D. Don's Monograph of the Genus Saxifraga. 401

S. oppositifolia. Linn. Sp. Pl. 575. Fl. Sueo. 359. 369. Fl. Lapp. 179. t.2.f.1. Fl.Dan. t.34. Gunn. Norv. 53. Huds. Angl. 180. Allion. P'edem. 1529. t.21.f.3. (bona.) Vahl. in Act. Hist. Nat. Hafn. 2. 1. p. 51. With. Brit. 404. Willd. Sp. Pl. ii. p. 648 . Lapeyr. Pyren. Saxif. p. 36. t. 16. (optima.) Lam. Encycl. vi. p.686. Smith Brit. ii. p.451. Engl. Bot. t.9. (bona.) Lain. et Decand. Fl. Franc. iv. p. 364. Sternb. Saxif. p.36. Hohenwart et Reiner It. i. p. 133. t. 3. (ex Sternb.) Wahlenb. Carpath. 118. Pursh Amer. Septent. i. p. $\$ 11$.

S. cærulea. Persoon Synops. i. p. 488.

S. caule repente, foliis quadrifariam imbricatis cartilagineis ciliatis. Hall. Helv. 980.

Sedum alpinum ericoides purpurascens. Bauh. Pin. 284. Prod. 152. Moris. Hist. i. p. 480. s. 12. t. 10. f. 36.

Habitat in rupibus alpinis Lapponiæ, Scotiæ, Helvetiæ, Spitzbergensis, Pyrenæorum, Angliæ et Americæ borealis. 4. (v. v. sp.)

Planta cæspitem planum et latum formans. Surculi breves, procumbentes, gemmiferi, rubescentes, villis viscidis levitèr adspersi. Caules numerosi, unciales, ereeti, uniflori, rubri, foliorum 2-3 jugis muniti. Folia ovata, plana, obtusa, glabra, ciliata, obscurè viridia ; adultiora quadrifariàm imbricata, apice cartilaginea; $1-2$ poris minutis sæpiùs perforata; juniora in surculis opposita, subdistantia ; caulina opposita, remota, obovata. Flos magnus, pulcherrimus, lilacinus, terminalis, solitarius, sessilis. Calyx glandulosus : laciniæ latè ovatæ, obtusæ, carnosæ, rectæ, obscurè trinerves, margine ciliatæ. $P e-$ tala obovata, lilacina, 5-nervia: nervis flexuosis ramosiusculis. Genitalia corollâ breviora; filamenta gracilia, rosea; antherce violacer. Styli breves, crassi.

59. S. bi- 
59. S. biflora, caule subtrifloro, foliis planis spathulatis laxis, petalis lineari-oblongis, genitalibus corolla longioribus.

S. biflora. Allion. Pedem. 1530.t.21. f. 1. (bona.) Lapeyr. Pyren. Saxif.p.37.t.17.(optima.) Lam.et Decand. Fl. Franc. iv. p. 365. Persoon Synops. i. p.488. Sternb. Saxif. p. 37. Hohenwart et Reiner. It. i. p. 138.t.2.f.2. (ex Sternb.)

S. oppositifolia, $\beta$. Willd.Sp. Pl.ii. p.648. Lam. Encycl. vi. p. 685.

S. foliis imbricatis ovatis, caulibus reptantibus bifloris. Hall. Helv. 981.

Habitat in Pyrenæorum et Helvetiæ alpibus. 4 . (v. s.)

OBs. Summoperè quidem affinis est S. oppositifolic, sed plantâ majore et laxiore, et notis constantibus in definitionibus expressis satìs distincta.

60. S. casia, foliis lineari-oblongis aggregatis cretaceo-glaucis insignitèr recurvatis carinatis, petalis rotundatis unguiculatis, caule oligophyllo multifloro.

S. cæsia. Linn.Sp. Pl.571. Jacq. Aust. t.374. Scop. Carn. ed. ii. 495. t. 15. Willd. Sp. Pl. ii. p.641. Lam. Encycl. vi. p. 676. Lam. et Decand. Fl. Franc. iv. p. 363. Persoon Synops. i. p. 487. Sternb. Saxif. p. 34.

S. recurvifolia. Lapeyr. Pyren. Saxif. p. 30.

S. foliis crassis duris recurvis subtùs sulcatis, basi ciliatis. Hall. Helv. 982.

S. alpina minima, foliis cæsiis deorsùm recurvis. Segu. Veron. 449. t. 9: $f .2$. (bona.)

Sedum alpinum album, foliolis compactis. Bauh. Pin. 284. Moris. Hist. iii. s. 12. t. 7. f. 32.

Sedum alpinum minimum, foliis cinereis, flore candido. Scheuch. Alp. 49. 141. t. 21. f. 1. 
Mr. D. Don's Monograph of the Genus Saxifraga. 403

Sedi species minima. Gesn. fasc. 24. t. 11. f. 30.

B. major, caule robustiore et altiore valdè villoso.

Habitat $\alpha$ in alpibus Helveticis, Austriacis, Pyrenaicis, Baldo; $\beta$ in Lusitaniâ (Gage). 4 . (v. v. c. et s. sp.; $\beta$ v. s. in Herb. Banks.)

Radix lignosa, ramosa. Surculi erecti, brevissimi, rigidissimi, cæspitem planum et valdè compactum formant. Caules plures, erecti, 2-3-pollicares, tenuitèr filiformes, rigidi, fragiles, oligophylli, multiflori, glabriusculi, fucati. Folia radicalia aggregata, imbricata, lineari-oblonga, obtusa, glabra, rigida, cretaceo-glauca, subtùs carinata, suprà convexa, foraminibus numerosis minutis perforata, basi angustata, ciliata, medio insignitèr recurvata: substantiâ frangibili crustaceâ ; caulina pauca, sparsa, parva;, squamæformia, adpressa. Flores lactei in paniculam parvam dispositi. Pedicelli in æstivatione decurvati, postremo erecti, calycesque pilis brevissimis glanduliferis parcè suppediti. Lacinia calycina breves, latè ovatæ, obtusissimæ, obsoletè trinerves, margine membranaceæ. Petala rotundata, triplinervia (nervis lateralibus ramosis), basi unguiculata: limbo orbiculato, retuso, patenti. Genitalia corollâ breviora.

61. S. diapensioides, foliis linearibus strictis carinatis aggregatoimbricatis cretaceo-glaucis, caule polyphyllo paucifloro densè glanduloso-piloso, laciniis calycinis elliptico-oblongis.

S. diapensioides. Bellardi Act. Acad. Taur. v. p. 227. ejustl. Append. ad Fl. Pedem. p. 21, t.3. Sternb. Saxif, p. 35. t. 9. (mala.)

S. cæsia, $\beta$. Lam. Encycl. vi. p. 676 . 
Habitat in alpibus Pedemontanis et Helveticis. $\psi$. (v. s. in Herb. Lessertiano specim. in cacumine Cenis montis lecta.)

Planta densissimè cæspitosa. Radix lignosa. Surculi lignosi, semiunciales, erecti, conferti, creberrimè foliosi. Caules erecti, teretes, polyphylli, 2- rarissimè 3-pollicares, pilis patentibus glanduliferis undique densè tecti. Folia surculina linearia, obtusa, stricta, cretaceo-glauca, undique arctè aggregato-imbricata, glabra, subtùs obtusè carinata, margine cartilaginea, basi ciliata, apice punctis 1-2 perforata ; caulina linearia, obtusa, densè glanduloso-pilosa, recta, sensìm parùm latiora. Flores 3-4 vel 5 in capitulum terminalem, campanulati, candidi, S. casiâ majores. Pedicelli breves calycesque pilis patentibus glanduliferis conferti. Calycis lacinice ellipticooblongæ, obtusæ. Petala basi angustata (unguiculata): limbo patente, orbiculato, 5-nervi. Stamina pistilla subæquantia; filamenta lutea; antherce aureæ.

OBs. Habitu omnind S.ccesia, à quâ tamen abundè discrepat: foliis strictis, caule polyphyllo densè piloso paucifloro, floribus majoribus, laciniis calycinis elliptico-oblongis.

62. S. fimbriata, rosulis sphæricis, foliis appressè imbricatis orbiculato-obovatis : marginibus membranaceis ciliisque longis fimbriatis, pedunculo solitario nudo unifloro.

Habitat in Capite Newnham dicto ad oras occidentales Americæ borealis. David Nelson. \% . (v. s. in Herb. Banks.)

Planta canescens cæspites planos patentes efficiens. Rosule confertissimæ sphæricæ. Folia appressè imbricata, obovata, trinervia, utrinque glabra, punctis pellucidis fenestrata, intùs concava, extùs convexa, apice orbiculata, margine 
Mr. D. Don's Monograph of the Genus Saxifraga. 405 margine membranâ scariosâ et ciliis longis cuspidatis inflexis fimbriata. Pedunculus solitarius, uncialis, uniflorus, nudus. Calyx obconicus: laciniæ brevè ovatæe, obtusæ, margine ciliatæ. Petala mihi ignota.

63. S. serpyllifolia, virens ; surculis repentibus, foliis ovatis obtusis petiolatis denudatis, caule filiformi oligophyllo unifloro, petalis orbiculatis : nervis ramosis.

S. serpyllifolia. Pursh Amer. Septent. i. p. 310.

Habitat in capite Newnham dicto, ad oras occidentales Americæ septentrionalis. David Nelson. $u$. (v. s. in Herb. Banks.)

Species distinctissima. Planta virens, patens, cæspitosa. Surculi ramosi, repentes, rigidi, densè foliosi. Caules plures, filiformes, graciles, erecti, 2-3-unciales, paucifolii, uniflori, rubescentes, fucati, glandulis brevissimis levitèr sparsi. Folia conferta, ovata, obtusa, petiolata, plana, recurvato-patentia, integerrima, utrinque glabra, viridia, nitida, impunctata : caulina linearia, obtusa, multò minora. Flos terminalis, magnus, aureus? Calyx nitidus parcè glandulosus : laciniæ breves, latæ, obtusæ. Petala orbiculata, brevè unguiculata, triplinervia : nervis ramosis, rectiusculis. Filamenta brevia, lutescentia? Antherce flavæ? Styli brevissimi.

64. S. parnassifolia, caule erecto folioso 3-4-foro, foliis cordatis amplexicaulibus glabris, petalis obovatis 5-nervibus.

Habitat in Nepaliæ alpibus. Wallich. 4. (v. s. in Herb. Lamb.)

Species ab omnibus longè diversa, plantam minorem Par. nassia palustris nè parùm refert. Caules plures, erecti, voL. XIII. $3 \mathrm{G}$ tripol- 
$406 M r$. D. Don's Monograph of the Genus Saxifraga.

tripollicares, teretes, glabri, rigidi, foliosi, 3-4-flori. Folia alterna, sessilia, cordata, amplexicaulia, obtusa, utrinque glabra, subtùs nervosa, margine glandulis levitèr ciliata. Pédunculi breves, uniflori, calycesque glandulis levitèr instructi. Flores lactei. Lacinic calycince triangulari-ovatæ, mueronatæ, trinerves. Petala obovata, 5-nervia (nervis simplicibus' rectiusculis), basi angustata. Anthere croeeæ.

65. S. androsacea, foliis radicalibus confertis ellipticis obtusis pilosis integerrimis tridentatisve, laciniis calycinis obtusissimis, petalis spathulatis, caule nudiusculo subbifloro.

S. androsacea. Linn. Sp. Pl.571. Gerard. Fl. Gall. Prov. 423. Jacq. Aust. iv. t. 389. Willd. Sp. Pl. ii. p.641. Isam. Encyel. vi. p. 674. 'ejusd. Fl. Franc. iii. p. 525. Lam. et Decand.Fl. Franc. iv p. 367. Persoon Synops. i. p.487. Sternb.Sarif.p.42.t.11.f.a. Wahlenb. Carpath. 116.

S. pyremaica. Scop. Carn. edit. 2. 498.

S. foliis hirsutis ellipticis et tridentatis, caule paucifloro. Hall. Helv. 984. Ibid.It. Helv. n.69. p. 292. t. 2.

S. alpina, Androsaces villosæ habitu. Hall. Comm. Nor. 1736. t. 1. f. 3.

Sedum alpinum tertium. Col. Ecphr. ii. p.66 et $67 . f$. ultima.

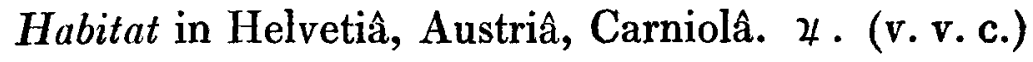

Planta densissimè cæspitosa habitu omninò Androsaces. Radix fibrosa. Caules erecti 2- rariùs 3-pollicares, nudiusculi, subbiflori, pilis glanduliferis articulatis patentibus tecti, sæpiùs foliis 1-2 muniti. Folia radicalia conferta, elliptica, obtusa, integra, rariùs tridentata, utrinque pilis articulatis instructa, basi in petiolum angustata, subtùs 
Mr. D. Dox's Monograph of the Genus Saxifraga. 407

subtùs conspicuè nervosa. Pedicelli brevissimi calyces. que pube viscidâ suppediti. Calyx obturbinatus : lacini:e ovatæ, obtusissimæ, nervosæ. Petala spathulata, candida, triplinervia (nervis simplicibus, strictis), calyce ferè triplò longiora. Filamenta brevia, lutea. Antherce flavæ.

66. S. spathulata, gemmifera; surculis crebrè foliosis, foliis integerrimis spathulatis fimbriatis, laciniis calycis ovatooblongis obtusis, petalis obovatis, caule nudiusculo subbiHoro.

S. spathulata. Desf. Atlant. ii. p. 342. t. 96. f. 2. Lam. Encycl. vi. p. 692. Persoon Synop. i. p. 489. Sternb. Saxif. p. 58.

Ilabitat in Atlantis cacumine prope Belide. Desfontaines. 4. (v. s. in Herb. Lessertiano specim. à Clariss. Desfontaines communicata.)

Planta. densè caspitosa, Surculi plures, breves, procumbentes, creberrimè foliosi, foliis emarcidis ad eorum bases persistentibus. Caules erecti, teretes, capillares, 1-2 $\frac{1}{2}$-pollicares, nudiusculi, pilis brevissimis raris adspersi, 1-3-pluri-flori è flosculis lateralibus sæpiùs abortiẹntibus (caule unifloro) ferè semper orti. Folia parva, spathulata, integerrima, fimbriata: laminâ orbiculatâ, basi in petiolum brevissimum angustatâ ; nonnulla trifida lobis acutiusculis necnon vidi. Pedicelli calycesque pube brevissimâ parcè suppediti, Lacinice calycince ovato-oblongæ, obtusæ. Petala obovata, triplinervia, lactea, calyce longiora. Genitalia petalis breviora. Stamina inæqualia; filamenta lutescentia; anthere aureæ.

OBs. Facie $S$. globuliferce, sed ab eâ satìs distincta, Forsàn ad ultimam sectionem meliùs relata esset. 
$408 M r$. D. Don's Monograph of the Genus Sarifraga.

67. S. Sedioides, caulibus erectiusculis, foliis lineari-lanceolatis acutis glabris, pedunculis elongatis capillaribus unifloris, petalis linearibus mucronulatis calycem subæquantibus.

S. Sedioides. Linn. Sp. Pl. 572. Jacq. Misc. ii. p. 134. t. 21. f. 22. (optima.) Willd. Sp. Pl. ii. p.642. (exclus. syn. Allion. Ped.) Lapeyr. Pyren. Saxif. p. 47. Lam. Encycl. vi. p. 675. (exclus. syn. Allion. Ped.) Persoon Synop. i. p. 488. Sternb. Saxif. p. 97. t. 7. f. « et $\beta$. (mala.) et t.9. $\beta$.

Saxif. trichoides. Scop. Carn. 496. t. 15. (bona.)

S. Hohenwartii. Sternb. Saxif. p. 26. t.7.

S. Seguierii. ejusd. t. 9. $\beta$.

S. alpina minima, foliis lingulatis in orbem actis, flore ochroleuco. Segu.Veron. 450. t.9.f.3. (pessima.)

S. alpina muscoides, foliis superioribus oblongis, inferior. rotundioribus et circumactis. Segu. Veron. iii. p. 203. t. 5. f. 3. (bona.)

B. colorata, petalis antherisque purpurascentibus.

S. Hohenwartii $\beta$. Sternb. Saxif. p. 26. t. 9. $\beta$.

$\gamma$. aphylla, foliis inferioribus sæpè trifidis.

S. aphylla. Sternb. l.c. p. 40. t. 11. $\beta$.

S. muscoides. Wahlenb. Carpath. 122.

Habilat $\propto$ in alpibus Tridentinis, Carinthiacis, Carniolicis, Salisburgens., Pyrenaicis, Arragonicis, Baldo ; $\beta$ et $\gamma$ in alpibus Austriacis, 4. (v. s.)

Planta cæspitosa, lætè virens, tenera. Radix fibrosa, capillacea. Caules numerosi, adscendentes, debiles, valdè foliosi, sesqui- vel bi-pollicis longi, glandulis brevissimis levitèr adspersi. Folia ima aggregata, spathulata, patentia ; superiora erecta, lineari-lanceolata, acuta, alterna ; omnia lætè viridia utrinque glabra, nitida, conspicuè trinervia, 
Mr. D. Dox's Monograph of the Genus Saaifraga. 409

trinervia, margine glandulis ciliata. Pedunculi elongati, capillares, uniflori, terminales, glandulis minutis adspersi. Flores minimi, lutescentes. Lacinice culycince ovatæ, obtusiusculæ, trinerves. Petala parva, linearia, mucronulata, calycem vix excedentia, trinervia : nervis parallelis simplicibus. Filamenta brevissima, lutea. Antherce flavæ.

The present species is readily distinguished by its slender habit and numerous ascending leafy stems, of a beautiful green, which are furnished with a few thin and scattered, short, glandular hairs ; by its long, slender, capillary peduncles ; and lastly, by its small, linear, pointed petals, scarcely exceeding the length of the calyx. I regret having been obliged to differ so widely in opinion from the Count de Sternberg, who certainly has not studied the present species with due care, as is evident from his description and figures, both of which are miserably defective in point of botanical accuracy. The following species, S. tenera, is distinguished from this, to which it is nearly related, by its much more tufted habit; by its obtuse leaves, which, together with the stems, are thickly clothẹd with glandular hairs; by the oblong laciniæ of its calyx ; and in having the flowers double the size, with obovate, retuse petals, nearly twice the length of the calyx. In the figures of S. sedioides given by Sternberg, the petals are erroneously exhibited as obovate; and were it not for the habit, which is clearly that of S. sedioides, I should certainly have been inclined to refer them to the following species. The figure given by him under the name of $S$. Hohenwartii shows the flowers much more correctly. The variety $\beta$ I have not seen : it therefore rests wholly on the authority of Sternberg, who states the petals. and anthers to be of a purplish colour. The varieties I have: marked agree with $S$. sedioides in every essential point; but how far they are to be regarded as permanent varieties I have nat had opportunities of determining.

68. S.te- 
68. S. tenera, surculis brevibus crebrè foliosis, foliis linearioblongis obtusis caulibusque glandulaso-pilosis, laciniis calycinis oblongo-ovatis, petalis obovatis retusis calycem superantibus.

S. tenera. Sut. Fl. Helv. i. p. 245. Vill. Delph. iii. p.666. Sternb. Saxif. p. 28. t. 9. f. 4 .

S. planifolia. Lapeyr. Pyren. Saxif. p.31. Lam. Encycl. vi. p.677. Lam. et Decand. Fl. Franc. iv. p. 367. Sternb. Saxif. p. 28. t. 7.f. 3. (mala.)

S. muscoides. Allion. Ped. 1528. t.61. f. 2. (exclus. synon.)

S. foliis mollibus ellipticis subhirsutis, caule paucifloro. Hall. Helv. n. 985.

S. alpina pallidè lutea, foliis latiusculis non incisis, radice crassâ. Mich. Pl. Rom. et Neapol. 829.

Sedum alpinum, tertio simile alterum. Colum. ii. p. 66. et 67. $f$. ad dextram.

Habitat in alpibus Helveticis, Pedemontanis, Pyrenæorum, et in Monte Cenisio. « . (v. s. specim. quæ Clariss. Kunth mihi benevole dedit.)

Herba densissimè cæspitosa. Surculi brevissimi sæpiùs tamen unciales aut ultra, creberrimè foliosi, ad basin foliis emarcidis aggregato-imbricatis. Caules capillares, 1-2pollicares, erecti, simplicissimi, 1-3-flori, pilis glanduliferis brevibus undique densè tecti. Folia radicalia et surculina lineari-oblonga, obtusa, conferta, mollia, utrinque pilis brevibus glanduliferis tecta ; caulina ovali-oblonga, in cæteris, radicalibus similia. Flores ochroleuci $S$. sedioidi dụplò majores. Calyces obconici, densè glanduloso-tomentosi : laciniæ oblongo-ovatæ, obtusæ. Petala obovata, retusa, calycem ferè duplò excedentia, tripli- 
Mr. D. Don's Monograph of the Genus Saxifraga. 411

triplinervia: nervis simplicibus; lateralibus incurvis; medio recto. Stamina subæqualia; filamenta lutescentia; antherce aureæ. Styli graciles, recti, stamina subæquantes.

Oвs. A S. sedioide facilè distinguitur: foliis cauleque densè glanduloso-pilosis, petalis obovatis retusis calycem duplò excedentibus.

An examination of specimens of the $S$.tenera of Suter, and of the S. planifolia of La Peyrouse, prove that they are the same; not even varieties: I have therefore preferred that of Suter as being the less objectionable name.

\section{§. Foliis 5-3-partitis petiolatis.}

69. S. geranioides, foliis reniformibus 3-5-lobo-palmatis pubescentibus longè-petiolatis : segmentis cuneatis incisodentatis, paniculâ coarctatâ multiflorâ, laciniis calycinis lineari-lanceolatis obtusis, petalis oblongis planis.

S. geranioides. Linn. Sp. Pl. 578. Amon. Acad. iv. p. 271. Willd. Sp. Pl. ii. p. 652. (exclus. synon. Gmel. Sib.) Lapeyr. Pyren. Saxif. p.66. t.43. (bona.) Lam. Encycl. vi. p.691. Lam. et Decand. Fl. Franc. iv. p.372. Persoon Synop. i. p. 489. Hort. Kew. iii. p. 70. Sternb. Saxif. p. 49.

S. quinquefida. Lam. Franc. iii. p. 533.

S. foliis radicalibus palmato-quinquelobis trifidis ; lateralibus coalescentibus; rameis subulatis, lacinis calycinis dilatatis. Gouan Illust. 28. $t$. 18. f. 2.

S. pyrenaica, tridactylites latifolia. Tournef. Inst. 253.

Häbitat in Pyrenæis. 4 . (v. v. c.)

Planta densè cxspitosa. Radix sublignosa, rudimentis foliopum emarcidorum suprà densè instructa. Sttrculi breves, conferti, 
$412 M r$. D. Don's Monograph of the Genus Saxifraga.

conferti, rigidi, erecti, rubescentes. Caules erecti, palmares, rigidi, rubri, pilis glanduliferis undique instructi. Folia radicalia longè petiolata, erecta, 3-5-lobo-palmata, cucullata, utrinque pube brevi densâ valdè glutinosâ densè obsita : lobi cuneati, inciso-dentati : dentibus magnis obtusis; caulina pauca sessilia inferiora digitata; superiora indivisa: segmentis lanceolatis. Petioli semiteretes, pilis viscidis suppediti. Panicula coarctata, multiflora. Bractea lanceolatæ, integræ, obtusæ. Flores campanulati, candidi. Calyces ut et pedicelli pube glutinosâ omninò tecti : laciniæ lineari-lanceolatæ, trinerves, apice reflexæ, obtusæ. Petala oblonga, triplinervia: nervis simplicibus, strictis. Stamina inæqualia ; filamenta elongata, lutescentia ; antherce aureæ. Styli breves, staminibus duplò breviores.

70. S. irriguc, foliis villosis; radicalibus 5-partito-palmatis longè petiolatis; caulinis digitatis: segmentis cuneato-oblongis mucronatis trifidis, paniculâ laxâ, laciniis calycinis linearibus acutis, petalis spathulatis.

S. irrigua. Fisch. Hort. Gorenk. Spreng. Cent. Spec. minus cognit. p. 36. Marsch. d Bieberst. Cent. Plant. Rar. Rossic. ii. t.73. Steven de Saxif. Cauc. in Mem. Mosq. iv. p. 82. n. 12. Sternb. Saxif. p. 60.

S. petræa. Pall. Ind. Taur. Habl. Tuur. p. 147.

S. aquatica. Marsch. à Bieberst. Fl. Taur. Cauc. i. p. 317 . (exclus. synon. Lapeyr. et Persoon.)

S. foliis radicalibus reniformibus 5-lobis multifidis; caulinis linearibus, caule subnudo. Gmel. Sib. iv. p. 171. (exclus. synon. Linn.)

Habitat in Tauriâ inter rupes ad fontes Salghir (Pallas, Marschall à Bieborstein), in Sibiriâ nempè in udis pratis sylvosis 
Mr. D. Don's Monograph of the Genus Saxifraga. 413

sylvosis ab Aldano ad Urak (Gmelin), in altissimis præruptis Jaikæ (Pallas). 4 . (v.v.c. et s. sp. in Herb. Pallas. munc Lamb.)

Planta cæspitosa, herbacea, magnitudine præcedentis at multò mollior et laxior, nunquam surculosa. Caules erecti, palmares, flexiliores, villis articulatis suppediti, virides. Folia radicalia cucullata, reniformia, 5-partito-palmata, longè petiolata; caulina trifida sessilia : segmenta radicalium cuneato-oblonga, trifida : lobis tridentatis : dentibus acutis, aristatis ; caulinorum lanceolata, indivisa, mucronata. Petioli semiteretes longissimi, lenti, erecti, suprà canaliculati, undique villis longis, articulatis, viscidis densè tecti. Panicula laxa, multiflora. Bractece palmatæ. Flores majores, campanulati, pulchri, candidi. Calyces cum pedunculis villis viscidis instructi : lacinix lineares, acutæ, intùs concavæ. Petala spathulata, triplinervia : nervis simplicibus, rectis. Stamina inæqualia; filamenta viridia; antherc luteæ. Styli elongati, staminibus subæquales.

This is a very distinct and well-marked species, readily distinguished from the preceding by its loose, herbaceous habit, slightly covered with long villous hairs; leaves much more deeply divided ; lobes acute ; stem limber, green, villous. Panicles loose, many-flowered; lacinic of the calyx acute; petals broader, spathulate; limb spreading. Marschall von Bieberstein in his Supplement to the Flora Taurico-Caucasica mentions the petals as being unequal, and slightly three-toothed at the apex; but these marks are by no means constant ; for I have never observed them either in cultivated or in dried specimens.

voL. XIII. 
$414 M r$. D. Don's Monograph of the Genus Saxifraga.

71. S. maderensis, surculis lignosis, foliis confertis cuneiformibus longè-petiolatis basi acutis apice inæqualitèr inciso-lobatis, laciniis calycinis latè ovatis acutis.

Habitat in Ins. Madeira. Masson. य . (v.s. in Herb. Banks.)

Planta densè caespitosa. Surculi erecti, rigidi, lignosi, basi rudimentis foliorum emarcidorum crebrè instructi. Caules plures, adscendentes, 4-unciales, filiformes, graciles, oligophylli, pauciflori, pilis brevissimis glanduliferis levitèr sparsi. Folia radicalia conferta, cuneiformia, longè petiolata, pubescentia, basi acuta, apice inæqualitèr inciso-lobata : lobis brevè ovatis, acutis ; caulina inferiora palmata; superiora indivisa, acuta. Petioli filiformibus, teretibus, rigidis, levitèr villis ciliati. Calyx obconicus, ut et pedicelli pube glutinosâ tectus : laciniæ triangulariovatæ, acutæ. Petaka non vidi.

72. S. pedatifida, foliis radicalibus reniformibus pedatifidis viscidis subvillosis : segmentis lineari-lanceolatis acutis, paniculâ fastigiatâ, laciniis calycinis lineari-lanceolatis mucronatis, petalis angustè spathulatis.

S. pedatifida. Ehrh. Exsicc. n. 15. Smith in Act. Soc. Linn. x. p. 340. Engl. Bot. t. 1278. (optima.) Compend. Fl. Brit. p. 67.

S. quinquefida, var. Lam. Fl. Fr. iii. p. 533 ?

ß. ladanifera, glabra; foliis profundiùs sectis cauleque glutinosis.

S. ladanifera. Lapeyr. Saxif. Pyren. p. 65. t. 42. Lam. Encycl. vi, p.691. Lam. et Decand. Fl. Franc. iv. p. 373. Persoon Syn. i. p. 490.

Habitat $\alpha$ in Helvetiæ alpibus (Ehrhart), in Pyrenæis (Tournefort), in rupibus Scotiæ montium (G. Don et J. Mackay); $\beta$ in Pyrenæis, La Peyr. 4 . (v.v.c.et s.sp. $\alpha$ et $\beta$.)

Herba 
Mr. D. Don's Monograph of the Genus Saxifraga. 415

Herba in cæspitibus densis, conicis, vegetans, villis mollibus præsertim folia et petioli, instructa; et tota succo glutinoso tecta, in $\beta$ (quæ nuda est) densiore et ladano simili nitido, et e quo venit gratus et subtilis odor, spirare quem memorat Clariss. La Peyrouse, et ipse observavi. Surculi erecti, sublignosi, 3-4-pollicares, basi rudimentis foliorum emarcidorum tecti. Caules erecti, palmares, glabriusculi, rubri, nitidi. Petioli longi, compressi, villosi (in $\beta$ nudi), basi dilatati et caulem amplexantes. Folia radicalia numerosa; adultiora patentia ; juniora erecta; omnia profundè tripartita : segmentis lateralibus 2-3-fidis, intermedio cuneato-trifido vel integerrimo: lobis lineari-lanceolatis acutis aristatisque; caulina brevè petiolata, profundè tripartita : segmentis linearibus integerrimis ; supremis et rameis simplicibus, lineari-lanceolatis, acutis. Paniculae confertie, fastigiatr, multiflora. Pedicelli calycesque pube brevissimâ glutinosâ tecti. Flores campanulati, candidi, S. geranioide multò minores : limbo patente. Calycis lacinia linearilanceolatæ, mucronatæ: mucrone aristato, inflexo. $P e-$ tala angustè spathulata, triplinervia : nervis simplicibus. Stamina pistillis subæqualia ; filamenta pallidè luteo-virescentia; antherce aureæ.

OBs. Species ab omnibus satis distincta. Plures Botanici cum S. geranioide, cui in pluribus sed præsertim habitu convenit, confusi sunt; tamen characteribus indicatis ab eâ etiam abundè discrepat. Var. $\beta$ parùm in habitu recedit, et ferè villorum absentiâ nec non succo ladano simili densiùs tecto; sed ut species diversa nequaquam habenda sit. 
73. S. ceratophylla, surculis lignosis, foliis bi-tri-partitis petiolisque rigidis glabris : segmentis subulatis corneo-mucronatis, caule glutinoso, calycibus fucatis glabris : laciniis ovatis apice recurvis mucronatis, petalis oblongis.

S. ceratophylla. Dryander in Hort. Kew. iii. p. 70.

S. trifurcata. Schrad.Hort. Gött. fasc. i. p.13.t.7. Sternb. Saxif. p. 49.

S. petræa. Herb. Pavon.

Habitat in Hispaniâ. Pavon. 4. (v. v. c. et s. spont. à Clar. Pavon comm. in Herb. Lamb.)

Planta densè cæspitosa, tota glaberrima. Surculi numerosi, breves, lignosi, stricti, rigidissimi, fragiles. Caules numerosi, erecti, palmares, ramosi, rigidi, fragiles, basi rubescentes, succo viscido undique fucati. Petioli longissimi, filiformes, rigidi, fragiles, nudi, suprà canaliculati. Folia profundè bi- tri-partita, carnosa, glaberrima : segmentis subulatis, divaricatis, suprà canaliculatis, apice mucrone corneo, recurvo instructis ; caulina petiolata, tripartita: segmentis simplicibus. Flores numerosi, candidissimi, in paniculam ramosam laxam dispositi. Calyces urceolati pedicellique succo viscoso undique obsiti et nitidissimè fucati : laciniæ ovatæ, erectæ, conniventes, extùs convexæ, margine membranaceæ, apice mucrone corneo recurvato instructæ. Petala oblonga, obtusa, integerrima, demùm flaccida, triplinervia : nervis simplicibus strictis.

74. S. obtusifida, surculis lignosis, foliis tripartitis petiolisque angustissimis rigidis glabris: segmentis linearibus obtusissimis, calycibus pubescentibus : laciniis ovatis obtusis, petalis obovatis.

Habitat in Hispaniâ. Pavon. $\psi$. (v.s. in Herb. Pavon. nunc Lamb.) 
Mr. D. Don's Monograph of the Genus Saxifraga. 417

Planta densissimè cæspitosa, glaberrima, intensè viridis. Surculi erecti, 1- aut $1 \frac{1}{2}$-pollicares, lignosi, rigidi, foliosi. Caules erecti, 4-unciales, oligophylli, glabri, 4-5-flori. Petioli angustissimi, simplices, glabri, subtùs carinati, rigidissimi. Folia profundè tripartita : segmenta linearia, obtusissima, glabra, nitida ; lateralibus porrectis, distantibus, sæpiùs bifidis. Pedicelli uniflori, pubescentes. Flores campanulati, albi. Calyx pubescens : laciniis ovatis, obtusis. Petala integerrima, obovata, triplinervia : nervis apice bi-vel tri-furcatis. Stamina stylos æquantia ; filamenta lutescentia; antherce flavæ.

Oвs. Species distinctissima, præcedentis habitu.

75. S. ajugifolia, surculis procumbentibus, foliis 5-partitis ; segmentis lanceolatis mucronatis, caule ramoso, laciniis calycinis ovatis mucronatis, petalis planis obovatis.

S. ajugifolia. Linn. Amen. Acad. iv. p.271. Sp. Pl. 573. Gerard. Fl. Galloprov. p. 224 . Willd. Sp. Pl. ii. p. 653. Lapeyr. Fl. Pyren. Saxif. p. 56. t.31. (mala.) Lam. Encycl. vi. p.692. Lam.et. Decand. Fl. Franc. iv. p. 371. Persoon Synop. i. p.489. Hort. Kew. iii. p.70. Sternb. Saxif: p. 46. Wahlenb. Carpath. 122.

Habitat in Galloprovinciæ montibus, et etiam in Pyrenæis. 4. (v. v. c.)

Herba virens, villis mollibus, raris, viscidis ad petiolos densioribus instructa, ante anthesin densè cæspitosa, postmodò laxa, surculosa. Surculi elongati, laxè procumbentes, rubescentes. Caules adscendentes, 4-6-unciales, ramosi, flexuosi, multiflori, villis viscidis levitèr adspersi, basi rubescentes. Folia radicalia et surculina longè petiolata, profundè 5-partita: segmentis lanceolatis, recurvatè mucronatis, divaricatis, utrinque glabris, margine ciliatis ; 
$418 M r$. D. Don's Monograph of the Genus Sanifraga.

ciliatis; caulina omnia indivisa, lanceolata, acuminata. Flores magni, campanulati, albi. Calyces pedicellique pilis glanduliferis obsiti : lacinix ovatx, trinerves, mucro$\therefore$ natæ, mucrone recurvo. Petala obovata, triplinervia: nervis simplicibus, rectiusculis.

76. S. affinis, surculis procumbentibus, foliis 5-partitis: segmentis linearibus mucronatis, laciniis calycinis linearibus aristatis, petalis oblongis : marginibus inflexis.

Habitat . . . . . . . . . . (v. v. c.)

Herba jucundè virens, villis mollibus et viscidis adspersa, ante anthesin densè cæspitosa, posteà laxă, surculosa. Surculi procumbentes, elongati, rubescentes, villis viscidis parcè instructi. Caules adscendentes, tripollicares, læves, nitidi, pauciflori. Folia radicalia 5-partita, surculina plerumque tripartita: segmenta linearia, mucronata : mucrone recurvo aristato ; caulina omnia indivisa, linearia, mucronata. Pedicelli elongati, uniflori, calycesque pube viscidâ obsiti. Flores albi præcedente minores. Calycis lacinice lineares, trinerves, aristatæ. Petala oblonga, triplinervia, margine inflexa: nervis rectiusculis, simplicibus.

I first noticed this species in the Royal Botanic Garden at Edinburgh, where the zeal and industry of my esteemed friend Mr. Macnab has brought together so many rarities. There I observed it for several years successively ; and having since seen it in several collections about London, I am convinced of its being sufficiently distinct from its nearest ally $S$. ajugifolia, with which it is not unfrequently confounded. Both it and ajugifolia being cultivated together in the Edinburgh Botanic Garden, on comparing them I found the following, and which subsequent obșer- 
Mr. D. Don's Monograph of the Genus Saaifraga. 419

observations have led me to consider permanent, marks. S. affi$n i s$ is a much smaller and slenderer plant, and of a more lively green colour. Segments of the leaves narrow, linear. Stems much slenderer and shorter, few-flowered. Lacinice of the calyx linear, terminated with a long point. Petals oblong, with their margins inflected. This curious conformation of the petals is of itself an important differential mark ; for in this respect it stands isolated among the numerous species which surround it, as Rosa involuta does among those of its tribe.

77. S. pentadactyla, surculis erectis brevibus, foliis longè-petiolatis glabris quinquepartitis: segmentis linearibus obtusis subtùs costatis, laciniis calycinis lanceolatis acutis, petalis obovatis : nervis ramosis.

S. pentadactylis. Lapeyr. Fl. Pyren. Sarif. p.64. t.40, Lam. Encycl. vi. p. 696. Lam. et Decand. Fl. Franc. iv. p. 374. Persoon Synop. i. p. 489.

Habitat in Pyrenæis, La Peyrouse. 4 . (v. s. in Herb. Banks.)

Herba glabra, læatè-virens, densè cæspitosa. Surculi erecti, breves, parùm lignosi, rigidi. Caules erecti, 3-5-unciales, ramosi, teretes, glabri, flexuosi. Petioli longissimi, compressi, lineares, glabri, subtùs costati, rigidiusculi. Folia radicalia brevissimè petiolata, patentia, surculina longè-petiolata, erecta, omnia profundè 5-partita : segmenta linearia, obtusa, patentia, subtùs costata. Flores candidi, in paniculam laxam dispositi. Peclicelli elongati calycesque glabri. Lacinice calycince lanceolatæ, acutæ, trinerves. Petala obovata, triplinervia: nervis flexuosis ramosis. Filamenta gracilia, stylis elongatis breviora.

This species is very nearly related, on the one hand, to my S.obtusificla, and on the other to S.exarata; but having only seen imperfect 
imperfect specimens of it, I am unable to decide positively to which of the two it is nearest allied. It appears to be nearer akin to S. obtusifida ; still, however, I think they are specifically different. At the suggestion of Sir James Edward Smith, I have taken the liberty of changing the termination of the specific name, as being less consonant to established rules.

78. S. latifida, surculis erectis brevibus, foliis radicalibus surculinisque latè-cuneatis glaberrimis 3-5-lobis : lobis latèovatis acutis, calycibus glabris : laciniis ovato-lanceolatis mucronulatis, petalis spathulatis : nervis simplicibus.

S. adscendens. Herb. Pavon.

Habitat in Hispaniâ. Pavon. 4. (v. s. in Herb. Lamb.)

Planta glaberrima, lætè-virens, cæspitosa. Surculi erecti, 2-pollicares, rigidiusculi. Caules erecti, palmares, ramosi, glabri, polyphylli, multiflori. Folia radicalia et surculina latè-cuneata, glaberrima, 3-5-loba: lobis latèovatis, mucronulatis, planis ; caulina inferiora conformia sed profundiùs lobata : lobis lanceolatis ; superiora indivisa. Pedunculi elongati, subbiflori, glabri. Calyces glabri : laciniæ ovato-lanceolatæ, mucronulatæ. Petala spathulata, candida, triplinervia : nervis simplicibus. Stamina pistillis breviora; filamenta lutescentia; antherce aureæ.

79. S. decipiens, villosissima; foliis 5-fidis trifidisve : segmentis ovato-oblongis obtusis muticis, laciniis calycinis triangulari-ovatis obtusis muticis, petalis orbiculatis.

S. decipiens. Ehrhart. Beytr. v. p. 47. Persoon Synop. i. p. 490. Sternb. Saxif. p. 55. t. 23.

S. cæspitosa. Fl. Dan. t. 71 .

S. petræa. 
S. petræa. Roth Tent. i. p. 184. With. Brit. 890.

S. palmata. Smith Brit. ii. p. 456 . Eng. Bot. t. 455.

S. villosa. Willd. Enum. 462.

Habitat in apricis saxosis Germaniæ (Ehrhart, Schreber, Panzer), in rupibus Cambro-Britanniæ (Griffith), Bohemix (Sternberg). 4 . (v. v. c.)

Ilerba villosissima, canescens, ante anthesin densè cæspitosa, postmodo laxa, surculosa. Surculi elongati, procumbentes. Caules erecti, foliosi, multifluri, 4-6-unciales. Folia radicalia 5-fida vel trifida: segmenta latè oblongo-ovata, obtusa, mutica; caulina ima sæpiùs partita; superiora indivisa, lanceolata. Flores magni, patentes, lactei. Calyces pedunculique pube canâ viscidâ densè tecti : laciniæ triangulari-ovatæ, obtusæ, muticæ, obsoletè trinervosæ. Petala plana, orbiculata, integerrima, triplinervia : nervis simplicibus, rectiusculis.

80. S. hirta, villosissima; foliis radicalibus 5-fidis; surculinis trifidis : segmentis ovato-lanceolatis acutis, laciniis calycinis triangulari-ovatis acutis, petalis obovatis.

S. hirta. Donn Cant. ed.5. 107. Engl. Bot. t.2291. Smith Compend. Fl. Brit. p. 66.

Ilabitat in rupibus Hiberniæ (J. T. Mackay), Scotiæ occidentalis (G. Don). น. (v. v. c. et s. spont.)

Herba villosissima, canescens, ante anthesin densissimè cæspitosa, posteà laxa, surculosa. Surculi decumbentes, flexuosi. Caules erecti, 3-5-pollicares, polyphylli, pauciflori, villis viscidis densè instructi, basi rubescentes. Folia radicalia 5-fida; surculina trifida petiolis dilatatis subæqualia : segmenta ovato-lanceolata, acuta ; caulina inferiora profundè tripartita : segmentis linearibus, mu- 
cronatis ; superiora indivisa. Flores albi, præcedente minores. Calyces pedicellique pilis glanduliferis confertissimè tecti: laciniæ latè triangulari-ovatæ, mucronatè acutæ. Pelala obovata, integra, triplinervia : nervis simplicibus, strictis. Stamina stylos subæquantia; filamenta flavida; antherc lutex.

Sir J. E. Smith has justly remarked in English Botany, that this species approaches very near to $S$. decipiens (palinata, Sm.) ; still, however, I think with him that it is specifically distinct. It differs from decipiens in its less robust habit, acute segments of its leaves, and acute laciniæ of its calyx, its smaller flowers, and obovate petals. My friend Mr. J. T. Mackay first discovered this species on the Irish mountains. It has also been observed by the late Mr. G. Don of Forfar, on rocks in the Western Highlands. The Scottish specimens in Mr. Don's Herbarium agree exactly with Irish ones from Mr. Mackay, and with the admirable figure in English Botany.

81. S. platipetala, villosa ; surculis elongatis, foliis 5-3-partitis : segmentis linearibus acutis aristatisque, laciniis calycinis ovatis mucronatis, petalis orbiculatis.

S. platipetala. Smith in Act. Soc. Linn. x. p. 391. Engl. Bot. t. 2276. (optima.) Compend. Fl. Brit. 66.

Habitat in Scotiæ alpibus, G. Don; in alpibus Cambro-Britannicis, Dawson Turner. $\psi$. (v. v. spont.)

Herba villosa, ante anthesin densissimè cæspitosa, posteà laxè diffusa, surculosa. Surculi numerosi, longissimi, prostrati. Caules erecti, 5-6-unciales, foliosi, multiflori. Folia radicalia profundè partita; surculina tri- rariùs quinque-partita, petiolis angustè linearibus duplò vel tripld breviora: segmenta linearia, acuta, setâ longâ tenui 
Mr. D. Don's Monograph of the Genus Saxifraga. 423

terminata; caulina inferiora profundè 5-partita; superiora indivisa, lanceolata, acuminata. Flores patentes, lactei, majusculi. Calyces pedunculique pube glandulosâ densè suppediti : laciniæ triangulari-ovatæ, mucronatæ (mucrone recto), conspicuè trinerves. Petala orbiculata, plana, integra, extùs præsertìm in æstivatione, ad apicem rosea, basi parùm angustiora, triplinervia : nervis lateralibus incurvis, ramulosis ; medio recto, simplici. Stamina æqualia, stylis vix longiora; filamenta pallida; anthere lutex.

82. S. incurvifolia, glabriuscula ; foliis radicalibus 5-fidis ; surculinis trifidis: segmentis lanceolatis obtusis incurvis, laciniis calycinis ovatis acutis, petalis subrotundis emarginatis.

S. incurva. Mackay in literis.

Habitat in Hiberniæ rupibus alpinis. J. T. Mackay. 4 . (v. v. c.)

Planta virens, densissimè cæspitosa, ante anthesin glaberrima, postmodùm villis longis viscidis adspersa. Surculi breves, erecti. Caules stricti, tripollicares, foliosi, 2-3flori. Folia radicalia aggregata, 5-fida, palmata ; surculina trifida petiolis latè dilatatis vix breviora: segmenta lanceolata, obtusa, incurvata; caulina inferiora palmatifida; superiora indivisa. Flores albi. Calyces pedicellique pilis glanduliferis suppediti : laciniæ latè ovatæ, acutæ, muticæ. Petala subrotunda, emarginata, triplinervia: nervis simplicibus.

The present species has, I believe, been found no where else except in Ireland. Having cultivated it for many years, I do 


\section{$424 M r$. D. Don's Monograph of the Genus Saxifraga.}

not hesitate to give it with confidence as a distinct species. Its short upright shoots ; its inflected leaves, and emarginate petals ; its stems never bearing above two or three flowers; and lastly, its being nearly smooth, will always prevent its being confounded with the three preceding species. In some respects, but especially in habit, it approaches near to S. caspitosa, Linn. It differs however from it by its emarginate petals ; by the longer and inflected segments of its leaves; and likewise by the whole plant being almost smooth, and nearly double the size.

83. S. denudata, glaberrima ; foliis radicalibus 5-fidis ; surculinis tripartitis : segmentis lineari-subulatis acutis, laciniis calycinis lanceolatis mucronulatis, petalis obovatis emarginatis.

Habitat in montibus Grampianis in Angusiâ Scotiæ. G. Don. u. (v. v. spont.)

Herba glaberrima, læetè viridis, in cæspitibus densis parvis vegetans. Surculi brevissimi, conferti, erecti, crebrè foliosi. Caules erecti, sesquipollicares, oligophylli, subbiflori, purrpurascentes, pilis glandulosis levitèr instructi. Folia radicalia 5-fida; surculina tripartita : segmenta lineari-subulata, acuta, aristâ terminata, carnosa, glabra, nitida ; caulina ima tripartita, cæteris indivisis. Flores campanulati, candidi. Calyces pilis glanduliferis parcè suppediti : laciniæ lanceolatæ, mucronulatæ mucronulo reflexo. Petala obovata, emarginata, trinervia: nervis simplicibus strictis. Filamenta luteo-virescentia. Antherce aureæ.

The late Mr. G. Don discovered this species many years ago on rocks on the summits of the mountains of Angus, near the confines of Aberdeenshire, where it grows in little dense tufts, flower- 
ing in June. The stem has never more than one or two flowers. The leaves are quite smooth and shining, except the petioles, which are slightly fringed with soft villous hairs. The narrower segments of its leaves, which are acute, straight and awned, and the lanceolate laciniæ of its calyx, as well as its obovate petals, at once distinguish it from $S$. incurvifolia. It cannot be confounded with $S$. caspitosa, as will be seen on a comparison of their characters. The late Mr. Don cultivated it under the name of S.lavis; but it is very distinct from the lavis known in the gardens, which is the S.condensata of Gmelin's $\mathrm{Fl}$. Badensis.

84. S. Sternbergii, glabra; foliis radicalibus palmatifidis ; surculinis trifidis indivisisve: lobis ovatis acutis muticis, laciniis calycinis ovatis mucronatis, petalis obovatis: nervis ramosissimis.

S. Sternbergii. Willd. Enum. p.462. Sternb. Saxif. p. 56. t. 24. (mala.)

S. palmata. Panz. in Sturm. Deutsch. Fl. 26. Heft. t. 10. f. 2. (ex Sternb. l.c.)

Habitat in Agro Norimbergensi Germaniæ. Panzer. 4 . (v. v. c.)

Herba lætè virens, glaberrima, densè cæspitosa. Surculi brevissimi, conferti. Caules erecti, 3-4-unciales, glabri, 2-3- rariùs 4-flori. Folia radicalia 5-fida, palmata; surculina trifida aut indivisa: lobis ovatis acutis muticis; caulina omnia indivisa, cuneata, acuta, glabra, nitida, conspicuè nervosa. Flores magni, albi. Calyces pedicellique pilis glanduliferis brevissimis adspersi : laciniæ ovatæ mucronatæ trinerves: mucrone recurvo. Petala obovata, triplinervia: nervis flexuosis, ramosissimis.

Oвs. 
Oвs. Figura Sternbergii, quæ dubia ob habitum diversum et caulem ramosum hirsutum, ad $S$. decipientem potiùs spectare videtur.

85. S. pulchella, glabra; foliis radicalibus 5-fidis ; surculinis trifidis : segmentis linearibus obtusis, laciniis calycinis latèovatis obtusis, petalis orbiculatis : nervis ramulosis.

Habitat in Germaniâ ? 4. (v. v. c.)

Herba glabra, saturatè virens, densissimè cæspitosa, ad anthesin pilis brevibus glanduliferis adspersa, surculosa.

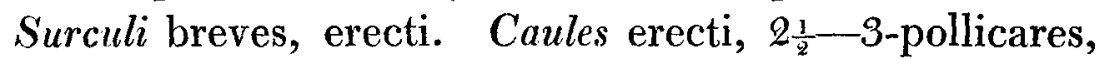
2-3-flori, nitidi, pilis glanduliferis parcè suppediti. Folia radicalia 5-fida, palmata; surculina trifida: segmenta linearia, obtusa, carnosa, marginata, apice mucronulo tenui instructa; caulina inferiora digitato- 5-partita ; superiora tripartita, Flores lactei, magnitudine ferè præcedentis. Calyces pedicellique pube glandulosâ instructi : laciniæ latè-ovatæ, obtusæ. Petala suborbiculata, triplinervia : nervis ramosiusculis. Stamina brevia; filamenta virescentia; anther $x$ luteæ.

My friend Mr. Anderson, of the Chelsea Botanic Garden, received this species from Germany under the name of S. Sternbergii. It is, however, in several respects very distinct from that species. I do not remember to have seen it any where else but with him, nor have I met with specimens of it either in the Herbariums of London or Paris.

86. S. tridentata, glabra; foliis radicalibus 5-fidis; surculinis longè petiolatis acutè tridentatis, laciniis calycinis triangulari-ovatis mucronatis, petalis spathulatis.

Habitat . . . . . . . . . . . . (v. v. c.) 
Herba densissimè cæspitosa, ante anthesin glaberrima, posteà surculosa, villis viscidis levitèr sparsa. Surculi brevissimi, erecti, conferti, crebrè foliosi. Caules erecti, triunciales, graciles, oligophylli, pauciflori, purpurascentes, nitidi, pilis glanduliferis parcè tecti. Folia radicalia patentia, 5-fida ; surculina erecta, longè petiolata (petiolis gracilibus villis ciliatis), spathulata, plerumque tridentata: dentibus brevibus ovatis mucronulatis; lateralibus minoribus. Pedicelli breves, uniflori, calycesque pube brevi viscidâ tecti. Flores nivei. Calycis lacinia triangulari-ovatæ, mucronatæ. Petala spathulata, triplinervia: nervis simplicibus, strictis. Stamina inæqualia; filamenta viridia; antherce aureæ.

I met with this plant in Mr. Knight's exotic nursery, King's Road, Chelsea. It is specifically distinct from all the species with which I am acquainted. Its native country, however, I have not been able to ascertain.

87. S. andicola, villosissima; foliis radicalibus trifidis : segmentis lanceolatis acutis; surculinis superioribus linearibus simplicibus acutis, laciniis calycinis ovatis acutis, petalis obovato-orbiculatis : nervis ramosis.

S. villosa. Pavon Mss.

Habitat in frigidissimis Peruviæ. Pavon. 4 . (v. s. in Herb. Pavon. in Mus. Lamb.)

Herba villosissima, densissime cæspitosa. Surculi breves, decumbentes. Caules erecti, sesqui- vel bi-pollicares, foliosi, 3-4-flori, villis viscidis confertissimè obsiti. Folia radicalia patentia, trifida, brevè-petiolata (petiolis dilatatis subtùs nervosis); surculina inferiora trifida: segmentis lineari-lanceolatis, acutis, subtùs conspicuè trinervibus, 
nervibus, superiora indivisa, lineari-lanceolata, acuta, subtùs trinervia ; caulina ima tripartita, superioribus indivisis. Flores lactei, subcorymbosi. Calyx densè glanduloso-pilosus : laciniæ ovatæ, mucronulatæ. Petala obovato-orbiculata, triplinervia : nervis lateralibus, conniventibus, ramosis; medio recto, subsimplici. Filamenta brevia, lutescentia. Antherce flavæ.

Nothing is probably more interesting to botanists than species of those genera, which are chiefly confined to the colder zones, from tropical climates. Among the rich and highly interesting harvest of plants discovered by the celebrated authors of the Flora Peruviana, Ruiz and Pavon, are several species of Saxifraga; of each of which there are excellent specimens in the Herbarium of Don Jose Pavon, now in the possession of A. B. Lambert, Esq. The present is totally distinct from every other species. I would have most willingly retained the name given to it by its discoverer; but as that name has been already applied to a very different plant, namely, S. decipiens, to prevent any ambiguity or confusion $I$ have judged it best to change it.

88. S. caspitosa, foliis radicalibus aggregatis 5-3-fidis indivisisve: segmentis lineari-lanceolatis obtusis, caule oligophyllo paucifloro, laciniis calycinis ovatis obtusis, petalis conniventibus obovato-rotundatis.

S. cæspitosa. Linn. Sp. Pl. 578. Fl. Suec. ii. n. 376. Fl. Lapp. edit. alter. 142. Gunn. Norv. n. 1047. t.7. f. 3. an etian f. 4? Smith Brit. ii. p. 455. Engl. Bot. t. 794. Prod. Fl. Grac. i. p. 277. Wahlenb. Lapp. 119.

S. gronlandicar Sp. Pl. 578. Gunner. Norv. 689. t.7. f. 1. (optima.) Lapeyr. Pyren. Saxif. p.39.t.19. Persoon Synop. i. p. 490. Sternb. Saxif. p. 53.

S. foliis 
S. foliis petiolatis trifidis, caule subfolioso viscido. Hall. Helv. n. 989.

S. tridactylites grœnlandica, cauliculis valdè foliosis. Dill. Eltham. p. 337. t. 353. f. 329.

S. tridactylites alpina minor et villosa. Tourn. Inst. 252.

Sedum tridactylites, alpinum minus. Bauh. Pin.284. Prod. 131.

Habitat in Lapponiæ, Sueciæ, Helvetiæ, Norvegiæ et Pyrenæorum alpibus ; etiam in Grœenlandiâ et rupibus alpinis Cambro-Britanniæ. 4 . (v. v. c. et s. spont.)

P'lanta densissimè cæspitosa, pilis glanduliferis brevibus confertissimè suppedita. Surculi brevissimi, creberrime foliosi, basi foliis emarcidis densè imbricati. Caules erecti, 1-2-unciales aut rariùs ultra, teretes, oligophylli, 1-3-flori, in cultâ sæpiùs 4-flori. Folia radicalia aggregata, imbricata, sæpius 5-fida, nunc 3-fida aut indivisa : segmenta lineari-lanceolata, obtusa, carnosa, obscurè nervosa; caulina ima palmata, summis plerumque tripartitis: segmentis linearibus. Pedicelli breves, uniflori, calycesque pube brevissimâ viscidâ tecti. Flores majusculi, lactei. Lacinice calycince ovatæ, obtusæ, carnosæe, obsoletè trinerves. Petala obovato-rotundata, conniventia, calyce duplo longiora, triplinervia : nervis simplicibus; medio recto; lateralibus curvatis. Filamenta lutea. Antherce flava.

Much confusion has existed, and still exists, even in our latest works on Saxifragce, regarding this species, which appears to have arisen chiefly from the improper synonyms Linnæus added to his plant. No doubt, had Linnæus seen the plant those authors which he quoted intended by their imperfect figures and descriptions, he would have been at once convinced of its being widely 
different from the Swedish and Lapland plant. Indeed no two species can be more dissimilar than it and the $S$. muscoides of Wulfen, which La Peyrouse and Sternberg in their excellent works still insist on as being the real caspitosa of Linnæus.

$S$. cespitosa varies much in size, and in the number of flowers on each stalk, as well as of its cauline leaves. There are specimens from the Linnæan Herbarium, collected by the late Dr. Solander on the Lapland alps, and preserved in the Banksian Herbarium, which accord exactly with Gunner's figure 3. They are taller and stronger than the general state of S. caspitosa; but in no essential points do they differ. Gunner's figure 4, notwithstanding the greater number of flowers, ought also to be referred to this plant; it certainly does not represent $S$. decipiens. I am inclined to think Willdenow's caspitosa belongs more probably to S. exarata than to this.

89. S. stellata, foliis creberrimis appressè imbricatis 5-fidis trifidisve: segmentis lineari-oblongis obtusis, caule bifloro, laciniis calycinis ovatis acutis, petalis obovatis.

S. stellata. Pavon Mss.

Habitat in frigidissimis Andium Peruviæ. Pavon. 4. (v. s. in Herb. Pavon. nunc in Mus. Lamb.)

Herba densè caspitosa, Fragosce corymbosa (Fl. Per.) habitu admodum similis, pube glandulosâ tecta. Surculi erecti, conferti, foliis undique crebrè imbricati. Caules erecti, vix unciales, graciles, biflori. Folia creberrima, appressè imbricata, omnia 5-fida vel trifida : segmenta lineari-oblonga, obtusa, carnosa, subtùs uninervia ; caulina simplicia, linearia, obtusa. Petioli breves, latissimè dilatati. Flores lactei, majusculi. Calyces pube glandulosâ brevi densè tecti: laciniæ ovatæ, acutæ. Petala obovata, triplinervia: nervis simplicibus strictis.

Ors. 
Mr. D. Dox's Monograph of the Genus Saxifraga. 431

Ons. A S. cespitosâ longè discrepat: habitu, foliis creberrimis appressè imbricatis, petiolis latissimè dilatatis, laciniis calycinis acutis et petalis obovatis.

91. S. Bonplandii, pubescens; foliis congestis 5-fidis trifidisve: segmentis linearibus obtusis, laciniis calycinis lanceolatis acutis, petalis obovatis.

S. peruviana. Bonpland in Sternb. Saxif. p. 55. t. 22.

S. alpina. Pavon Mss.

Habitat in Andium Peruvianorum summis Cordilleras dictis. Pavon, Bonpland. 4 . (v.s. in Herb. Pavon. nunc in Mus. Lamb.)

Herba densissimè cæspitosa, pilis brevissimis glanduliferis confertissimè obtecta. Surculi breves, adscendentes, crebrè foliosi. Caules numerosissimi, unciales, erecti, oligophylli, glanduloso-tomentosi. Folia radicalia et surculina congesta, imbricata, quinque- vel tri-partita : segmenta linearia, obtusa, carnosa, enervia ; caulina inferiora tripartita: summis simplicibus lineari-lanceolatis. Petioli brevissimi, lineares. Flores albi, terminales, terni, capitati, subsessiles, rariùs solitarii. Calyces obconici, tomento glanduloso densè tecti : laciniæ lanceolatæ, acutæ, rectæ. Petala obovata, triplinervia : limbo orbiculato, patente: nervis simplicibus; lateralibus incurvis. Stamina stylis longiora; filamenta alba; antherce flavx.

This is the only species of Saxifraga discovered by the illustrious travellers Humboldt and Bonpland in South America. While in Paris, my esteemed friend M. Kunth, the celebrated editor of the Nova Genera et Species Plantarum, had the kindness to permit me to examine the specimens of this plant in the Humboldtian Herbarium. These specimens appeared more diffuse and stronger than those of S. alpina (Pavon) in the Lam- 
$432 M r$. D. Don's Monograph of the Genus Saxifraga.

bertian Herbarium; but in every essential point they seemed to coincide.

91. S. magellanica, caulibus cæspitosis procumbentibus, foliis linearibus trifidisve confertissimis glabris, ramis floriferis nudis axillaribus brevissimis unifloris. Lam. Encycl. vi. p. 686.

S. magellanica, foliis congestis viscoso-pubescentibus ; inferioribus trifidis; superioribus simplicibus, floribus subbinatis subsessilibus. Persoon Synop. i. p. 491. Sternb. Saxif. p. 39. t. 11. a.

Habitat ad Fretum Magellanicum. Cominerson.

Planta crspitosa. Caules breves, procumbentes, foliosi. Folia inferiora trifida; superiora indivisa, linearia, obtusa, glabriuscula. Flores solitarii, brevissimè pedunculati. Pedunculi nudi. Calyx glaber : laciniis linearibus, obtusis. Petala obovata, calyce dupld longiora. Lam. loc. cit. (ex Gall. vers.)

I am sorry that while at Paris I neglected to examine the specimens of this in Commerson's Herbarium; I have therefore followed Lamarck, as being the first who described it, in preference to Persoon and Sternberg, whose descriptions, and also the figure of the latter, disagree with Lamarck's description in some important points.

92. S. exarata, pubescens ; foliis radicalibus quinque- tri-partitisve ; surculinis tripartitis : segmentis linearibus obtusissimis suprà exaratis, caule multifloro, laciniis calycinis ovato-oblongis obtusis, petalis obovatis : nervis simplicibus.

S. exarata. Villars. Delph. iv. p.674. t. 45. Lam. et Decand. Fl. Franc. iv. p. 374. 
Mr. D. Don's Monograph of the Genus Saxifraga. 433

S. nervosa. Lapeyr. Pyren. Saxif. p. 63. t. 39. Lam. Encycl. vi. p. 696. Persoon Synop. i. p. 490. Marsch.d Bieberst. Fl. Taur. Cauc. i. p.316. Sternb. Saxif. p. 52.

S. hypnoides. Allion.Ped.1538.t.21. $f$.4. (excl. synon.)

$\beta$. pubescens, foliis radicalibus surculinisque profundè tripartitis : segmentis lateralibus bifidis, floribus longè pedunculatis subcorymbosis.

S. pubescens. Poir. Act.Toul. iii. p. 327. Lam. et Decand. Fl. Franc. iv, p. 375 . Sternb. Saxif. p. 53.

S. mixta $\alpha$ et $\beta$. Lapeyr. Pyren. Saxif. p. 41. t.21. Persoon Synop. i. p. 490.

S. cæspitosa. Villars. Delph. iv. p.672. (excl. syn.) Wulfen in Jacq. Collect. i. p. 290 ? Willd. Sp. Pl. ii. p.656?

$\gamma$. intricata, foliis radicalibus confertis patentibus cuneatis 5 -fidis, pedunculis divaricatis.

S. intricata. Lapeyr. Saxif. Pyren. p. 58. t.33. Lam. et Decand. Fl. Franc. iv. p. 374. Persoon Synop. i. p. 490.

Habitat $\alpha$ in summis alpibus Pyrenæorum (La Peyrouse), Delphinatus (Villars), Sabaudiæ et Pedemontis (Allioni), Caucasi (Marschall d Bieberstein); $\beta$ et $\gamma$ in Pyrenæis (La Peyrouse), $\beta$ etiam in 'Terrâ Novâ (Herb. Banks.) u. (v. v. c. $\alpha$, et s. spont. $\beta$ et $\gamma$.)

Planta ante anthesin densissimè cæspitosa, posteà surculosa, pilis brevissimis glanduliferis densè pubescens. Surculi erecti, bi- vel tri-unciales, rigidiusculi. Caules erecti, 3-4- rariùs 5-pollicares, multiflori, pube brevi viscidissimâ confertè suppediti. Folia radicalia 5-3-partita, deflexo-patentia, rosulata; surculina erecta, tripartita, rarissimè indivisa: segmenta linearia, obtusissima, suprà nervis lineatis exarata ; caulina profundè tripartita : segmentis lateralibus sæepè bifidis. Petioli lineares plani, conspicue 
$434 M r$. D. Don's Monograph of the Genus Sarifiaga.

conspicuè trinerves. Pedunculi filiformes, uniflori, folio profundè tripartito bracteam mentiente ad basin cujusque instructi, laterales subæquales; terminali breviore. Flores candidi. Calyces obconici, pube brevi densâ instructi : laciniæ ovato-oblongæ, obtusæ, carnosæ, obsoletè trinerves. Petala obovata, calyce duplò longiora, triplinervia, apice retusa: nervis simplicibus, strictis. Stamina subæqualia ; filamenta lutea; antherc aureæ.

I have reduced to this plant the Saxifraga intricata and mixta of La Peyrouse, and the pubescens of Poiret, as neither of them affords sufficient or permanent characters to establish them as distinct species. It varies much in size and in the number of the segments of its leaves; and likewise in the number of flowers on a stalk; but its prominent features are always the same.

93. S. Pavonii, pubescens; foliis tripartitis : segmentis linearibus acutis nervosis, petiolis linearibus dilatatis subtùs costatis, laciniis calycinis lineari-lanceolatis acutis, petalis obovatis.

Habitat in Andium Peruvianorum locis frigidissimis. Pavon. భ. (v. s. in Herb. Pavon. nunc in Mus. Lamb.)

Herba pubescens, in cæspitibus densis, planis vegetans. Surculi brevissimi, basi foliis emarcidis crebrè instructi. Caules erecti, 4-5-unciales, oligophylli, 3-5-flori, pilis brevissimis glanduliferis tecti. Folia omnia tripartita, subtùs insignitèr costata ; inferiora deflexo-patentia ; superiora erecta : segmenta linearia, acuta ; lateralibus rarissimè unidentatis; caulina inferiora tripartita; superiora simplicia, lineari-lanceolata, acuta. Petioli dilatati, lineares. Pedunculi elongati, uniflori calycesque pube brevissimâ glandulosâ densè tecti. Flores lactei, ad siccationem 
Mr. D. Don's Monograph of the Genus Sarifraga. 435

cationem lutescentes. Calycis lacinice lineari-lanceolatie, acutæ. Petala obovata, triplinervia: nervis rectiusculis, simplicibus.

Oвs. A precedente distinctissima: segmentis foliorum acutis, laciniis calycinis lineari-lanceolatis acutis et aliis characteribus.

94. S. pedemontana, pubescens; foliis aggregatis cuneato-spathulatis digitato-sectis exaratis : segmentis lineari-oblongis integris tridentatisve, floribus corymbosis, laciniis calycinis lineari-elongatis acutis, petalis oblongo-spathulatis.

S. pedemontana. Allion. Ped.n.1540.t.21. f. 6. (optima.) Lam. et Decand. Fl. Franc. iv. p.37\%. Persoon Synop. i. p. 490.

S. cymosa. Waldst. et Kit. Pl. Rar. Hung. p. 91. t. 88.

S. heterophylla. Sternb. Saxif: p. 50. t. 20. f. 1. et 2.

Habitat in alpibus Pedemontanis (Allioni, Bellardi, et Balbis), Marmaroszensibus (Waldstein et Kitaibel). 4 . (v. s. in Herb. Ventenat. nunc in Mus. Lessertiano).

Planta densè caspitosa. Radiv fusca, foliorum emarcidorum rudimentis densissimè tecta. Surculi brevissimi, densè foliosi. Caules erecti, teretes, 4-5-pollicares, multiflori, pube brevissimâ glutinosâ undique tecti. Folia aggregata, cuneato-spathulata, levitèr pubescentia, digitatìm secta, suprà exarata, subtùs costata; adultiora deflexo-patentia; juniora erecta: segmentis lineari-oblongis, acutis, integerrimis tridentatisve; caulina inferiora cuneata, digitato-secta; suprema tripartita : segmentis linearibus acutis. Flores magni, campanulati, candidi, corymbosi. Calyces profundè 5-partiti pedicellique pube brevi viscidâ densè tecti : laciniæ lineares, elongatic, 
Mr. D. Don's Monograph of the Genus Saxifraga.

elongatre, acutæ, rectæ. Petala oblongo-spathulata, triplinervia : nervis rectis, simplicibus. Genitalia petalis breviora; filamenta capillaria, lutescentia; antherce aureæ. Styli erecti, staminibus breviores.

I had an opportunity, while in Paris in August 1821, of examining several very fine specimens of this truly distinct species in the Herbarium of the late M. Ventenat, now in the possession of Baron Benjamin De Lessert. I take this opportunity, therefore, of acknowledging my thanks to M. De Lessert for his kindness in permitting me to examine his extensive and valuable collection. These specimens were collected on the Pedemontese alps by Drs. Bellardi and Balbis, who communicated them to M. Ventenat. The Count de Sternberg is of opinion, that the caspitosa of Wulfen is the same as this species; but I am rather inclined to think (judging from the description) that Wulfen's plant belongs to $S$. exarata.

95. S. moschata, pubescens; foliis radicalibus trifidis ; surculinis trifidis indivisisve nervosis : segmentis linearibus acutiusculis, caule filiformi subracemoso, petalis angustè-ovalibus calycem vix superantibus.

S. moschata. Wulfen in Jacq. Misc. ii. p. 128. t. 21 . f. 2. (bona.) Murr. Syst.Veg. xiv. p.414. Willd. Sp. Pl. ii. p.656. Lapeyr. Pyren. Saxif. p.61.t.37. (media.) Lam. Encycl. vi. p. 695. Persoon Synop. i. p. 490. Sternb. Saxif. p. 41. t. 11. f.3.

S. cæspitosa. Scop. Carn. 494. t. 14.

S. exarata. Allion. Ped.1539. f. 2. (mala.)

S. muscoides. Sternb. Saxif. p.39. t.11.f. 2. (omiss. var. $\beta$ et $\gamma$, et exclus. synon. Smith Brit.)

Sedulum quod moschatellina alpina lutea vocari potest. Gesn. fasc. xxv. t. 6. f. 31 .

Tridactylites 
Mr. D. Don's Monograph of the Genus Saxifraga. 437

Tridactylites alpina. Bauh. Hist. iii. p. 754. (fig. benè.)

Habitat in alpibus Carinthiacis, Carniolicis, Sabaudicis, Salisburgensibus, inque Pyrenæis. 4. (v.v. c.)

Planta ante anthesin densè cæspitosa, læviuscula, postmodùm surculosa, glandulis brevissimis densè pubescens. Surculi erecti, elongati, graciles. Caules erecti, filiformes, graciles, 2-3-unciales, nudiusculi, 3-5-flori. Folia radicalia trifida, patentia, longè-petiolata ; surculina plerumque trifida rariùs indivisa, erecta, etiam longè petiolata, omnia suprà lineis exarata: segmenta linearia, acutiuscula. Petioli angustè lineares, tenues, submembranacei, suprà lineâ exarati. Flores racemosi, brevè pedicellati, ad basin cujusque pedicelli folio tripartito bracteam mentiente instructi. Calyces obconici, densè glandulosi pubescentes: laciniæ lineares, obtusæ. Petala angustè ovalia, acutiuscula, lutea, triplinervia, calyce parùm longiora: nervis simplicibus, strictis. Filamenta brevissima, virescentia. Antherc luteæ.

The Count de Sternberg's $t .11 . f .3$. is a very good representation of this plant, and not inferior to Jacquin's ; but he has inadvertently confounded it with the two following, from which it is very distinct. His variety $\gamma \mathrm{I}$ have no doubt belongs to S. pygmaa.

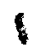

96. S. muscoides, glaberrima; foliis radicalibus integris trifidisve; surculinis omnibus linearibus indivisis obtusis enervibus, caule gracillimo subtrifloro, petalis linearibus calyce parùm longioribus.

S. muscoides. Wulfen in Jacq. Misc. ii. p. 125. Willd. Sp. Pl. ii. p. 656. (exclus. synon. Scop. Carn.) Lam. Encycl. vi. p.697. Persoon Synop. i. p.491. Lam. et DevoL. XIII.

$3 \mathrm{~L}$

cand. 
cand. Fl. Franc. iv. p. 376. Marsch. d Bieberst. Fl. Taur. Cauc. i. p. 316. Sternb. Saxif. p. 39.

S. cæspitosa. Huds. Angl.p. 181. (exclus. synon. Linn. et Fl. Dan.) Lapeyr. Pyren. Saxif. p. 59. t. 35. an item t. 34? Sternb. Saxif. t. 11. f. 1 (media.)

S. moschata. With. Brit. ii. p. 406.

S. pyrenaica. Vill. Delph. iii. p. 671 .

S. pyrenaica, foliis partim integris partim trifidis. Tournef. Inst. 253. Segu. Veron. iii. p. 205. et i. p. 451. t.9. f. 4. (benè.) Hall. Opusc. 292. t. 1.

S. foliis integris et trifidis, caule subnudo paucifloro. Hall. Helv. 988.

Habitat in alpibus Carinthiacis (Wulfen), Helveticis (Haller), Tridentinis (Seguier), Delphinatis (Villars), Gilanensibus Persiæ (Herb. Pallas), Caucasicis (Marschall à Bieberstein), Pyrenæorum (La Peyrouse), in montibus supra Ambleside in Westmorlandiâ (Hudson). u. (v.v. c.)

Planta virens glaberrima, densissimè cæspitosa. Surculi erecti, longiusculi, graciles. Caules erecti, biunciales, nudiusculi, filiformes, gracillimi, plerumque triflori, levitèr glandulosi. Folia radicalia, integra vel trifida : lobis brevibus obtusis ; surculina omnia linearia, indivisa, obtusa, enervia, marginata, utrinque glaberrima nitida, rariùs ad margines glandulis brevissimis parcissimè instructa. Pedicelli breves, graciles; laterales medio longiores calycesque glandulis brevissimis suppediti. Lacinice calycince lanceolatæ, obtusissimæ, trinerves. Petala linearia, pallidè lutescentia, obtusa, emarginata, trinervia, calyce parùm longiora: nervis parallelis, simplicibus. Genitalia brevissima; filamenta pallida; antherce fuscre.

'The above species, notwithstanding its being probably the most 
$M r$. D. Dow's Monograph of the Genus Saxifraga. 439

most distinct of the whole section, has given rise to much confusion. It has been regarded by most authors as the real caspitosa of Linnæus, as I have already shown in speaking of that plant. I am glad in being able to fix it as a British species, and also to restore to it the synonyms of Hudson and Withering, which I have done without hesitation from specimens collected at Ambleside in Westmoreland, and which had been sent to my late father, and preserved in his Herbarium.

97. S. pygmea, glaberrima; surculis brevissimis rosulatis, foliis lanceolatis enervibus glabris apice obscindente-obtusis, laciniis calycinis latè ovatis, petalis ovalibus vix calyce longioribus.

S. pygmæa. Haworth Misc. Nat. p. 168.

S. muscoides $\gamma$ hemisphærica. Lapeyr. Pyren. Saxif. p. 60. t.36. (optima.) Persoon Synop. i. p. 491.

S. moschata. Engl. Bot. t. 2214. (exclus. synon.)

S. moschata, $\beta$. Lapeyr. l. c. p. 62. t. 38.

S. moschata $\gamma$. Sternb. Saxif. t. 11. $\beta . f .2$.

Habitat in Pyrenæis, La Peyrouse.

Planta glaberrima, densissimè cæspitosa, patula, humi depressa. Surculi brevissimi, rosulati, crebrè foliosi. Caules filiformes, graciles, paucifolii, 3-4-flori, glandulis brevissimis suppediti. Folia lanceolata, patentia, rosulata, carnosa, enervia, marginata, glabra, nitida, apice obscindente-obtusa. Flores hujus sectionis omnium minimi fulvo-lutescentes. Calyces pedicellique glandulosi : laciniæ breves, latè-ovatæ, obtusissimæ, trinerves. Potala ovalia, integra, vix calyce longiora, viridi-lutescentia, punctis nitidis suprà adspersa, trinervia: nervis simplicibus, füsco-rubris. Filamenta brevissima, purpurea. Antherce minutæ, fulvæ. 
$440 M r$. D. Don's Monograph of the Genus Saxifraga.

$\mathrm{O}_{\mathrm{B}}$. Præcedenti valdè affinis, sed satìs differt: humiliore et densiore, surculis vix ullis, foliis lanceolatis brevioribus crassioribusque apice obscindente-obtusis, laciniis calycinis brevibus latè-ovatis, petalis ovalibus integris : nervis fusco-rubris, filamentis purpureis, antheris fulvis.

Mr. Haworth first distinguished this species in his Miscellanea Naturalia, and gave it the very apt name which it now bears. This plant is given in English Botany as a British species, and, on the authority of the late Mr. James Donn of Cambridge, is said to be a native of Scotland: but some other plant must have been intended; for I doubt much whether the present has been ever found any where in Britain. In Scotland I am certain it has not.

98. S. tricuspidata, foliis radicalibus aggregatis cuneiformibus ciliatis acutè tridentatis, caule adscendente racemoso, petalis lanceolatis calyce tripld longioribus. Willd. Sp. Pl. ii. p. 657 .

S. tricuspidata. Rottb. Act. Hafn.x. p.446.t.6. Gunn. Norveg. 1046. Fl. Dan. t.976. (bona.) Retz. Prod. Fl. Scand. ed. ii. n.522. Lam. Encycl. vi. p.693. Persoon Synop. i. p.490. Sternb. Saxif. p.54. Pursh Amer. Sept. i. p. 313.

Habitat in Grœnlandiâ et Terrâ Novâ. $\psi$. (v. s. in Herb. Banks.)

Planta densissimè cæspitosa, glabra. Surculi brevissimi. Caules laterales, adscendentes, teretes, 4--5-unciales, oligophylli, glabriusculi, multiflori. Folia radicalia aggregata, oblongo-cuneata, apice acutè tridentata: dente medio majore triangulari; lateralibus mucronatis : paginâ utrinque glabrâ : margine ciliato ; caulina inferiora tridentata; superiora indivisa. Pedicelli elongati, uniflori, calycesque levitèr glandulosi. Flores lutei, magnitudine 
Mr. D. Don's Monograph of the Genus Saxifraga. 441

S. Hirculi. Lacinice calycina breves, ovatæ, obtusæ. Petala lanceolata, calyce triplò longiora, punctata, triplinervia : nervis parallelis, simplicibus. Filamenta lutescentia, stylis longiora. Antherce croceæ.

99. S. tridactylites, foliis primordialibus integris spathulatis; caulinis quinquefidis trifidisve, calycibus urniformibus : laciniis brevissimis, petalis obovatis apice truncatis.

S. tridactylites. Linn. Sp. Pl. 578. Fl. Suec. 353. 375. Gerard. Fl. Gall. 422. Gouan Monsp. 210. Gunn. Norv. 544. Scop. Carn. 550. Pollich. Pal. 403. Huds. Angl. 182. Lightf. Scot. 224. Curtis Lond. fasc. ii. t. 28. Vill. Delph. IV. p. 669. Roth Germ. i. 184. ii. 469. With. Brit. 406. Hoffm.Germ. 145. Willd. Sp. Pl. ii. p.654. Lam. Encycl. vi. p.693. Smith Brit. ii. p.455. Engl. Bot. t.501. (media.) Lam. et Decand. Fl. Franc. iv. p. 369. Persoon Synop. i. p. 490. Marsch. d Bieberst. Fl. Taur. Cauc. i. p.315. Sternb. Saxif. p.44. t.17. Wahlenb. Lapp. 218. ejusd. Carpath. 121.

S. annua. Lapeyr. Pyren. Saxif. p. 53.

S. foliis omnibus trilobis basi angustis, caule erecto. Linn. Fl. Lapp. 173. Hort. Cliff. 168.

S. foliis petiolatis trilobatis, caule erecto ramoso et folioso. Hall. Helv. 986.

S. foliis trifidis basi angustis, caule erecto. Roy. Lugd. Batav. 457. Sauv. Monsp. 208.

Sedum tridactylites tectorum. Bauh. Pin. 285. Moris. Hist. iii. p. 478. s. 12. t. 9. f. 31. (bona.)

Paronychia altera. Dod. Pempt. 113. Tabern. 805.

Paronychia rutaceo folio. Blackw. t. 212.

$\beta$. alpicola, major; foliis radicalibus congestis; caulinis numerosioribus plerumque 5-dentatis, fioribus duplo majoribus.

S. tridac- 
$442 M r$. D. Don's Monograph of the Genus Sarifraga.

S. tridactylites, $\beta . \quad$ Linn. Sp. Pl. ed. i. p. 404. Fl. Suec. 353. 375. Fl. Lapp. 173. (exclus. synon. Pona.)

S. adscendens. Sp. Pl, ed.altera 579. Mant. p. 884. Allion. Ped. 1537. t. 22. f. 3... Wulfen apud Jacq. Coll. i. p. 197. t. 11. 12. f. 1.2. Persoon Synop. i. p. 490.

S. petræa. Gunn. Norv. 427. t.9.f.1.3. (exclus. synon. et descrip. Linn.) Fl. Dan. t.680. Vahl. in Act. Hist. Nat. Hafn. 2. 1. p. 10. Willd. Sp. Pl. ii. p.654. (exclus. synon. Linn.) Lam. Encycl. vi. p.694. (exclus. synon. Linn.) Lam. et Decand. Fl. Franc. iv. p. 370. Wahlenb. Lapp. 219. (exclus. synon. Linn.) ejusd. Carpath. 122. (exclus. synon. Linn.)

S. hypnoides. Scop. Carn. 499. t. 16.

S. Scopolii. Vill. Delph. IV. p. 670.

S. controversa. Sternb. Saxif. p. 43. t. 16. fig. omnes.

Sedum tridactylites alpinum, caule folioso. Bauh. Pin. 284. Habitat $\alpha$ in Europæ arenosis copiosè ; $\beta$ in Lapponiæ, Norvigiæ, Sabaudiæ, Carinthiæ, Carpathorum alpibus. $\odot$. (v. v. spont. $\alpha, \beta$ v. s.)

Radix fibrosa, annua. Caules erecti, ramosi, teretes, flexuosi, multiflori, pilis brevibus glanduliferis instructi. Folia radicalia conferta, spathulata, patentia, indivisa, petiolata ; caulina cuneiformia, carnosa, quinquefida aut trifida vel rariùs tridentata : basi angustata petiolique glandulis ciliata, lobis obtusiusculis. Pedunculi recti, filiformes, subuniflori, calycesque pube viscidâ brevi tecti. Flores parvi, candidi. Calyces urniformes: laciniæ brevissimæ, obtusæ, obscurè trinerves. Petala obovata, trinervia, apice truncato-obtusa, calyce pauld majora : nervis simplicibus, rectis. Filamenta alba, brevissima. Antherce luteæ. Styli recurvati.

100. S. pe- 
Mr. D. Don's Monograph of the Genus Saxifraga. 443

100. S. petraa, folliis radicalibus 5-lobo-palmatis ; caulinis tripartitis incisisque, pedunculis longissimis unifloris, laciniis calycinis linearibus acutis, petalis obovatis apice truncatis emarginatisque calyce duplo majoribus.

S. petræa. Linn.Sp.Pl.578. (exclus. plerisq. synon.) Wulfen in Jacq. Coll. i. p. 200 . Jacq. Icon. Rar. i. t. 81. (bona.) Hoffm. Germ. 145?

S. geranioides. Host. Synop. 231.

S. rupestris. Willd. Sp. Pl. ii. p. 653.

S. Ponæ. Sterab. Saxif. p. 47. t.18. (mula.) et t.11.f.6.

S. alba petræa. Pona Bald. apud Clus. Hist. ii. p. 337 . cum figurâ bonâ. Pona It.p. 183. Segu. Veron. i. p. 447.

S. bianca. Calceol. It. 12.

Sedum tridactylites majus album. Bauh. Pin.284. Prod. 31. Raii Hist. XIX. p. 1043. Moris. Hist. iii. p. 379. s. 12. t. 9. f. 28. (bené.)

Sanicula aizoides alpina trifido folio major alba. Pluken. Alm. 331. t. 222. f. 3.

Habitat in præruptis saxosis Montis Baldis (Pona, Seguier, Sternberg), in Carinthiæ alpibus (Wulfen). $\odot$. (v. s. in Herb. Banks.)

Planta diffusè ramosa, pilis patentibus glanduliferis instructa. Radix fibrosa, annua. Caules erecti, basi ramosi, 4-5-unciales. Rami elongati, subfastigiati. Folia radicalia longè petiolata, 5-lobo-palmata, basi subreniformia : lobis latè ovatis, obtusis ; caulina omnia petiolata, ima tripartita ; summa indivisa, elliptica, utrinque acuta, multinervosa: segmentis inferiorum cuneatis; lateralibus bifidis medio plerumque trifido: lobis acutis. Pedunculi longissimi, uniflori, calycesque pube viscidâ tecti. Flores candidi, illis $S$. tridactylitis quadruplò.

majores. 
444 Mr. D. Don's Monograph of the Genus Saxifraga.

majores. Calyx urceolatus : laciniæ lineares, acutæ, trinerves. Petala obovata, calyce duplo majora, triplinervia, apice truncata et emarginata : nervis simplicibus.

The above description was taken from a specimen collected on Mount Baldo, and preserved in the Banksian Herbarium. Notwithstanding the very accurate figure which Pona has given of this plant, authors have been much disagreed regarding it. It is undoubtedly the plant Linnæus intended by his $S$. petraa, although his synonyms are very incorrect. The learned Gunner justly remarks, in speaking of his petrea (tridactylites $\beta$ ), that it ill accorded with the description in the Species Plantarum, which has evidently been taken from figures or specimens of the present species, although Linnæus regarded them as the same.

101. S. adscendens, foliis profundè tripartitis : segmentis cuneatis multifidis, pedunculis multifloris, petalis ovalibus integris, caule adscendente paniculato.

S. adscendens. Vahl. in Act. Hist. Nat. Hafn. 2.1. p. 12. Willd. Sp. Pl. ii. p. 655. (exclus. omnib. synon. præter Vahlii et Gouanii.) Lam. Encycl. vi. p.695. (exclus. plerisq. synon.) Lam. et Decand. Fl. Franc. iv. p.370. (exclus. syn. Linn.)

S. petræa. Gouan Illust. 29. t. 17. f. 3. (bona.)

S. aquatica. Lapeyr. Pyren. Saxif. p.53. t.28. (optima.) Persoon Synop. i. p. $490 . \quad$ Sternb. Saxif. p. 48. t. 19. f. 1. et 2. (bonce.)

ß. caule virgato, foliorum lobis acutis subpinnatis, petalis lutescentibus. Lapeyr. loc. cit. t. 29.

Habitat $\alpha$ et $\beta$ in scaturiginosis Pyrenæorum. $u_{\text {. (v.s. } \alpha \text { in }}$ Herb. Vent. nunc in Mus. Lessertiano, et item in Herb. Banks.) 
Mr. D. Don's Monograph of the Genus Saxifraga. 445

Radix fibrosa, perennis, cæspitosa. Surculi plures, breves, foliosi. Caules adscendentes, pedales aut ultra, foliosi, crassitie pennæ anserinæ, succulenti, pilis glanduliferis patentibus confertè suppediti. Folia radicalia petiolata, 5-lobo-palmata, camosa, utrinque glabra: segmentis latè cuneatis, inciso-dentatis; caulina omnia petiolata, profundè tripartita : segmenta in lobis lanceolatis obtusiusculis multisecta. Petioli breves, ad bases præsertìm radicalium latissimè dilatati. Flores coarctato-paniculati, albi, rariùs lutescentes. Pedunculi multiflori calycesque pube glandulosâ tecti. Calyx obconicus : laciniæ ovatooblongæ, obtusiusculæe. Petala ovalia, integra, triplinervia: nervis simplicibus, rubescentibus. Stamina inæqualia stylis longiora; filamenta lutescentia; antherce aureæ.

This, which is a very distinct species, is the largest of the whole section, often exceeding a foot in height. I have retained Vahl and Willdenow's name in preference to that of La Peyrouse, on account of its priority.

102. S. cuneata, glabra; foliis inferioribus longè-petiolatis cuneatis 5-lobatis; superioribus subsessilibus lanceolatis indivisis, caule adscendente paniculato, petalis oblongis.

S. cuneata. Willd. Sp. Pl. ii. p.658. Lam. Encycl. vi. p. 700. Persoon Synop. i. p. 489.

S. cuneifolia. Cavan. Icon. iii. p. 25. t. 248.

IIabitat in Hispaniæ montibus frigidis juxta Castellfort. Cavanilles. 4 .

Radix fibrosa, perennis. Caules plures, adscendentes, glabri. Folia inferiora longè petiolata (petiolis fliformibus), cuneata, utrinque glabra, basi integerrima, apice 5-loba (lobis ovatis, acutis); superiora indivisa, sessilia, lancerol. Xi11. $3 x$ olata. 
olata, acuta. Flores paniculati. Pedunculi elongati, filiformes, stricti, uniftori, calycesque leviusculi. $L a-$ cinice calycince ovate, acutæ. Petala oblonga, obtusa, candida. Stamina corollâ breviora. Cavan. loc. cit.

Oвs. Exempla hujus speciei nunquam à me visa; attamen ex descriptione et figurâ Clariss. Cavanillesii speciem ab omnibus esse satis diversam licet judicare. An rectè in hac sectione aut meliùs in quartâ sit collocanda?

103. S. globulifera, gemmifera ; surculis brevibus, foliis surculinis 5-fidis trifidisve nunc simplicibus lanceolatis acutis aristatisque, floribus paniculatis, laciniis calycinis ovalioblongis obtusis, petalis obovatis.

S. globulifera. Desf. Atlant. ii. p.342. t.96.f.1. Lam. Encycl. vi. p.699. Persoon Synop. i. p. 490. Sternb. Saxif. p. 45.

Habitat in cacumine Atlantis. Desfontaines. 4 . (v. s. in Herb. Lessertiano, specim. à Clar. Desfontainio communicata.)

Planta cæspitosa. Radix fibrosa. Surculi 1-2-unciales, foliosi, basi rudimentis foliorum emarcidorum instructi. Caules erecti, filiformes, tripollicares, foliis paucis minutis muniti, glabri. Folia radicalia et surculina, petiolata, 5-fida vel trifida (segmentis lanceolatis), nunc simplicia lanceolata, acuta, setâ diaphanâ terminata, triplinervia : nervis divisis. Petioli ciliati. Axilla foliorum gemmis subrotundis, pedunculatis, è foliis (simplicibus) ciliatis appressè imbricatis, posteriorum surculorum formatis instructæ. Flores candidi, S. hypnoide duplò minores, 5-7 in paniculam dispositi. Pedicelli tenues calycesque pube glutinosâ levitèr suppediti. $L a-$ cinice calycince ovali-oblongæ, obtusæ. Petala obovata, calyce 
$M r$. D. Don's Monograph of the Genus Saxifraga. 447 calyce duplò longiora, triplinervia: nervis simplicibus rectis.

OBs. S. hypnoidi affinis, sed satis distincta.

104. S. hypnoides, gemmifera; surculis longissimis procumbentibus, foliis radicalibus quinque- tri-partitisve; surculinis simplicibus linearibus rigidis ciliatis mucronatoaristatis, laciniis calycinis triangulari-ovatis aristatis, petalis subrotundo-obovatis.

S. hypnoides. Sp. Pl.579. Fl. Dan. t.348. Mill. Dict. 12. IHuds. Angl. 182. Lightf. Scot. 224. With. Brit. 407. Villars Delph. iv. p. 674. t. 45. Willd. Sp. Pl. ii. p. 658. Lapeyr. Pyren. Saxif. p.57. t. 32. Smith Brit.ii. p. 457. Engl. Bot. t. 454. (mala.) Lam. Encycl. vi. p. 698. Persoon Synop. i. p.490. Lam. et Decand. Fl. Franc. iv. p.376. Sternb. Saxif. p. 45.

S. procumbens; foliis linearibus integris trifidisque. Hort. Cliff. 168. Roy. Lugdb. 453. Sauv. Monsp. 208. Gort. Gelr. 248.

Sedum alpinum, trifido folio. Bauh. Pin. 284. Moris. Hist. iii. p. 479. s. 12. t. 9. f. 26. (bené).

Sedum muscosum, trifido folio. Raii Syn. 354.

Sedum alpinum 7. Clus. Painn. p. 491.

$\beta$. viscosa, mollior et laxior; floribus majoribus.

S. viscosa. Hortorum.

$\gamma$. angustifolia, surculis adscendentibus, foliis longioribus.

$\mathrm{S}$. angustifolia. Hortulanorum.

ঠ. muscosa, duplò minor et tenerior; segmentis foliorum. minimis, floribus minoribus.

\&. pulchella, robustior; surculis crassioribus rigidioribusque, gemmis obtusis confertioribus, foliis surculinis latioribus suprà sulco exaratis, petalis latioribus. 
$448 M r$. D. Don's Monograph of the Genus Sarifraga.

Habitat $\propto$ in alpibus Helveticis, Austriacis, Pyrenaicis, Cambro-Britannicis, Angliæ borealis ; in Scotiæ montibus passim; $\beta, \gamma, \delta, \varepsilon$ in alpiłus Scoticis. $\psi$. (v.v. spont.)

Herba ante anthesin densissimè cæspitosa, glaberrima, posteì laxa, surculosa, villis mollibus adspersa. Surculi procumbentes, longissimi, rigidiusculi, rubescentes. Caules erecti, 3-4-unciales, rubescentes, nitidi, fragiles, 2-4-flori. Folia radicalia quinque- vel tripartita rariùs indivisa, glabra, margine villis parcis ciliata: segmentis linearibus, aristatis; surculina omnia indivisa, linearia, acutissima, aristâ longâ terminatâ, ad axillas gemmis ovatis, acutis instructa; caulina pauca, lineari-lanceolata, indivisa. Pedunculi elongati, subuniflori calycesque pube brevissimâ viscidâ densè suppediti. Lacinia calycince triangulari-ovate, trinerves, mucronato-aristatæ: mucrone recto. Petala subrotundoobovata, plana, conspicuè triplinervia, candida, apice extùs rosea: nervis simplicibus, rectis.

105. S. condensata, surculis procumbentibus abbreviatis, foliis radicalibus 5-partitis; surculinis trifidis: segmentis linearibus glabris aristatis, laciniis calycinis triangulariovatis acutis muticis, petalis ovalibus.

S. condensata. Gmel. Fl. Baden. ii. p. 226. t.3.

S. densa et levis. Hortulanorum.

Habitat in Sponhemiæ rupibus ( $\left.{ }^{\mathrm{C}} \mathrm{melin}\right)$, in alpibus Scoticis (G. Don). u. (v. v. spont.)

Herba glaberrima, nitida, jucundè viridis, ante anthesin densissimè cæspitosa, postmodò surculosa. Surculi procumbentes, abbreviati, gemmis destituti. Caules plures, erecti, bi- rariùs tri-pollicares, nudiusculi, glaberrimi, nitidi, 
Mr. D. Don's Monograph of the Genus Saxifraga. 449 nitidi, 2-3-flori. Folia radicalia 5-partita; surculina trifida ad axillas nuda : segmenta angustè linearia acuta et brevè aristata. Pedunculi glabri, nitidi, uniflori, in æstivatione curvati. Calyx pube brevissimâ levitèr instructus : laciniæe ovatæ, acutæ, muticæ. Petala ovalia, alba, triplinervia, apice extùs rosea : nervis simplicibus, strictis.

This species approaches near to the preceding; but having proved it in cultivation, I am now fully satisfied of its being a distinct species. Its habit is so different, that it may be known at all times of the year by it alone. Its surculi are three times shorter than those of hypnoides, always quite smooth and green, never red, and destitute of the bulbous buds so remarkable in S. hypnoides. The latter species is found alike in the plains, as well as on the tops of mountains. The $S$. condensata, on the contrary, is met with only in elevated regions. It is not confined to one spot alone, but extends over all the Scottish mountains.

106. S. elongella, surculis erectis brevibus, foliis radicalibus 5- tri-fidisve; surculinis plerumque tridentatis: dentibus mucronulatis, laciniis calycinis ovatis muticis, petalis obovatis.

S. elongella. Smith in Act. Soc. Linn. x. p. 340. Engl. Bot. t. 2277. (exclus. synon. Donn Cantab.) Compend. Fl. Brit. 66.

Habitat in Angusiâ Scotiæ in rupibus humidis juxta Lintrathen. G. Don. $\psi$. (v. v. c.)

Herba densissimè cæespitosa, ante anthesin glaberruma, postmodùm villis tenuissimis parcissimè instructa. Surculi erecti, breves, rigidiusculi, basi foliis emarcidis crebrè 
instructi. Caules erecti, bi- rariùs tri-unciales, subnudi, 2-3-flori, glabriusculi. Folia radicalia 5-fida aut trifida, (segmentis lanceolatis,) rarissimè simplicia; surculina plerumque tridentata aut rarò indivisa : dentibus latè ovatis, mucronulatis. Petioli tenues, dilatati. Pedunculi longissimi, uniflori, calycesque pilis glanduliferis levitèr sparsi. Lacinice calycine ovatæ, acutæ, muticæ, trinerves. Petala obovata, utrinque alba, triplinervia: nervis lateralibus, curvatis, ramulosis ; medio simplici, recto.

'This species is totally distinct from all the varieties of $S$. hypnoides, one variety of which is often cultivated in the gardens under the name, and mentioned in Donn's Cambridge Catalogue. I am therefore happy in having an opportunity of giving a full description of the real plant. In its native habitat it frequently bears long solitary peduncles, terminated by only one flower: but culture alters it in this respect.

107. S. leptophylla, surculis procumbentibus longissimis, foliis radicalibus 5-partitis; surculinis tripartitis indivisisve: segmentis lineari-lanceolatis acutissimis divaricatis, laciniis calycinis oblongo-ovatis, petalis spathulatis integris.

S. leptophylla. Persoon Synop. i. p. 490.

S. retroflexa. Hortulanorum.

B. angustifida, tenerior; segmentis foliorum angustioribus.

S. angustifida. Hortulanorum.

Habitat $\alpha$ in alpibus Helveticis, et in Cambro-Britanniæ montibus; $\beta$ in montibus Cambro-Britannicis. $\psi$. (v.v.c.)

Planta ante anthesin glaberrima, densissimè cæespitosa, posteà laxè diffusa, surculosa, villis viscidis levitèr sparsa. 
sparsa. Surculi decumbentes, filiformes, graciles, longissimi, virides, gemmis destituti. Caules plures, erecti, 3-4-pollicares, flexuosi, glabriusculi, nitidi, multiflori. Folia radicalia profundè 5-partita; surculina tripartita rariùs indivisa, in axillis nuda: segmentis lineari-lanceolatis, acutissimis, aristatis, divaricatis ; lateralibus horizontalitèr porrectis. Flores cernui, candidi. Pedunculi elongati calycesque pilis glanduliferis suppediti. Lacinice calycince oblongo-ovate, trinerves, mucrone reflexo apice instructe. Petala spathulata, integerrima, triplinervia : nervis simplicibus, rectis. Stamina æqualia; filamenta alba; antherce aureæ.

This species, as well as its variety $\beta$, is cultivated by my friend Mr. Macnab, of the Royal Botanic Garden, Edinburgh, who received them from Wales. I have since my arrival in London had an opportunity of examining flowering specimens of it. The spreading divaricated segments of its leaves are a very striking character, and readily distinguish it from its congeners; but nevertheless it affords sufficient marks besides that to rank it as a species.

108. S. lcetevirens, surculis procumbentibus elongatis, foliis 5-3partitisve: segmentis linearibus acutis, laciniis calycinis lanceolatis mucronatis, petalis spathulatis emarginatis.

Habitat in Scotiæ alpibus. G. Don. 4. (v. v. spont.)

Herba lætissimè virens, ante anthesin densissimè crespitosa, glaberrima, posteà laxè diffusa, surculosa, villis longis adspersa. Surculi elongati, procumbentes, gemmis destituti. Caules pauci, erecti, tripollicares, glabri, oligophylli, subtriflori rariùs uniflori. Folia radicalia 5partita ; surculina omnia tripartita : segmenta linearia, acuta, 
acuta, apice recurvata; caulina ima 5-fida, superiora indivisa lanceolata, acuminata. Flores campanulati, candidi, in æstivatione cernui. Calyces pedicellique pube viscidâ instructi : laciniæ lanceolatæe, trinerves, mucronatæ: mucrone recurvo. Petala spathulata, triplinervia, apice emarginata : nervis simplicibus, strictis, viridibus.

This very distinct and elegant species was first discovered by the late Mr. G. Don of Forfar, on the mountains of Angusshire and $\Lambda$ berdeenshire, where it grows on moist rocks in very elevated situations. I have also observed it myself subsequently on hills to the north of Loch-Lomond. Plants of it from that quarter are now growing in the garden of my highly valued friend, Patrick Neill, Esq., Secretary of the Wernerian Natural History and Caledonian Horticultural Societies of Edinburgh.

In concluding this Monograph, I have to make (p. 348) an important alteration in the specific character of $S$. ligulata, namely, to substitute glabris for utrinque hirsutis; the paginæ of the leaves being quite smooth. A similar alteration is also necessary in the description of the same species. 